\title{
Mapping Global Risk of Crop Yield Under Climate Change
}

\author{
Weihang Liu, Shuo Chen, Qingyang Mu, Tao Ye, and Peijun Shi
}

\section{Introduction}

Risk of crop yield under climate change refers to the potential changes in crop yield (mean yield, interannual yield variability, and lower extreme yield) caused by climate change. Increases in the interannual variability of yield and the likelihood of lower yield extremes can affect the livelihoods of farmers (Morton 2007), increase pressure on inter-temporal food reserves (Bobenrieth et al. 2013), induce large price changes in the global market or even destabilize regions of the world (Sternberg 2011). The risk of crop yield is one of the primary drivers of food system instability (IPCC 2017), and its response to climate change is critical to understanding the impact of climate change on food security (FAO 2019). Previous studies have mostly focused on the variation in the mean yield in response to climate change (Ray et al. 2015). Climate change impacts on crop yield risk, however, remains a key research gap (IPCC 2017).

Recent studies have provided evidence for changes in the yield risk of major cereal crops and identified significant global impacts of climate change, either at the country level or the $0.5^{\circ}$ grid level (Osborne and Wheeler 2013; Iizumi and Ramankutty 2016). These studies have been followed up by regional county-level analysis of the interannual yield variability of maize. Most recently, efforts have been concerned with predicting the impact of future climate change on the interannual yield variability, focusing on wheat and maize at both the global and regional scales, using site-based process-based crop models (Liu et al. 2019) and statistical models (Urban et al. 2012; Ben-Ari et al. 2018; Tigchelaar et al. 2018).

This study evaluated the changes in the global staple crop yield risk from three aspects - mean yield, interannual yield variability, and lower extreme yield-under the RCP2.6-2030s, RCP2.6-2050s, RCP4.5-2030s, RCP4.52050s, RCP8.5-2030s, and RCP8.5-2050s scenarios. The crop yield risk was evaluated by using multi-model ensemble (MME) simulation with global high spatial resolution $\left(0.25^{\circ}\right)$ climate forcing data. Emulators of global gridded crop models (GGCM) were developed to ensure efficient prediction (Lobell and Burke 2010; Holzkämper et al. 2012; Oyebamiji et al. 2015; Raimondo et al. 2020). The present results may provide crucial information for climate risk assessment and effective adaptations.

Authors: Weihang Liu, Shuo Chen, Qingyang Mu, Tao Ye, Peijun Shi.

Map Designers:

Wheat: Weihang Liu, Jing'ai Wang, Ying Wang.

Maize: Qingyang Mu, Jing'ai Wang, Ying Wang.

Rice: Shuo Chen, Jing'ai Wang, Ying Wang.

Language Editor: Tao Ye.

W. Liu $\cdot$ S. Chen $\cdot$ Q. Mu $\cdot$ T. Ye $(\bowtie) \cdot$ P. Shi

Faculty of Geographical Science, Beijing Normal University,

Beijing, 100875, China

e-mail: yetao@bnu.edu.cn

T. Ye $\cdot$ P. Shi

State Key Laboratory of Earth Surface Processes and Resource

Ecology, Beijing Normal University, Beijing, 100875, China 
Fig. 1 Technical flowchart for mapping crop yield risk of the world under climate change, taking wheat as an example. GGCM = Global Gridded Crop Model; MME = Multi-model ensemble; $\mathrm{GCM}=$ General Circulation Model

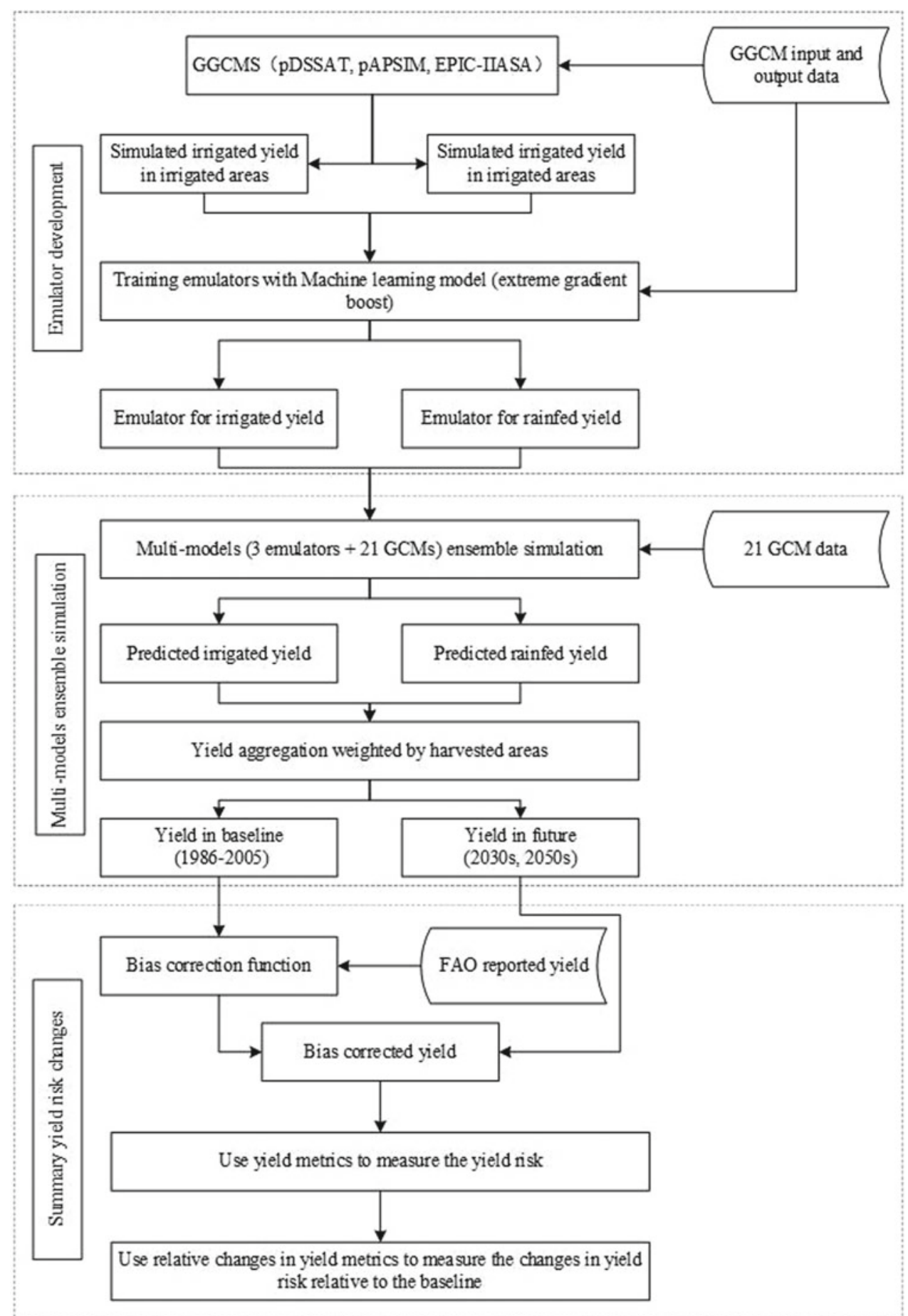

\section{Method}

The method for detecting changes in the wheat yield variability for future climate scenarios includes the following steps (Fig. 1): (1) Develop emulators for the process-based models in the GGCMs; (2) Conduct MME prediction of the global wheat yield at fine spatial resolution; (3) Correct the bias in the predicted global yield using country-level reported yield to best capture the actual interannual yield variability; (4) Summarize yield risk change. Figure 1 shows the technical flowchart for mapping the risk of crop yield of the world under climate change. 


\subsection{Development of the Global Gridded Crop Model (GGCM) Emulators}

\section{Emulator training via extreme gradient boosting}

The development of the emulators consists of training machine learning models on specific GGCM input and output datasets so that the models may replicate the complex process of yield simulation within the crop model. Variables that have been frequently reported to significantly influence wheat yield were prepared as the predicting variables (Folberth et al. 2019), and they cover climate, soil type, length of vegetation growth period, and management practices. All the data for training were computed/adapted from the GGCMs' input and output datasets. For climate data, the monthly variables and the growing season variables were considered. Soil properties, the length of vegetation growth period, and management practices were site-specific variables.

In total, six emulators were trained for the three GGCMs (pDSSAT, pAPSIM, and EPIC-IIASA) each with two cultivation possibilities (rainfed and irrigation). An extreme gradient boosting (XGB) algorithm was used due to its better performance in terms of goodness-of-fit, cross-validation errors, and computation efficiency than the random forest algorithm (Folberth et al. 2019). The predicting variables and the simulated yield in the GGCMs were randomly split into training and validation sets that contained $75 \%$ and $25 \%$ of the samples (Yue et al. 2019), respectively.

\section{Predicting global crop yield by MME simulation}

The MME yield prediction was performed at the global level for the $0.25^{\circ}$ grids for the years 1986-2005 (baseline period), 2016-2035 (the 2030s), and 2046-2065 (the 2050s) under the RCP2.6, RCP4.5, and RCP8.5 scenarios. The MME approach has been proven to be a reliable method in reproducing the main effects anticipated for climate change when simulations are compared with observation (Asseng et al. 2015; Frieler et al. 2017). The large climate model-crop model emulator setup in our framework enabled a robust MME estimate as well as analysis of spatial heterogeneity and inter-model uncertainty (Martre et al. 2015). There were 432 treatments (13 or 21 general circulation models $(\mathrm{GCMs}) \times 3$ emulators for the baseline period, RCP2.6-2030s, RCP2.6-2050s, RCP4.5-2030s, RCP4.5-2050s, RCP8.5-2030s, and RCP8.5-2050s) each simulated for 20-year periods. For future yield predictions, planting dates, soil properties, and management practices were assumed to remain constant through time. The MME median across the 3 emulators and the 13 or 21 GCMs was taken as the final estimate.
Bias correction of the predicted yield in the baseline period and in future applications

The emulator-predicted global wheat yields were corrected for bias using the national yield reports of the FAO. Rainfed and irrigated yield were first aggregated to the grid and national levels using an area-weighted average (Müller et al. 2017).

\subsection{Measuring the Yield Risk}

To fully describe the yield risk, the conventional approach was to derive the probability distribution or the cumulative distribution of the yield (Coble et al. 2010; Ye et al. 2015). In this study, we computed the mean yield (multi-year average), yield interannual variability (multi-year standard deviation), and the lower yield extremes (multi-year 10th percentile) across different 20-year periods. To account for the uncertainty associated with the projected input climate data, the computation was conducted for simulated yield series derived independently with each GCM and emulator, and the results of the MME median were reported.

\section{Results}

\subsection{Wheat Yield Risk}

Globally, countries with higher mean wheat yield are mainly located in Europe, while those with lower yield are mainly located in East Africa, the Middle East, and the northern United States. The change of yield risk shows a complex connection with warming. For higher emissions and warming scenarios, although countries at higher latitudes would be more likely to experience higher interannual variability of yield, their mean yield and lower extreme yield tend to increase, compared with the baseline period. Countries at low latitudes, e.g., India, would suffer more, that is, its lower extreme yield will be much worse in the future while its yield interannual variability slightly declines.

From the perspective of mean wheat yield, among the top 10 wheat-producing countries in the world (Fig. 2), the mean yields of France and Germany stand out, exceeding 6 t/ha. The mean yields of the other wheat-producing countries are lower than $3 \mathrm{t} / \mathrm{ha}$. There are two patterns of variation of the mean yields under warming conditions. On the one hand, the rising temperature will bring a favorable effect on mean wheat yield. For example, the mean yields in China, the United States, Russia, France, Canada, Germany, and Turkey will gradually climb up with increasing warming. On the 


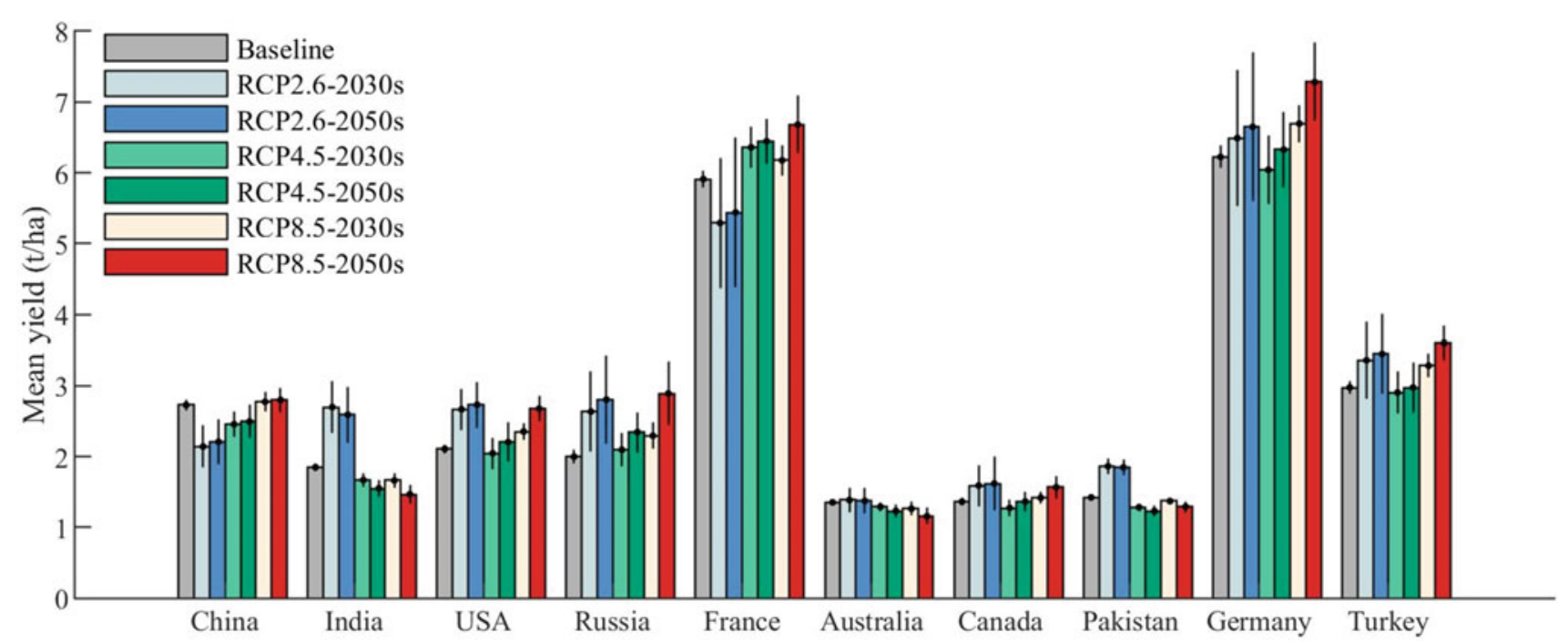

Fig. 2 Mean wheat yield of the top 10 major wheat-producing countries (in descending order by total production). The error bar represents the one standard deviation across the 21 general circulation models (GCMs) and three emulators

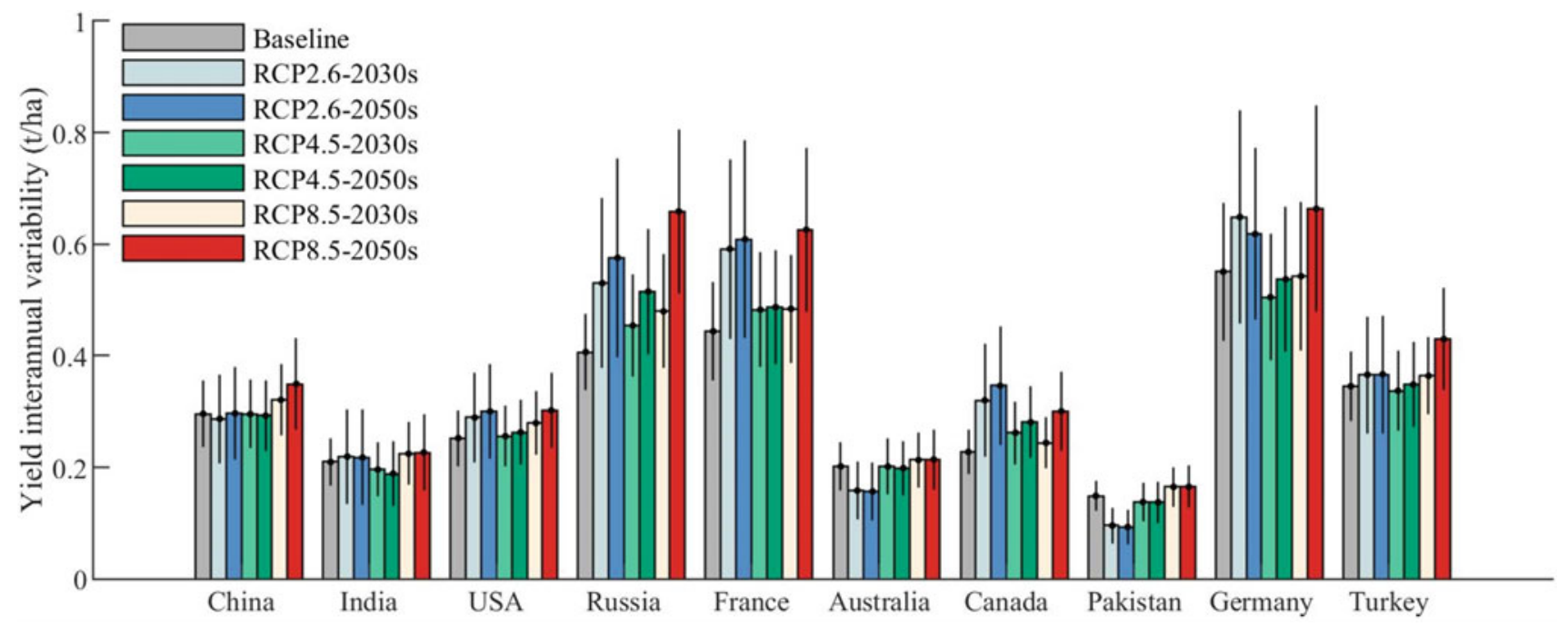

Fig. 3 Wheat yield interannual variability of the top 10 major wheat-producing countries (in descending order by total production). The error bar represents the one standard deviation across the 21 general circulation models (GCMs) and three emulators

other hand, warming will impose an adverse influence on the other wheat-producing countries such as India, Australia, and Pakistan, whose mean yields will fall during the future periods.

From the perspective of wheat yield interannual variability, among the top ten wheat-producing countries in the world (Fig. 3), Russia, France, and Germany have higher wheat yield interannual variability. China, India, and the United States - the top three countries in wheat production - are at the middle level, while Pakistan has the lowest interannual variability. With increasing warming (e.g., higher emissions scenario or further into the future), the interannual variability will rise in all countries, but the degree will vary. In China, the interannual variability of yield will grow insignificantly under the medium emissions scenario (RCP4.5) but will increase slightly (less than 0.4 t/ha) under the high emissions scenario (RCP8.5). The interannual variability in France is flat under the three scenarios of RCP4.5-2030s, RCP4.5-2050s, and RCP8.5-2030s. However, when the temperature rises to a considerable degree (RCP8.5-2050s), the interannual variability will increase sharply.

From the perspective of lower extreme wheat yield, among the top ten wheat-producing countries in the world (Fig. 4), the countries with the highest lower extreme wheat yield are France and Germany, where the yields are as high 


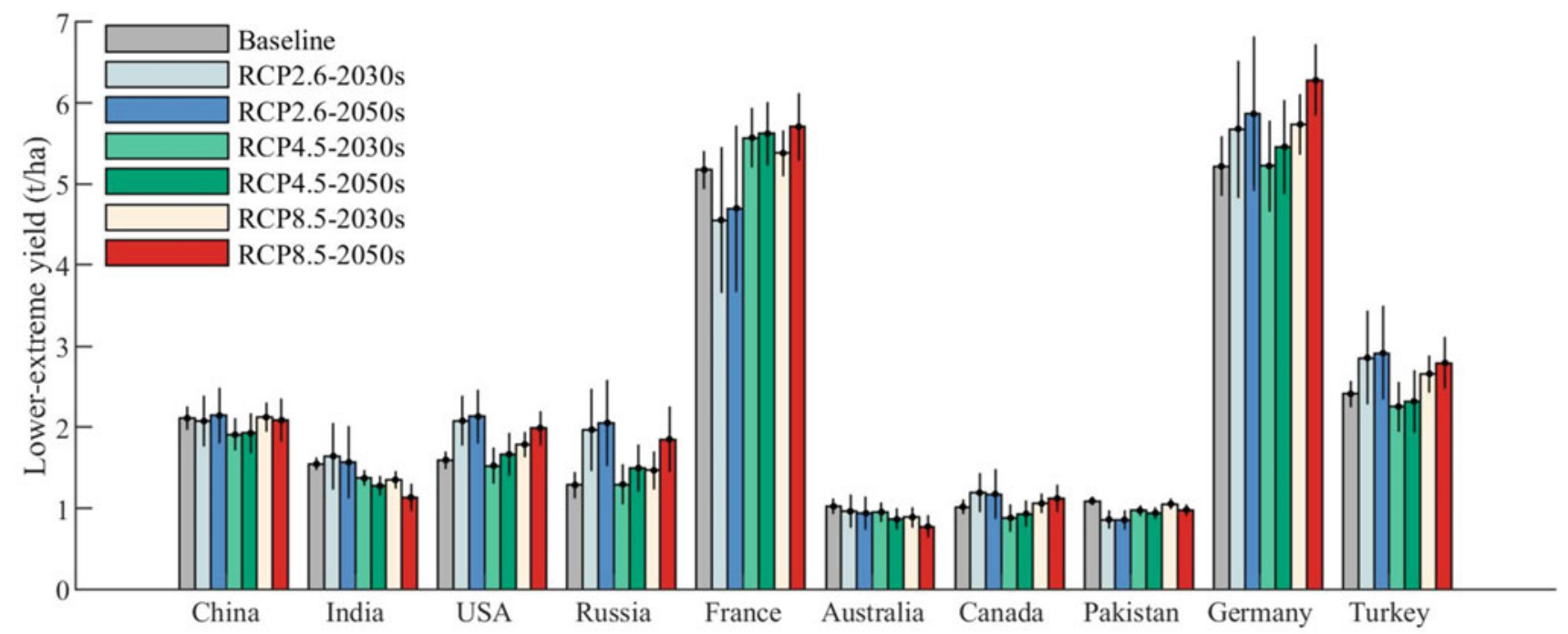

Fig. 4 Lower extreme wheat yield of the top 10 major wheat-producing countries (in descending order by total production). The error bar represents the one standard deviation across the 21 general circulation models (GCMs) and three emulators

as $4-6 \mathrm{t} / \mathrm{ha}$, while the countries with the lowest wheat yield are Australia, Canada, and Pakistan, where the yields can be as low as $1 \mathrm{t} / \mathrm{ha}$. The relationship between changes in lower extreme wheat yields and warming is not uniform across countries: with the increase of warming, most countries show an overall upward trend, but India and Australia show a downward trend. For example, a warmer world will cause lower extreme wheat yield in India to become even lower. However, it will have a favorable impact in high latitude areas, especially in the United States, where the lower extreme wheat yield will increase steadily under the four scenarios of RCP4.5-2030s, RCP4.5-2050s, RCP8.5-2030s, and RCP8.5-2050s.

\subsection{Maize Yield Risk}

Globally, countries with higher mean maize yield are mainly located in Europe, northern China, and the United States while those with lower yield are mainly located in central Africa and southern India. Climate change will have a two-sided effect on maize production in most of the regions. Warming will reduce the maize yield interannual variability risk (lower variability) but increase the lower extreme wheat yield risk (lower yield) in the regions between south of the Sahara and north of the equator in Africa and northern India. Similarly, it will increase the variability risk (higher variability) but reduce the extreme yield risk (higher yield) in

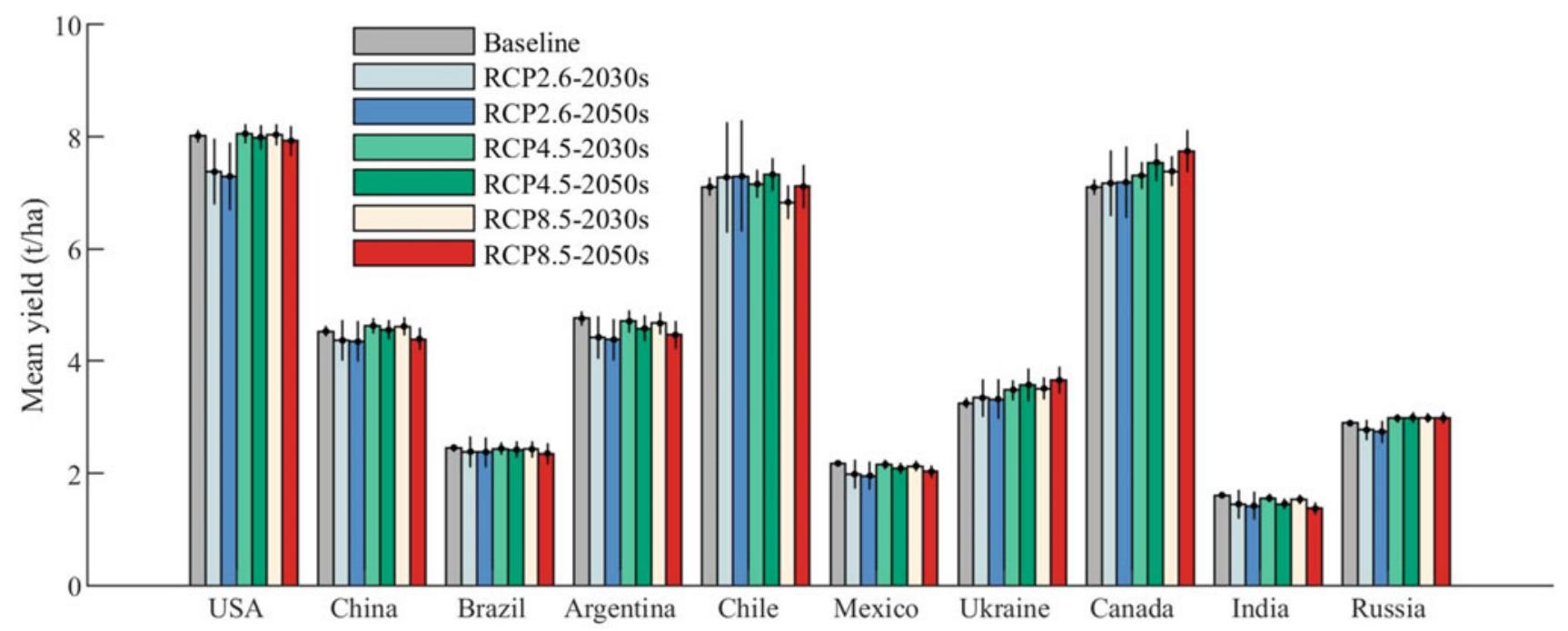

Fig. 5 Mean maize yield of the top 10 major maize-producing countries (in descending order by total production). The error bar represents the one standard deviation across the 21 general circulation models (GCMs) and three emulators 


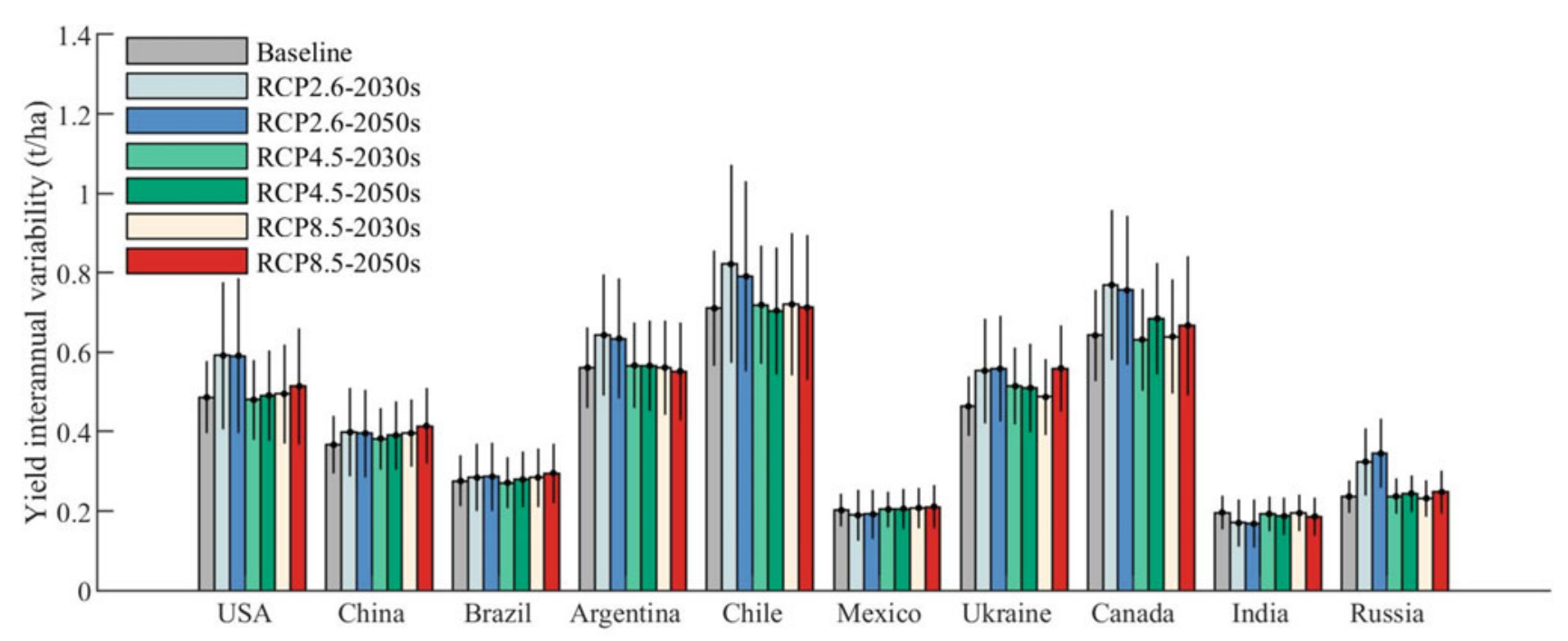

Fig. 6 Maize yield interannual variability of the top 10 major maize-producing countries (in descending order by total production). The error bar represents the one standard deviation across the 21 general circulation models (GCMs) and three emulators

Europe and southeast Africa. On the contrary, the North China Plain and the central United States will be surely harmed from warming, while the Great Lakes region of the United States and central South America will benefit from it.

From the perspective of mean maize yield, among the top ten maize-producing countries in the world (Fig. 5), the United States, Chile, and Canada have the highest mean maize yields, with values higher than $7 \mathrm{t} / \mathrm{ha}$. The mean maize yields of China and Argentina are moderate (around 4.5 t/ha), while that of Brazil, Mexico, Ukraine, and India are lower, ranging from $1.5 \mathrm{t} / \mathrm{ha}$ to $3.5 \mathrm{t} / \mathrm{ha}$. Few maize-producing countries will benefit from warming excluding Ukraine and Canada, whose mean maize yield will increase during the future periods. The mean maize yield of the United States, China, Brazil, Chile, and Russia in the future periods tend to maintain a relatively consistent level compared to that in the baseline period. In comparison, the mean maize yields of Argentina, Mexico, and India will decline slightly in the future.

From the perspective of maize yield interannual variability, among the top ten maize-producing countries in the world (Fig. 6), in Chile and Canada, the interannual variability is higher than $0.6 \mathrm{t} / \mathrm{ha}$. Conversely, in Mexico, India, and Russia, it is low and about $0.2 \mathrm{t} / \mathrm{ha}$. With the increase of warming, the interannual variability of the United States, China, Brazil, and Mexico will show a steady increasing

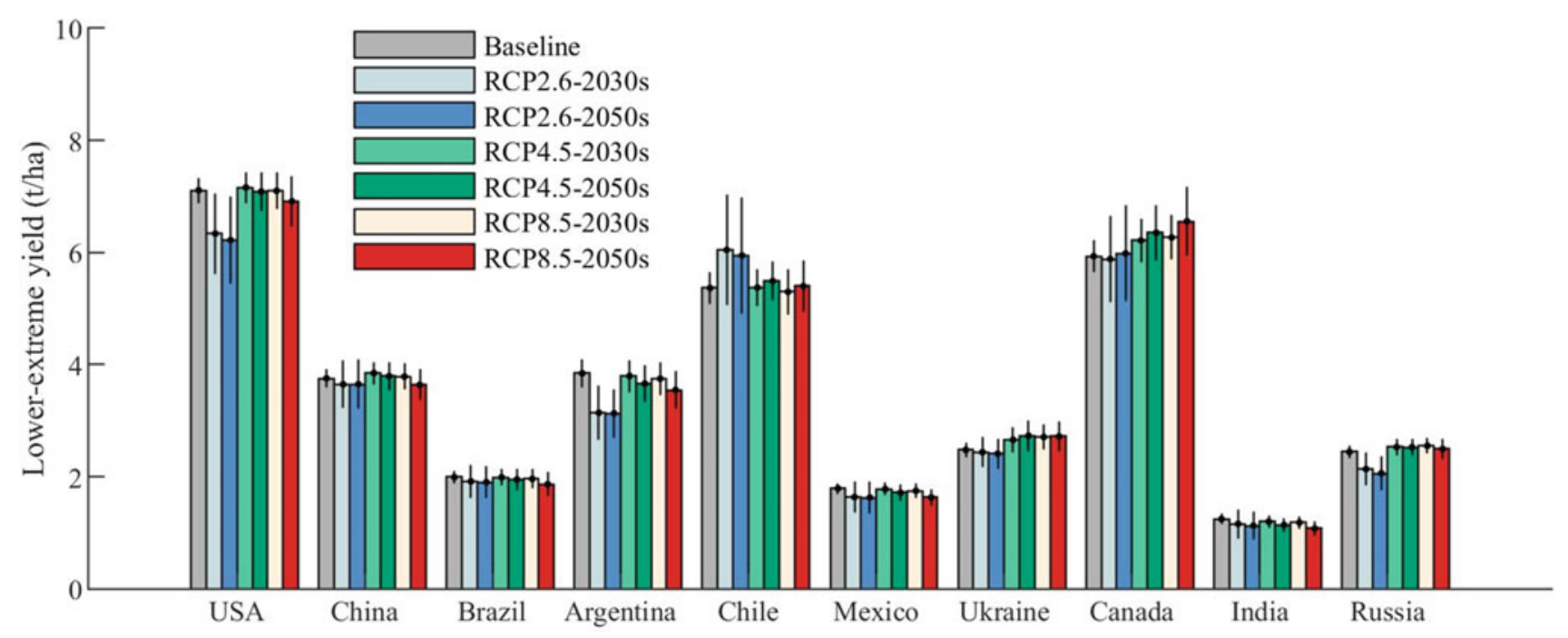

Fig. 7 Lower extreme maize yield of the top 10 major maize-producing countries (in descending order by total production). The error bar represents the one standard deviation across the 21 general circulation models (GCMs) and three emulators 
trend-for example, under the RCP4.5 and RCP8.5 scenarios, the interannual variability will become higher over time in Canada and Russia. However, the interannual variability under the RCP4.5-2050s scenario will be slightly higher than that under the RCP8.5-2030s scenario. In contrast, the interannual variability in Argentina, Chile, and India will show a descending trend in general.

From the perspective of lower extreme maize yield, among the top ten maize-producing countries in the world (Fig. 7), lower extreme yields are higher in the United States, Chile, and Canada, with values greater than $5 \mathrm{t} / \mathrm{ha}$ during all the periods and under all the scenarios. There are large differences in the relationship between the changes of warming and lower extreme maize yield among the top ten maize-producing countries. The lower extreme maize yield in Canada tends to grow as temperature rise, but in most of the countries (such as the United States, China, Brazil, Chile, Ukraine, and Russia), it will fall after rising. The rising lower extreme maize yield in short term may be a result of the increasing precipitation. However, the lower extreme maize yields in Argentina, Mexico, and India will be generally on the decline.

\subsection{Rice Yield Risk}

Globally, countries with higher mean rice yield are mainly located in the Mediterranean region, China, the southeastern United States, and Peru while those with lower yield are mainly located in Africa. There is uncertainty about the risks in some areas, such as central Africa and coastal Asia, because they will have increasing yield interannual variability but higher lower extreme rice yield. However, in general, climate change will reduce the rice yield risk at mid-latitude regions, especially Ukraine, northeastern China, and southeastern South America, where yield interannual variability will reduce along with the increasing lower extreme rice yield. Conversely, most of the regions in the low-latitude area, namely those in eastern Africa, southern Asia, and northern South America, would experience higher risk in terms of yield interannual variability and lower extreme yield.

From the perspective of mean rice yield, among the top ten rice-producing countries in the world (Fig. 8), China, the United States, and Spain have the highest mean rice yields (more than $6 \mathrm{t} / \mathrm{ha}$ ) and Peru and Iran have lower but still considerable mean yields (around $5.5 \mathrm{t} / \mathrm{ha}$ ). Indonesia and Ukraine have the mean rice yields of 4 t/ha, while Brazil, India, and Nigeria have the lowest ones (less than $2.5 \mathrm{t} / \mathrm{ha}$ ). Warming has little effect on mean rice yields, especially for Brazil, India, Peru, Spain, Nigeria, and Iran, where yields will remain largely unchanged under the RCP4.5-2030s, RCP4.5-2050s, and RCP8.5-2030s scenarios, although they will decrease under the RCP8.5-2050s scenario compared with that in the baseline period. However, the mean rice yields of China and Ukraine will increase slightly while those of Indonesia and the United States will decrease marginally.

From the perspective of rice yield interannual variability, among the top ten rice-producing countries in the world (Fig. 9), Ukraine has the greatest interannual variability $(>0.8 \mathrm{t} / \mathrm{ha}$ ), followed by Indonesia ( $>0.6 \mathrm{t} / \mathrm{ha})$. However, as the top three rice-producing countries, China, Brazil, and India have relatively little interannual variability. In several major rice-producing countries, the increase of interannual variability of rice yield has a weak positive relationship with the increase of warming. In China, Brazil, India, Indonesia,

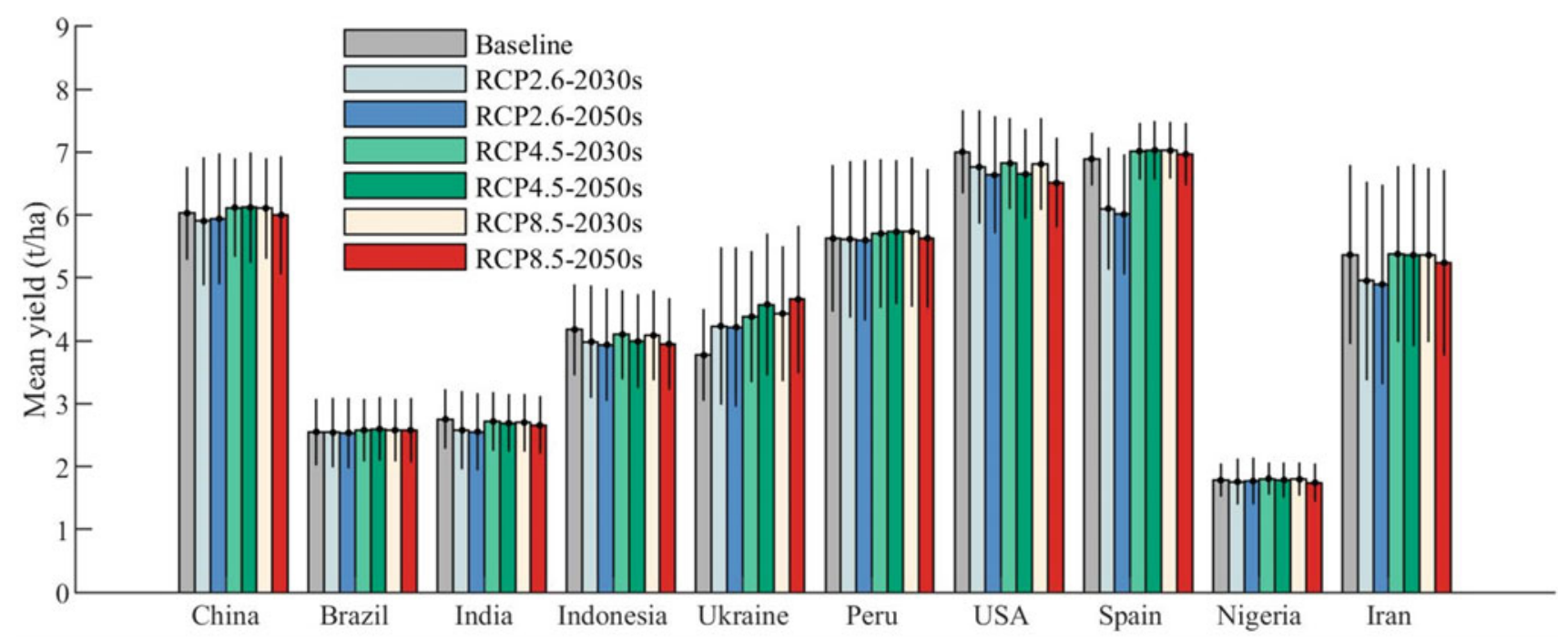

Fig. 8 Mean rice yield of the top 10 major rice-producing countries (in descending order by total production). The error bar represents the one standard deviation across the 21 general circulation models (GCMs) and three emulators 


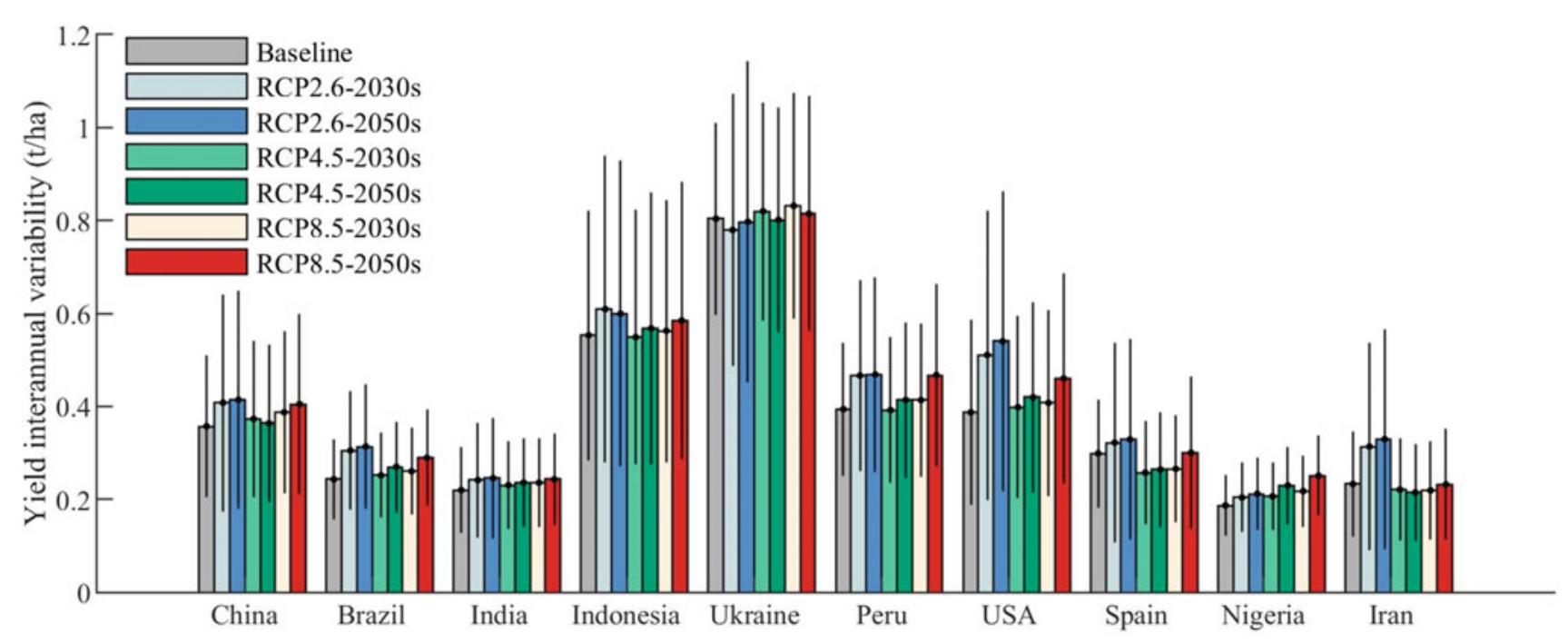

Fig. 9 Rice yield interannual variability of the top 10 major rice-producing countries (in descending order by total production). The error bar represents the one standard deviation across the 21 general circulation models (GCMs) and three emulators

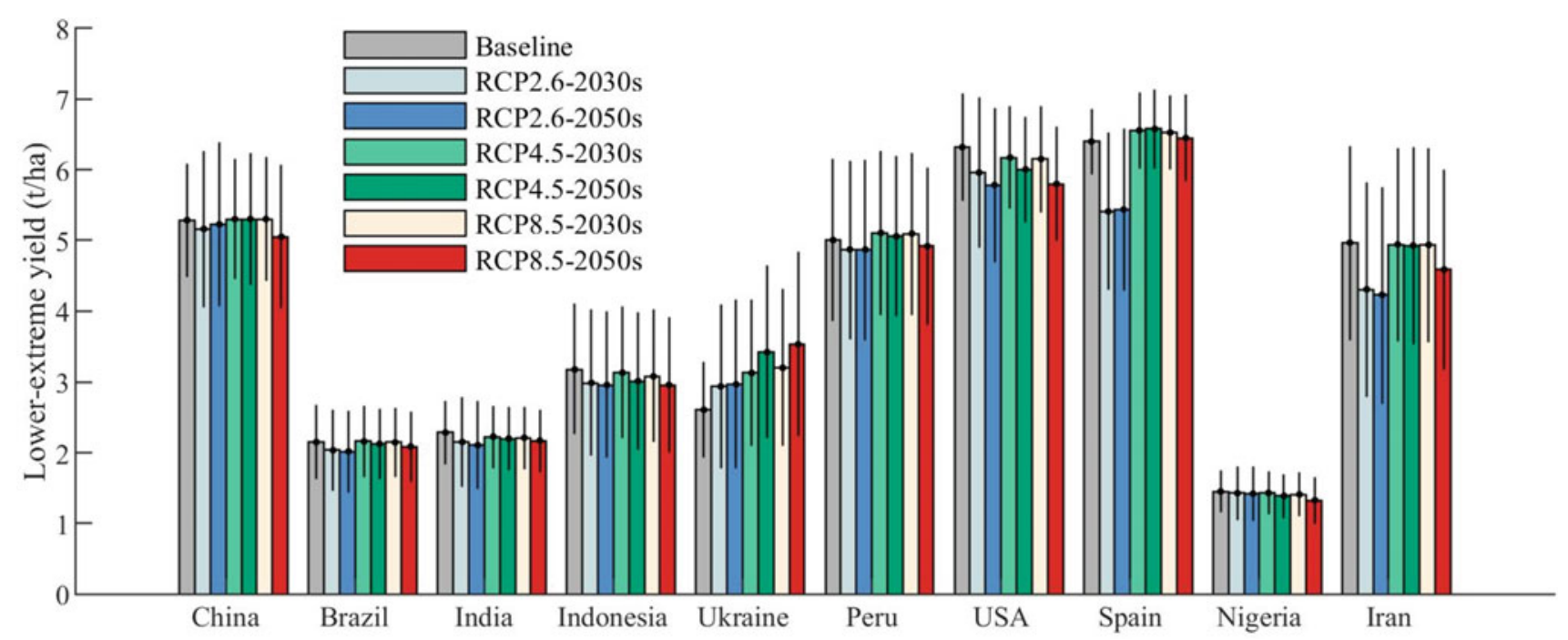

Fig. 10 Lower extreme rice yield of the top 10 major rice-producing countries (in descending order by total production). The error bar represents the one standard deviation across the 21 general circulation models (GCMs) and three emulators

Peru, the United States, and Nigeria, the interannual variability of rice yield will increase as the climate gets warmer, but the trend is not significant. On the other hand, the interannual variability of rice yield in Ukraine will show a fluctuating upward trend, that is, under the high emissions scenario (RCP8.5), interannual variability will be higher than that in the medium emissions scenario (RCP4.5), but the interannual variability in the near future (the 2030s) is higher than that in the far future (the 2050s). In Spain and Iran, the yield interannual variability will decrease first, but increase slightly when it is much warmer.
From the perspective of lower extreme rice yield, among the top ten rice-producing countries in the world (Fig. 10), the lower extreme rice yield is high in China, the United States, and Spain ( $>5$ t/ha), followed by Brazil and India (23 t/ha) and Nigeria (1-2 t/ha). Among the top ten rice-producing countries, the lower -extreme rice yields in China, Brazil, Peru, and Spain will increase first and then decrease under higher emissions scenario and further into the future, but in Ukraine the lower extreme rice yield will keep increasing. The lower extreme rice yields in India, Indonesia, the United States, Nigeria, and Iran will generally decrease. 


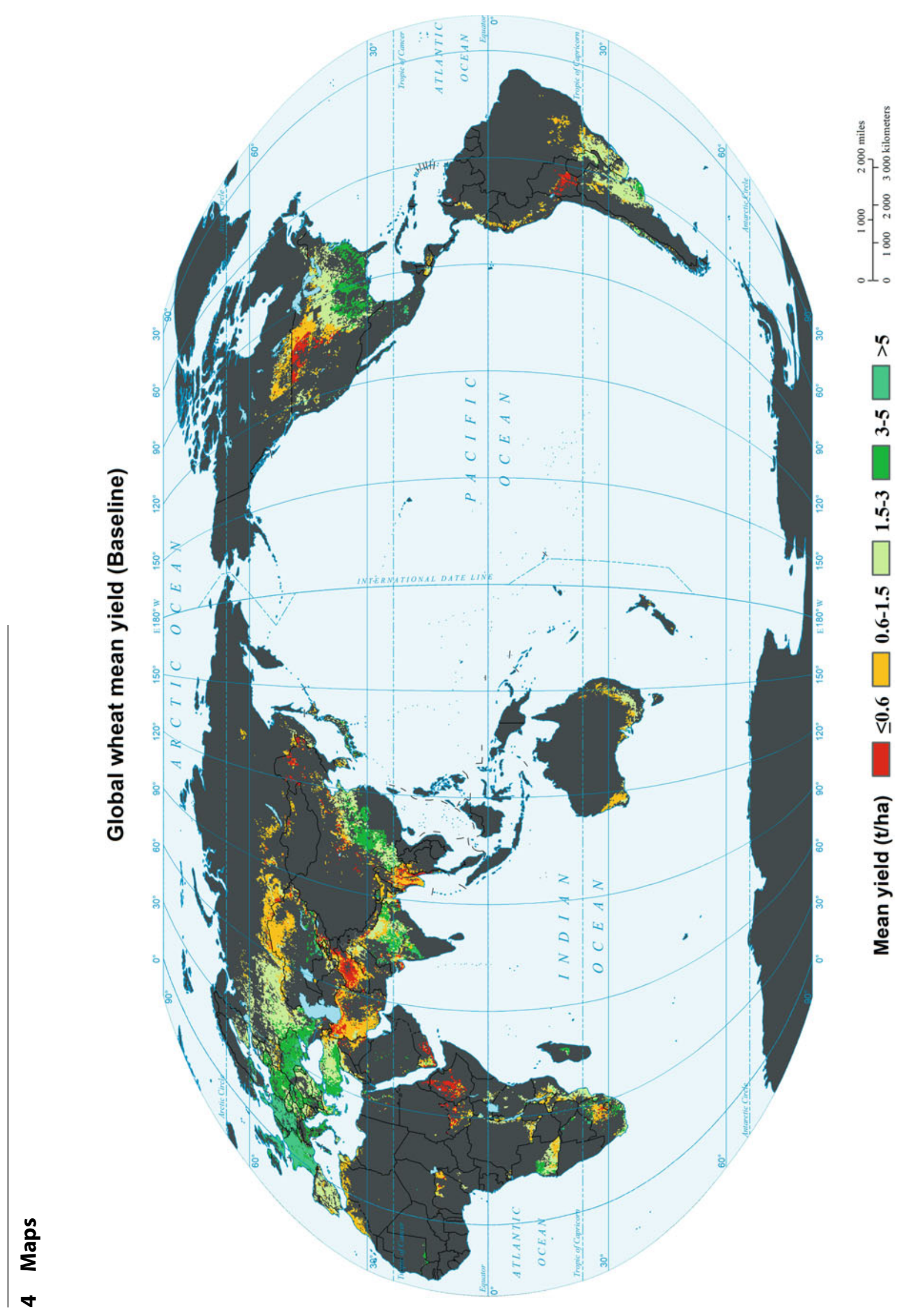




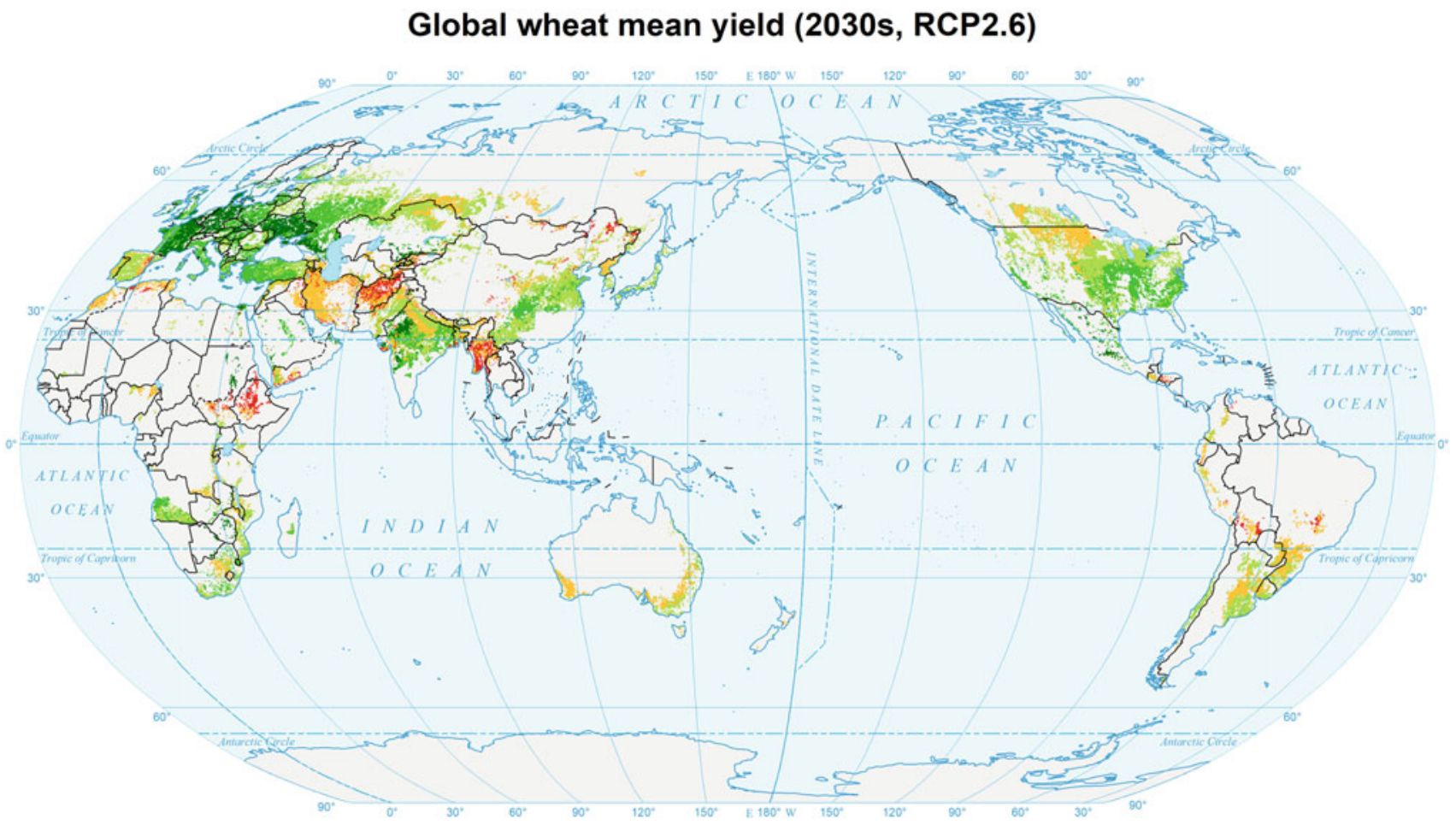

Mean yield (t/ha) $\quad \leq \mathbf{0 . 6} \square$ 0.6-1.5 $\square$ 1.5-3 $\square$ 3-5 $\square>\mathbf{5} \quad \begin{aligned} & 0 \quad 1000 \quad 2000 \text { miles } \\ & 010002000 \text { kilometers }\end{aligned}$

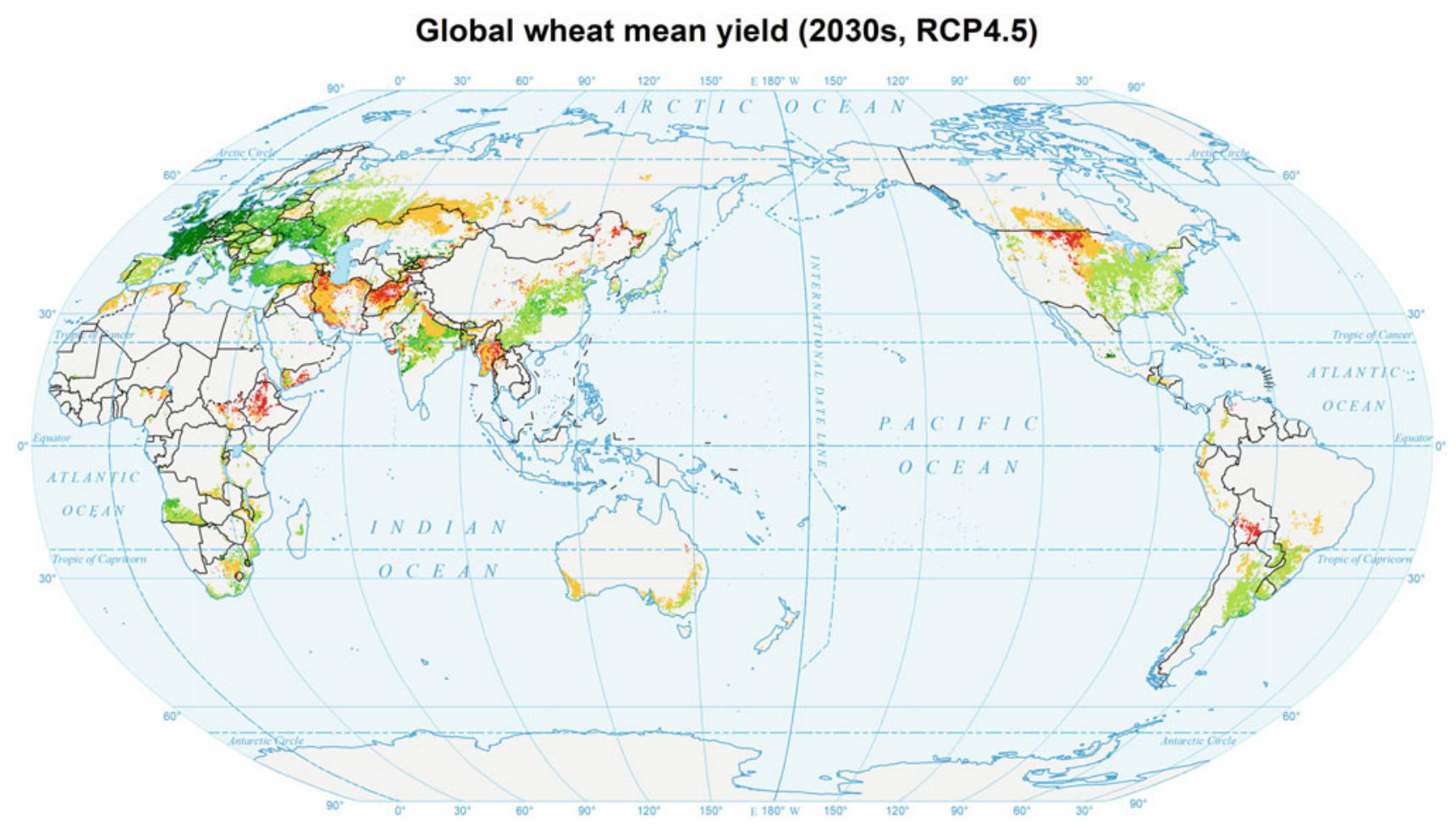

Mean yield (t/ha) $\quad \leq \mathbf{0 . 6} \square \mathbf{0 . 6 - 1 . 5} \square \mathbf{1 . 5}-\mathbf{3} \square \mathbf{3 - 5} \square>\mathbf{5} \quad \begin{aligned} & 0 \quad 1000 \quad 2000 \text { miles } \\ & 010002000 \text { kilometers }\end{aligned}$ 


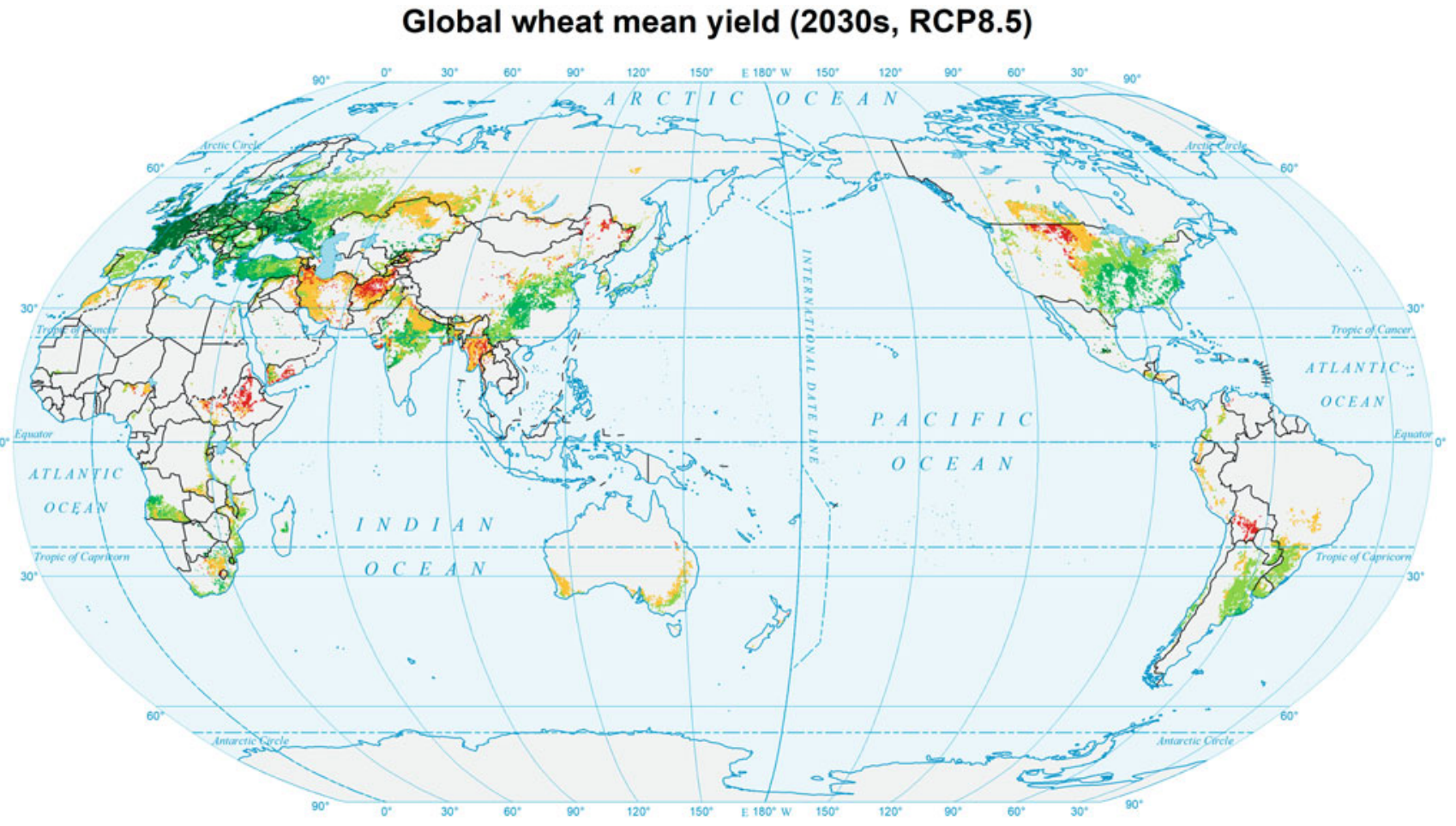

Mean yield (t/ha) $\square \leq \mathbf{0 . 6} \square$ 0.6-1.5 $\square$ 1.5-3 $\square$ 3-5 $\square>\mathbf{5} \quad \begin{aligned} & 0 \\ & \stackrel{1}{0} 10002000 \text { kilometers }\end{aligned}$

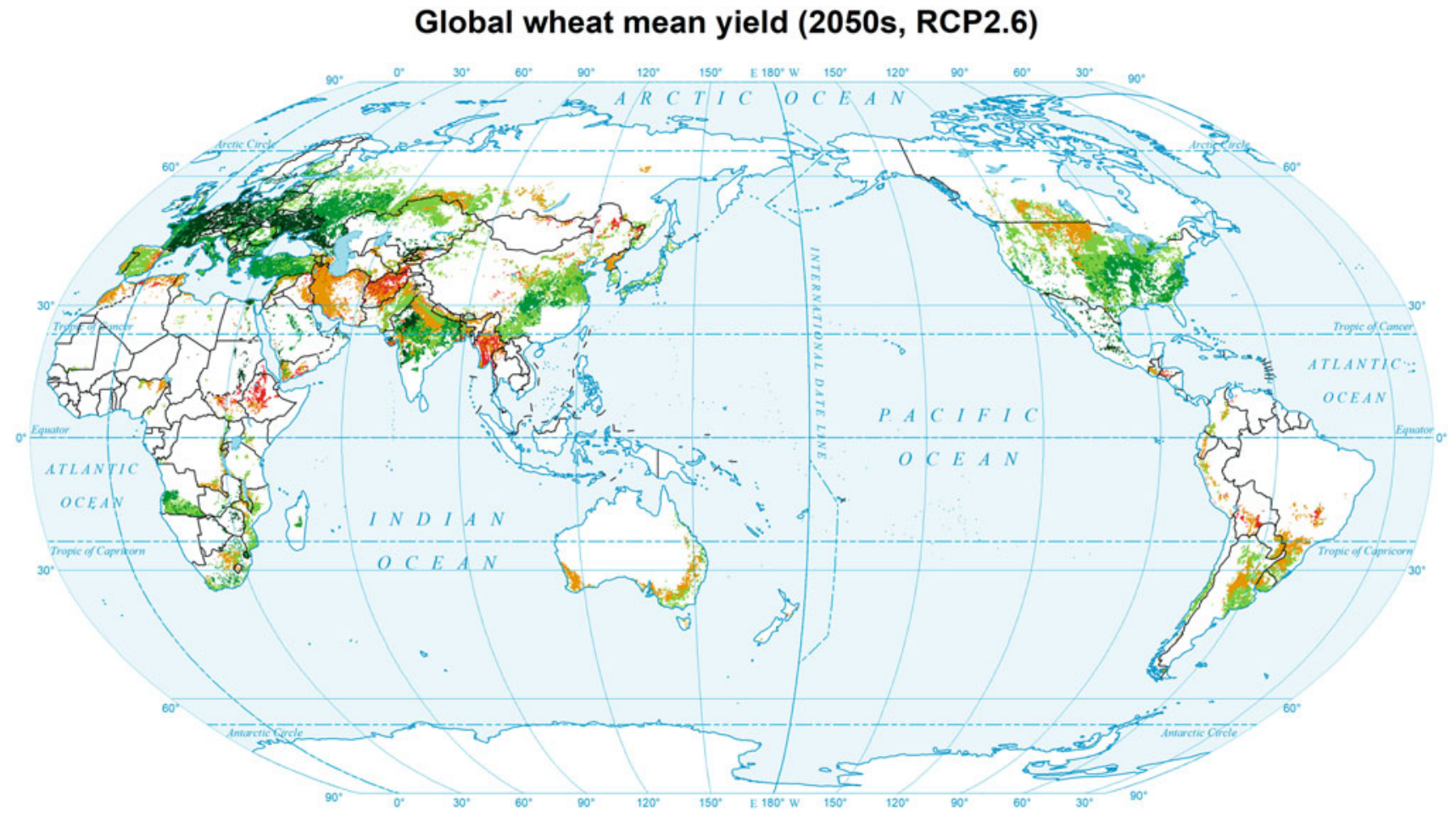

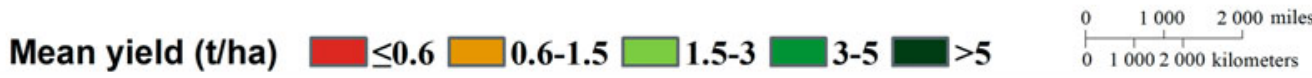




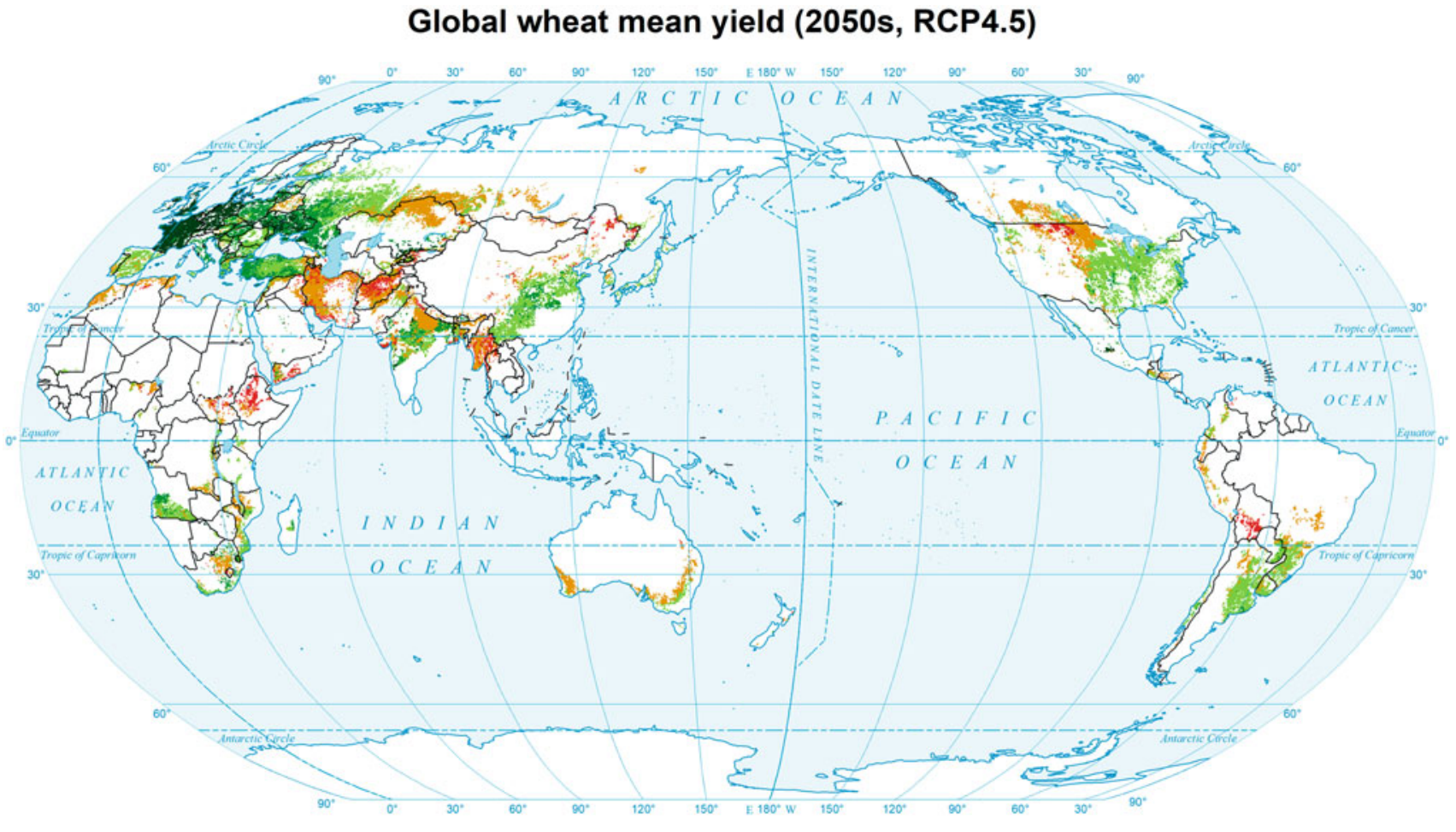

Mean yield (t/ha) $\quad \leq \mathbf{0 . 6} \square$ 0.6-1.5 $\square$ 1.5-3 $\square=3-5 \square>\mathbf{5} \quad \begin{aligned} & 0 \quad 1000 \quad 2000 \text { miles } \\ & 010002000 \text { kilometers }\end{aligned}$

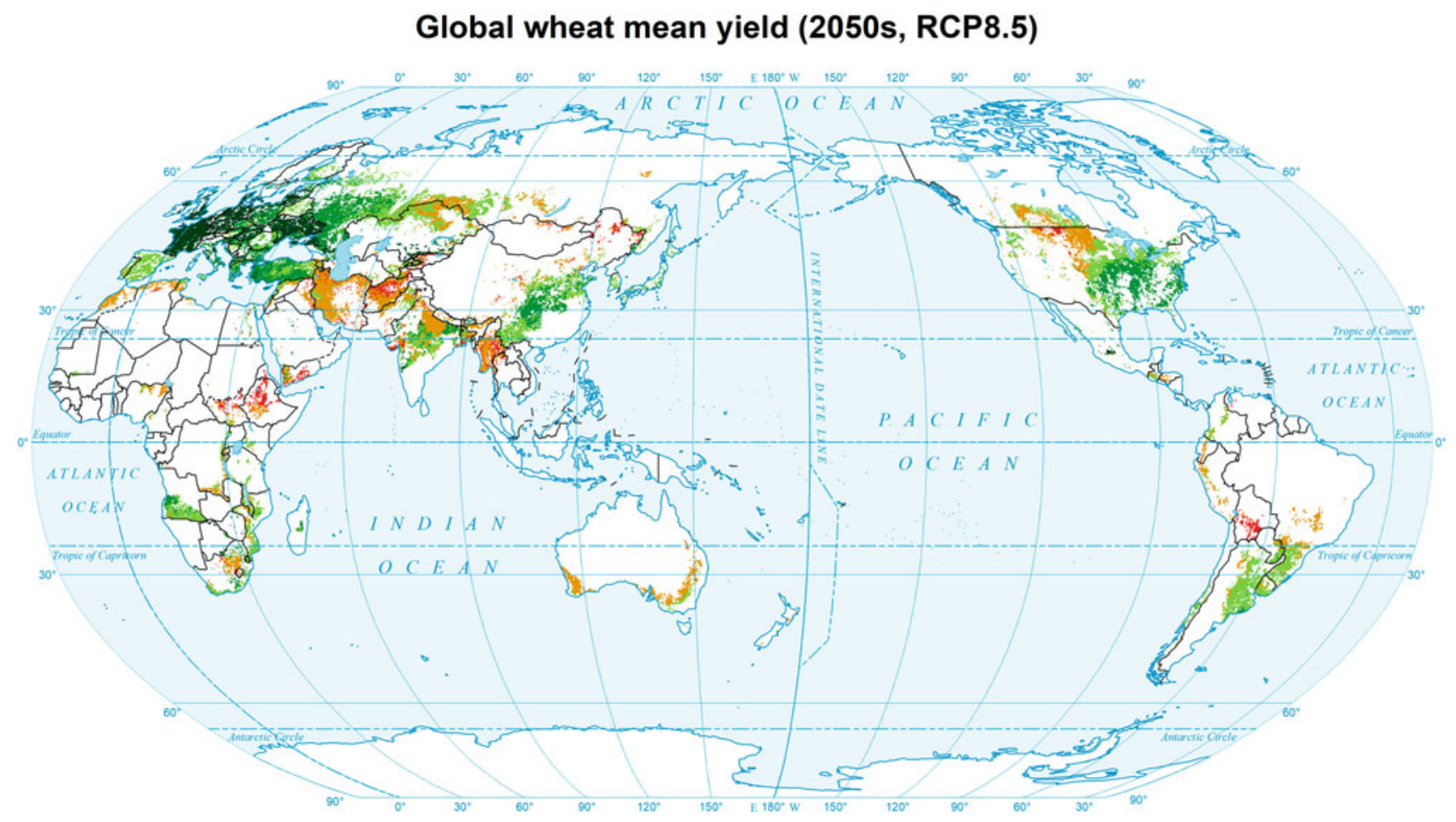

Mean yield (t/ha) $\square \leq \mathbf{0 . 6} \square \mathbf{0 . 6 - 1 . 5} \square \mathbf{1 . 5}-3 \square-3-5 \square>\mathbf{5} \quad \begin{aligned} & 0 \quad 1000 \quad 2000 \text { miles } \\ & 010002000 \text { kilometers }\end{aligned}$ 


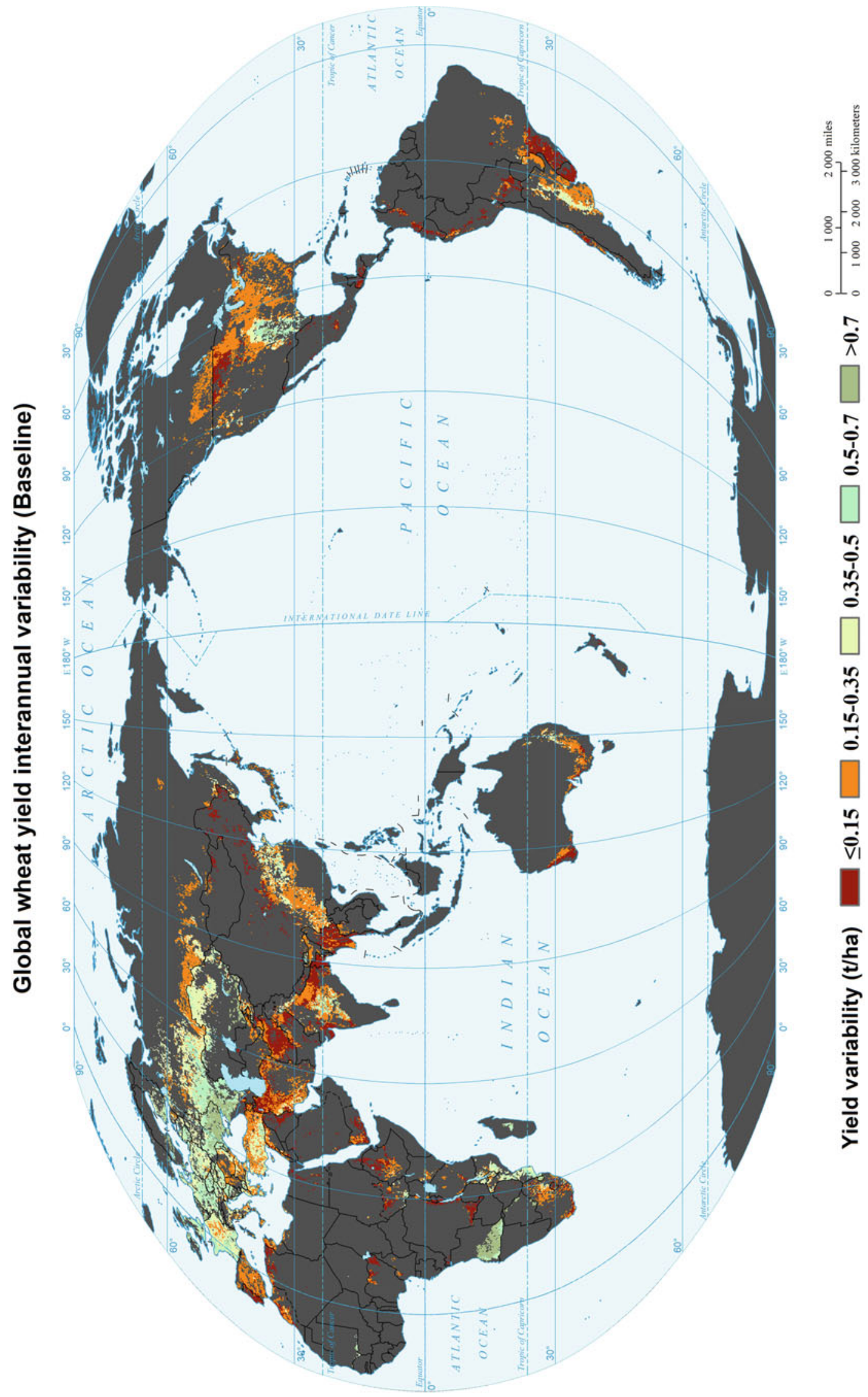


Global wheat yield interannual variability (2030s, RCP2.6)

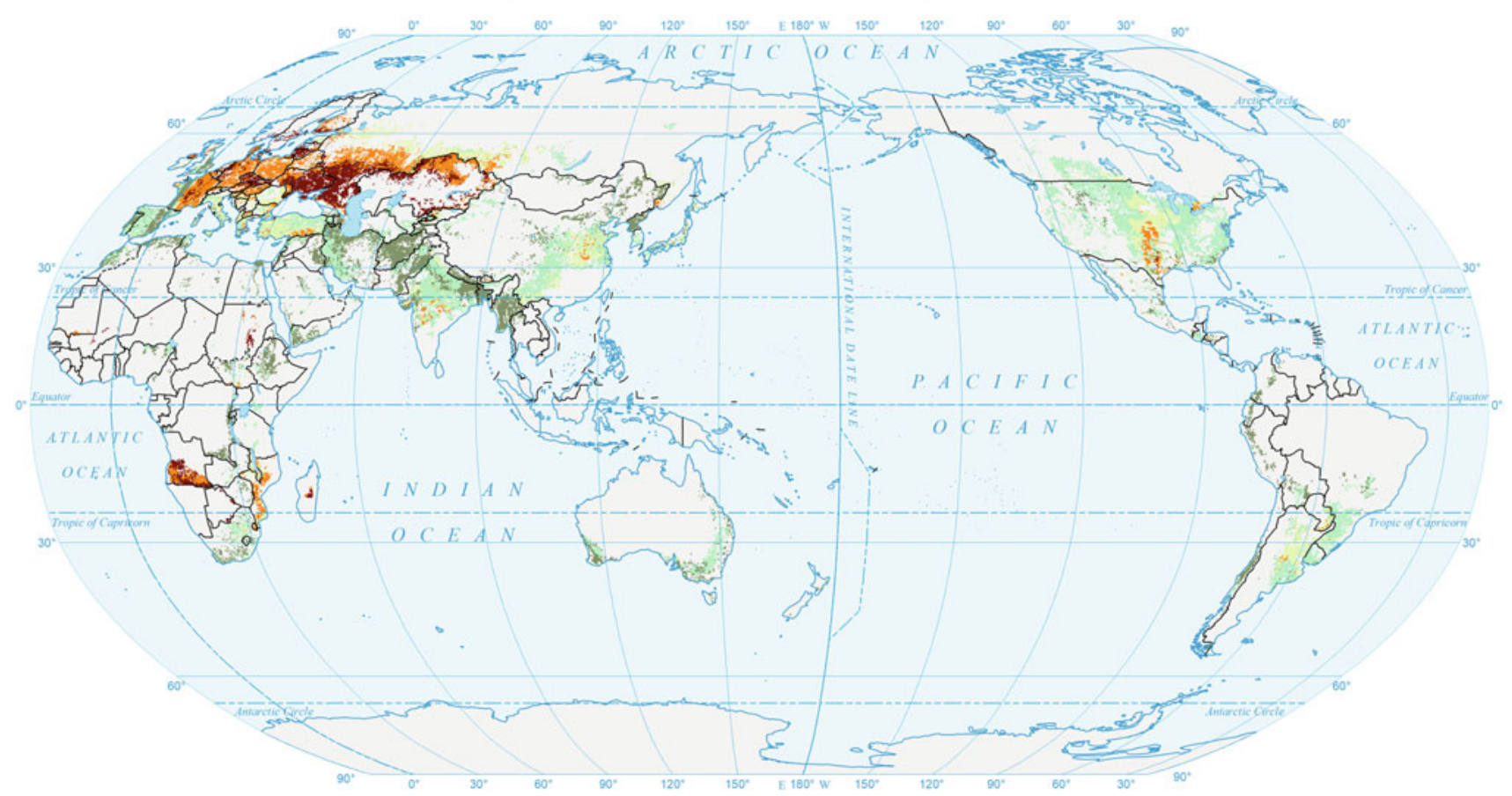

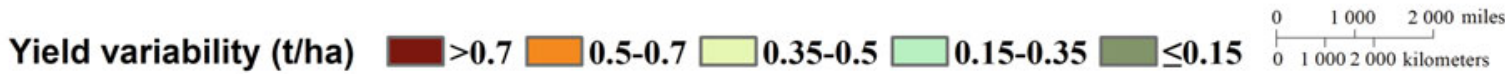

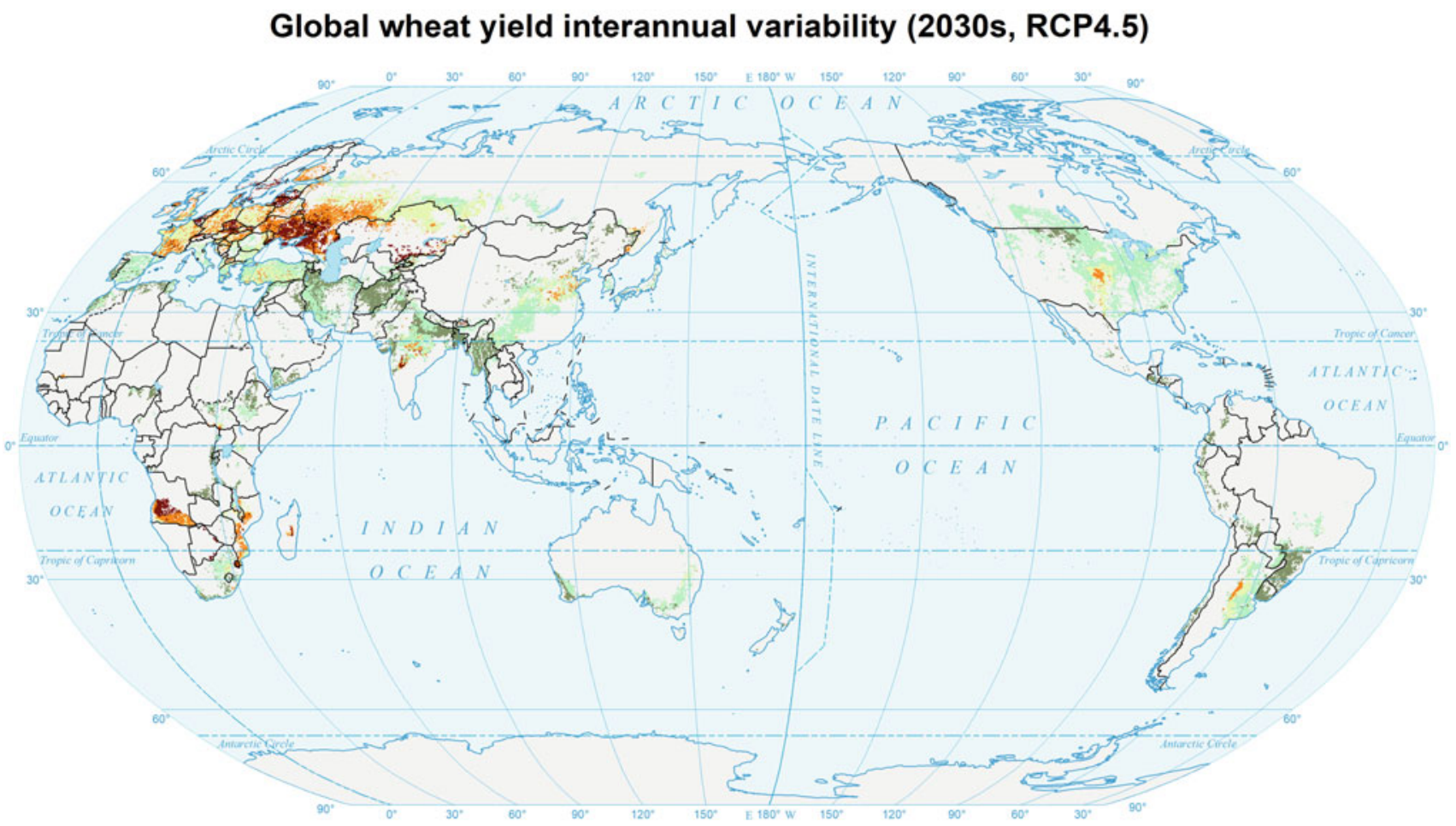

Yield variability (t/ha) 
Global wheat yield interannual variability (2030s, RCP8.5)

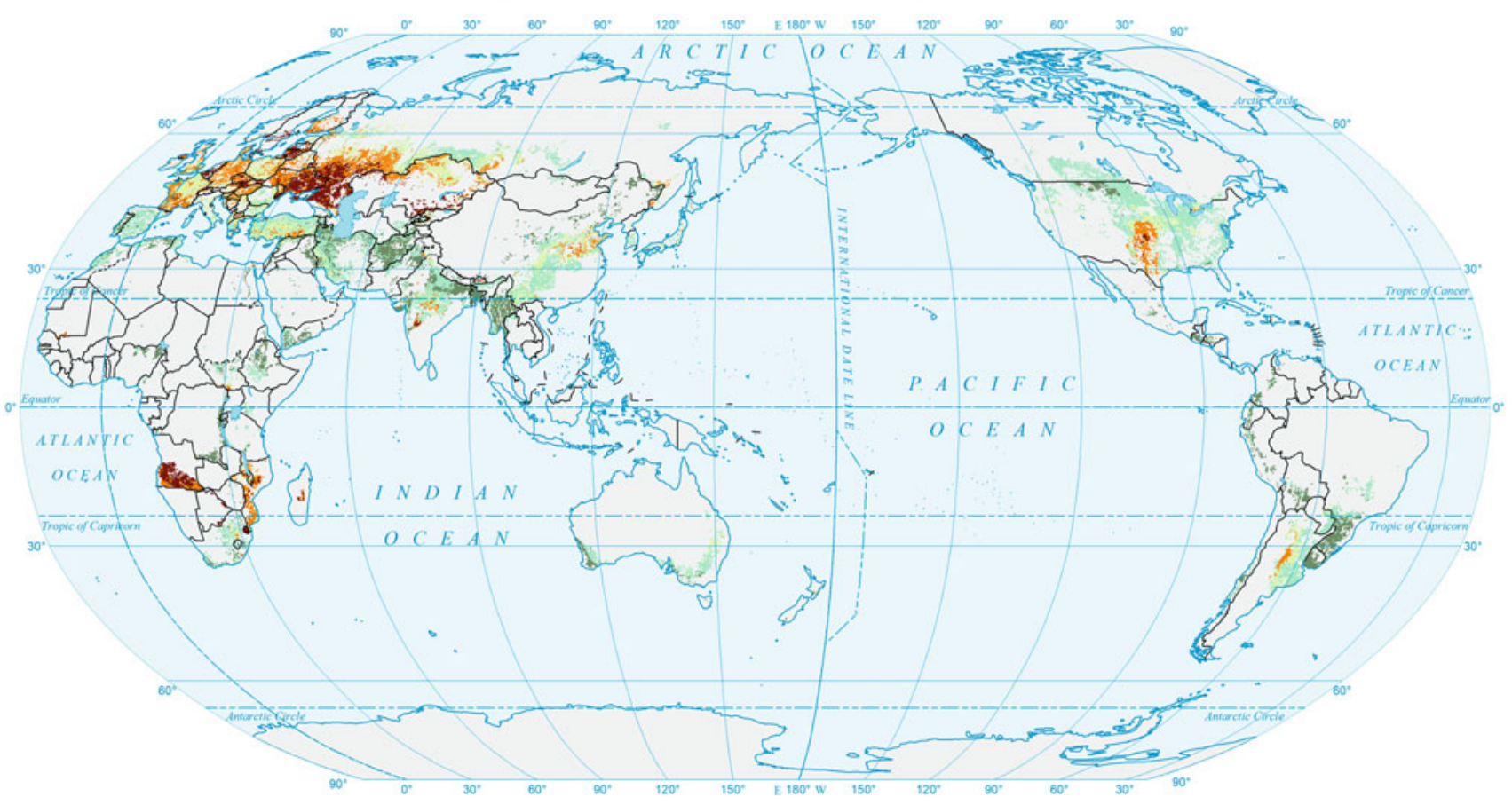

Yield variability (t/ha)

$>0.7 \square 0.5-0.7$

$0.35-0.5$

$0.15-0.35$

$\mathbf{0 . 1 5} \stackrel{0}{\stackrel{10}{1000} \quad 2000 \text { miles }}$

Global wheat yield interannual variability (2050s, RCP2.6)

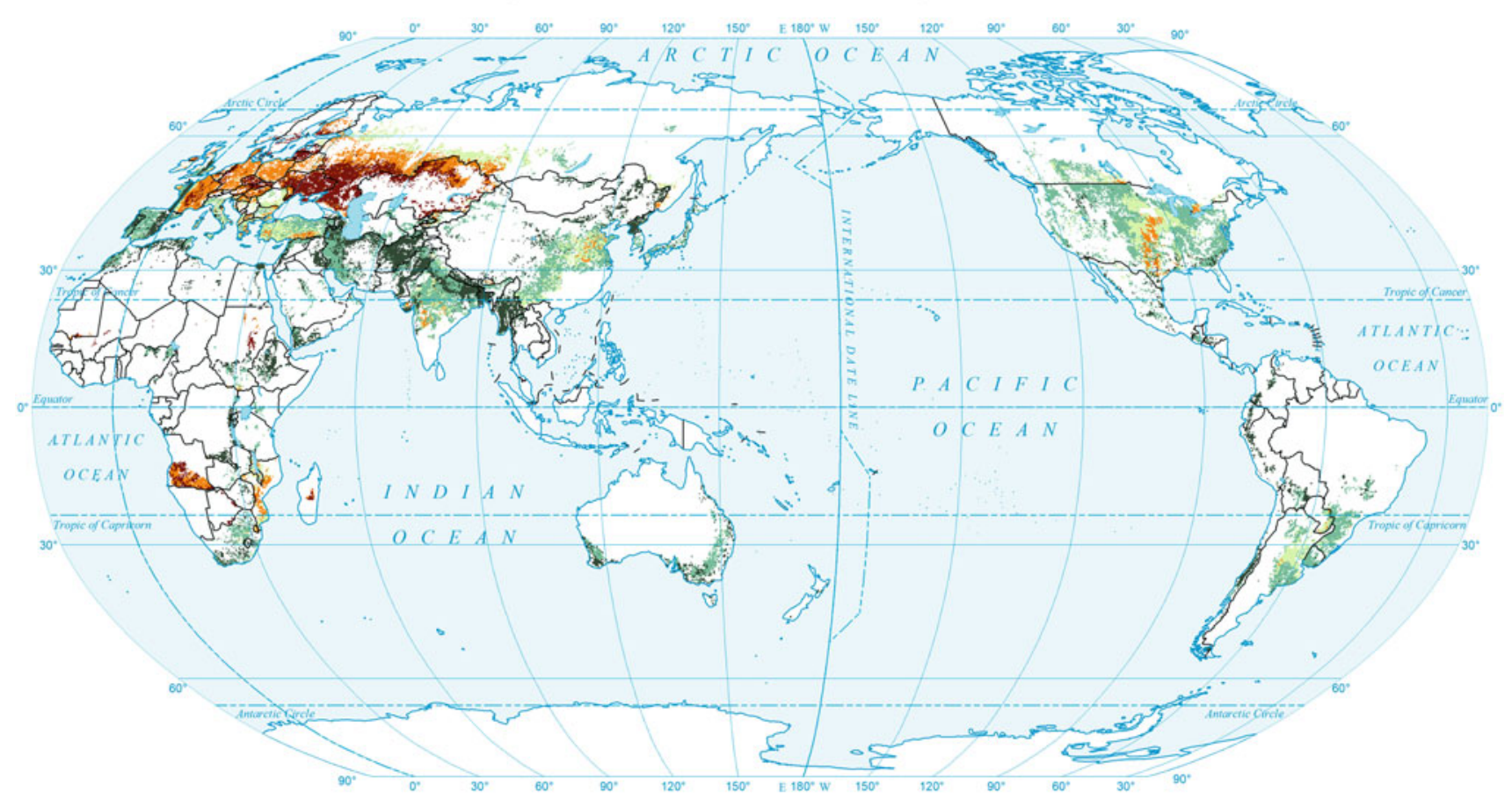


Global wheat yield interannual variability (2050s, RCP4.5)

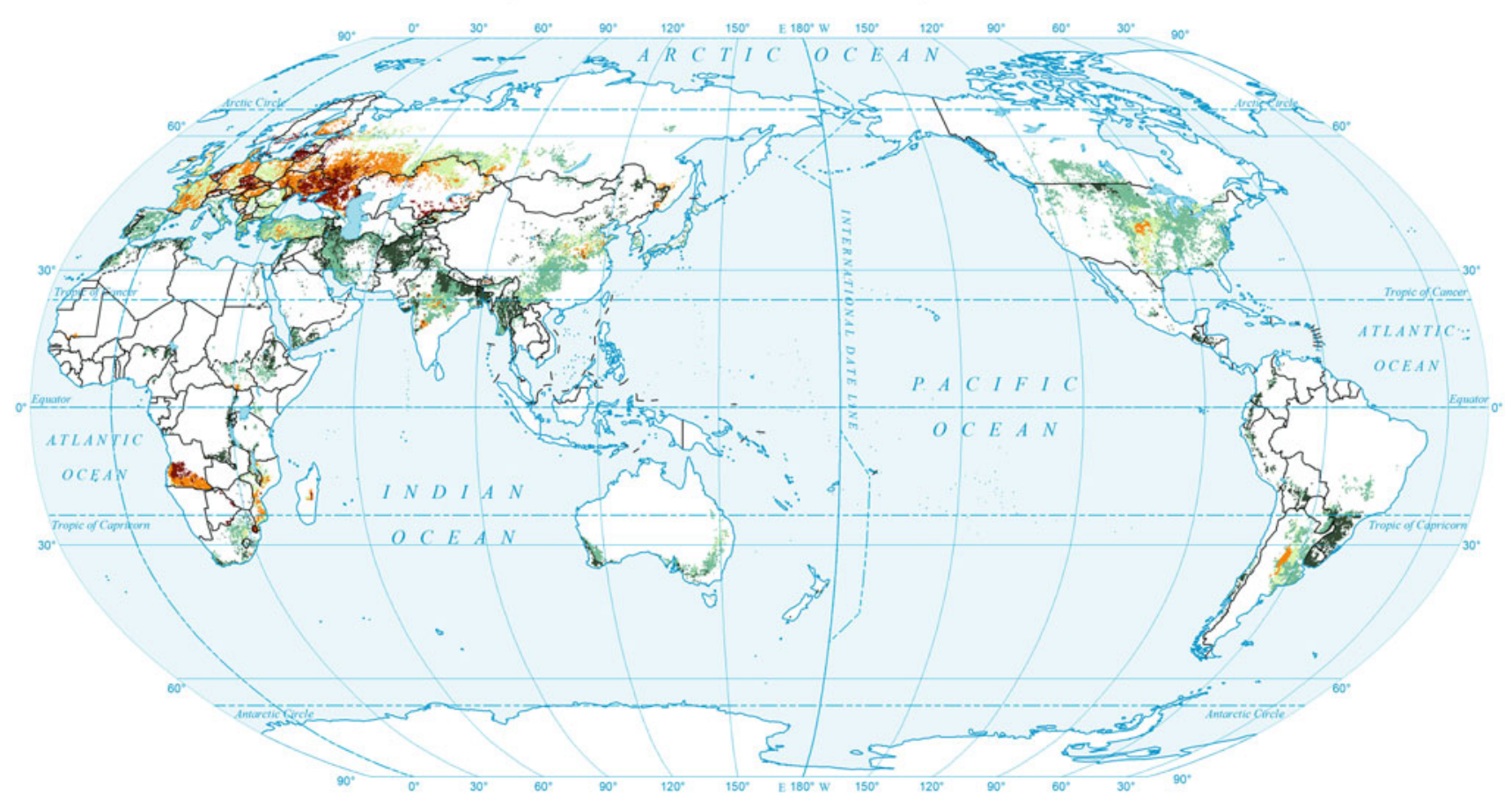

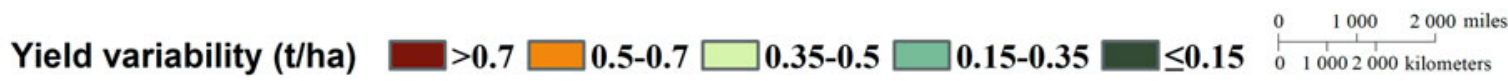

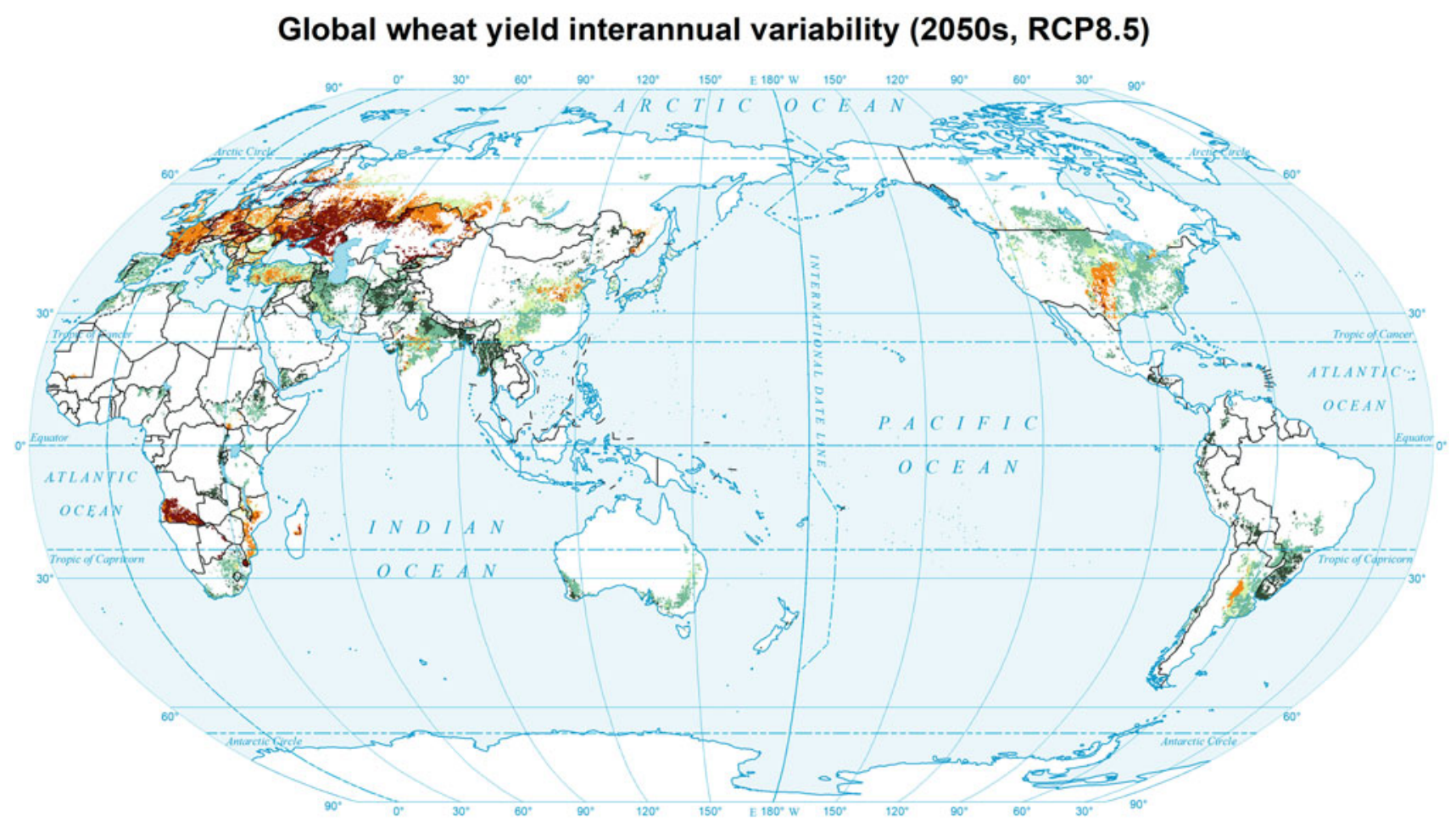

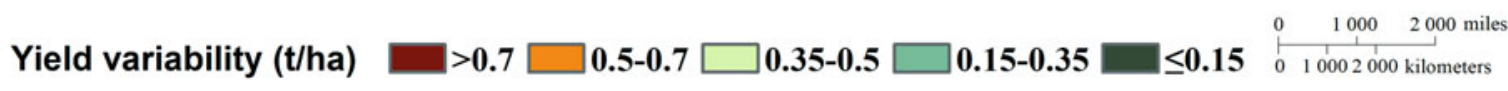




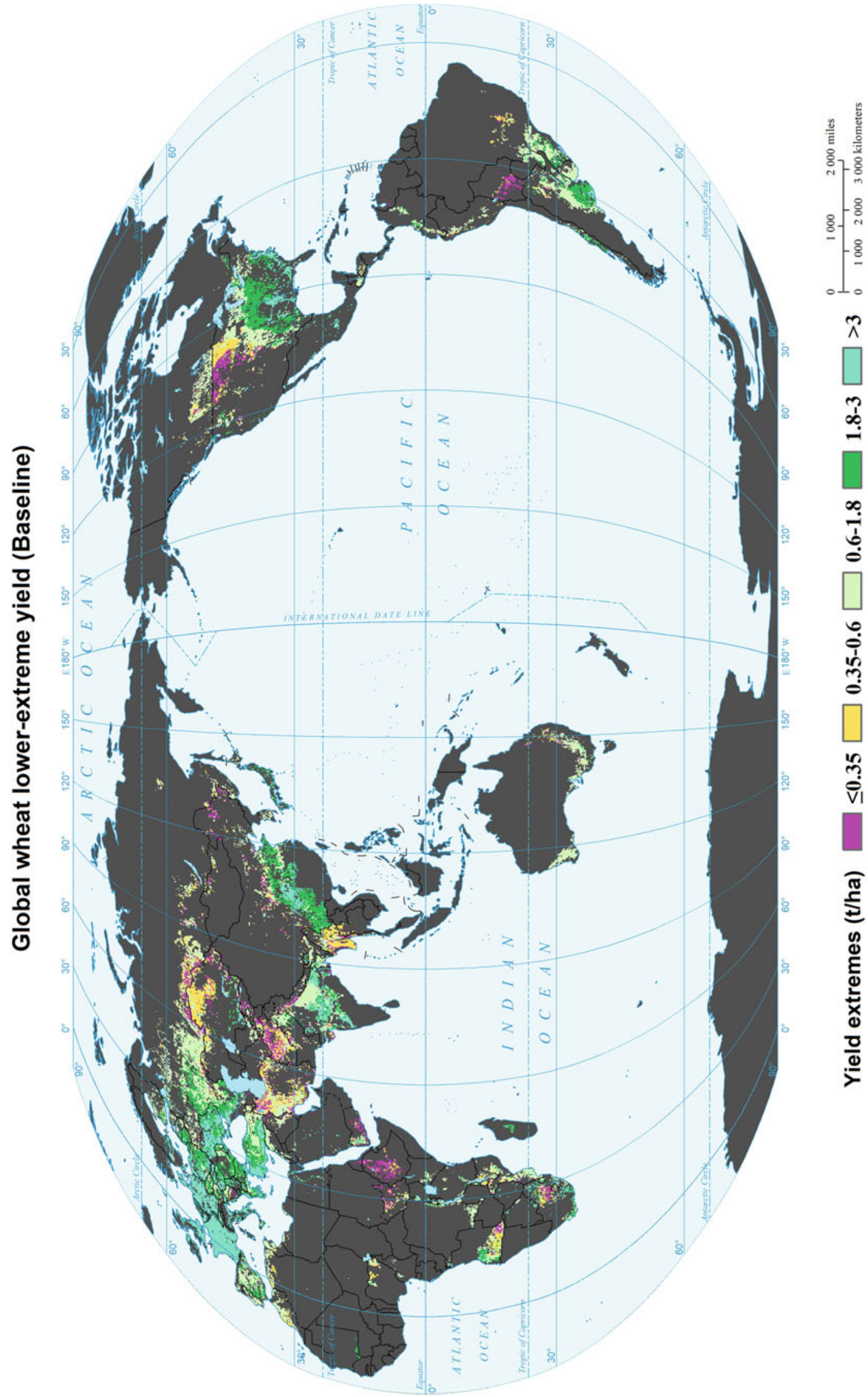




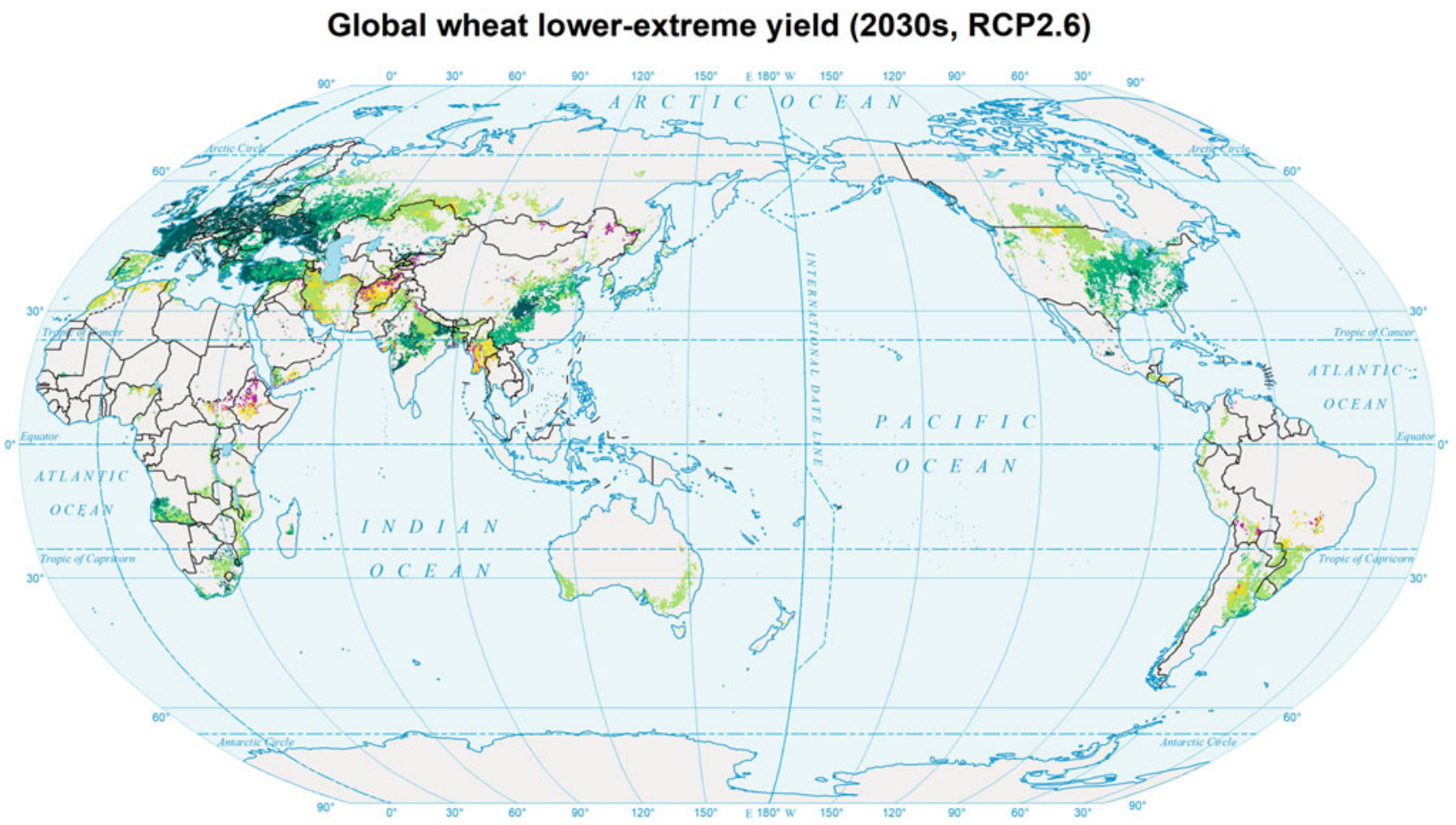

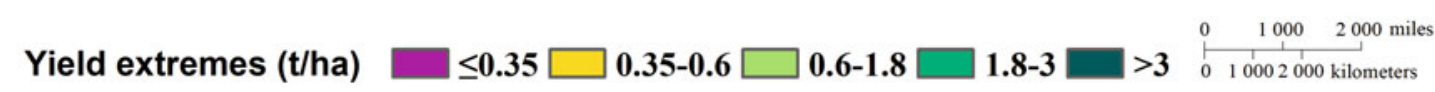

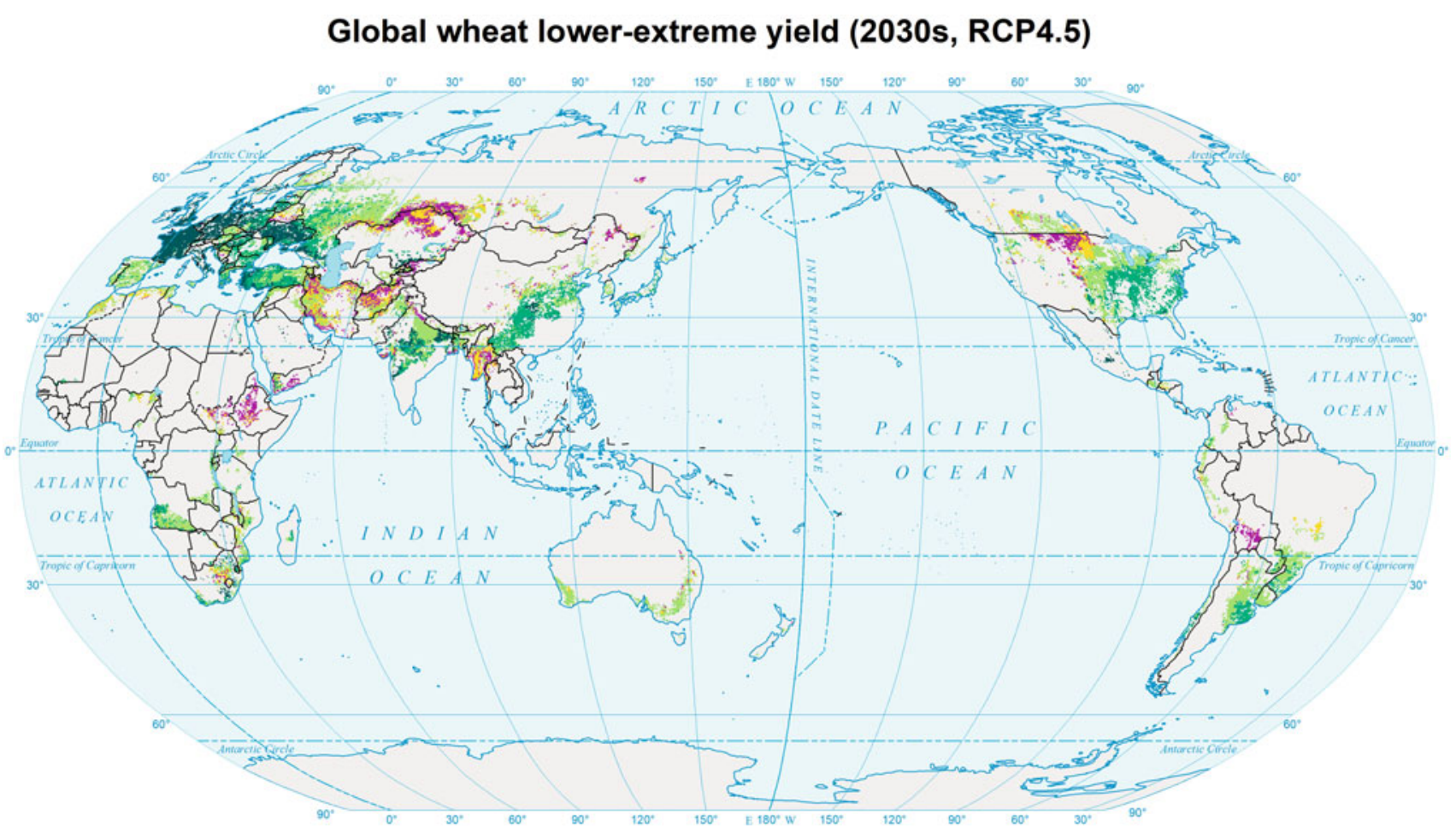

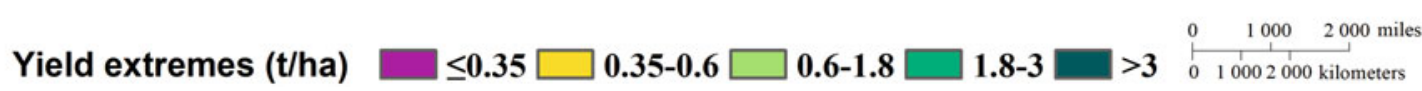




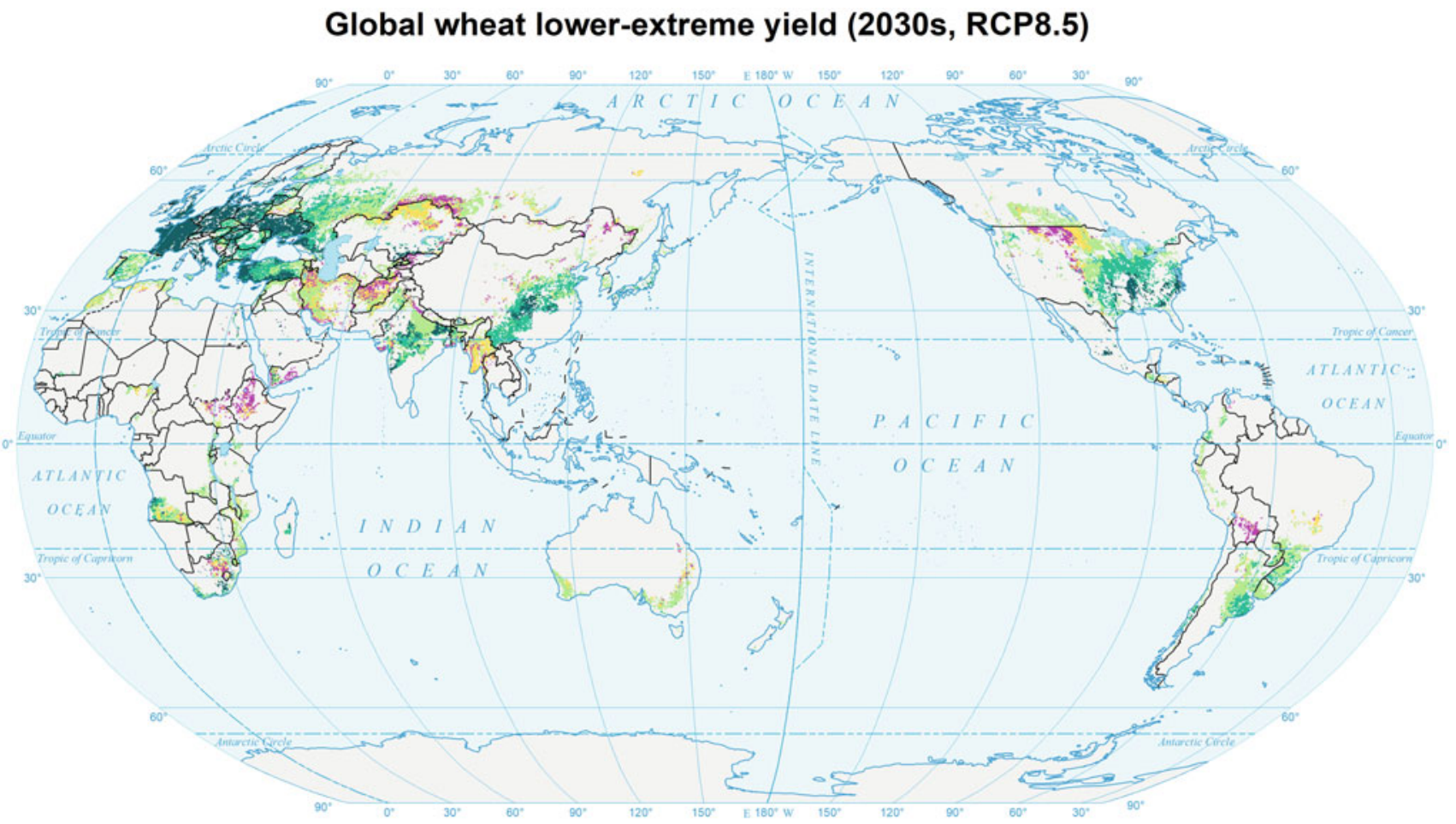

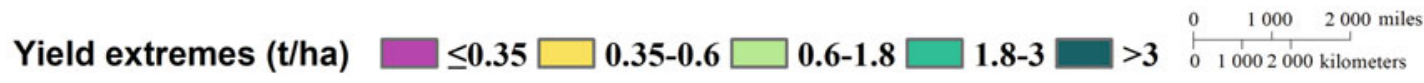

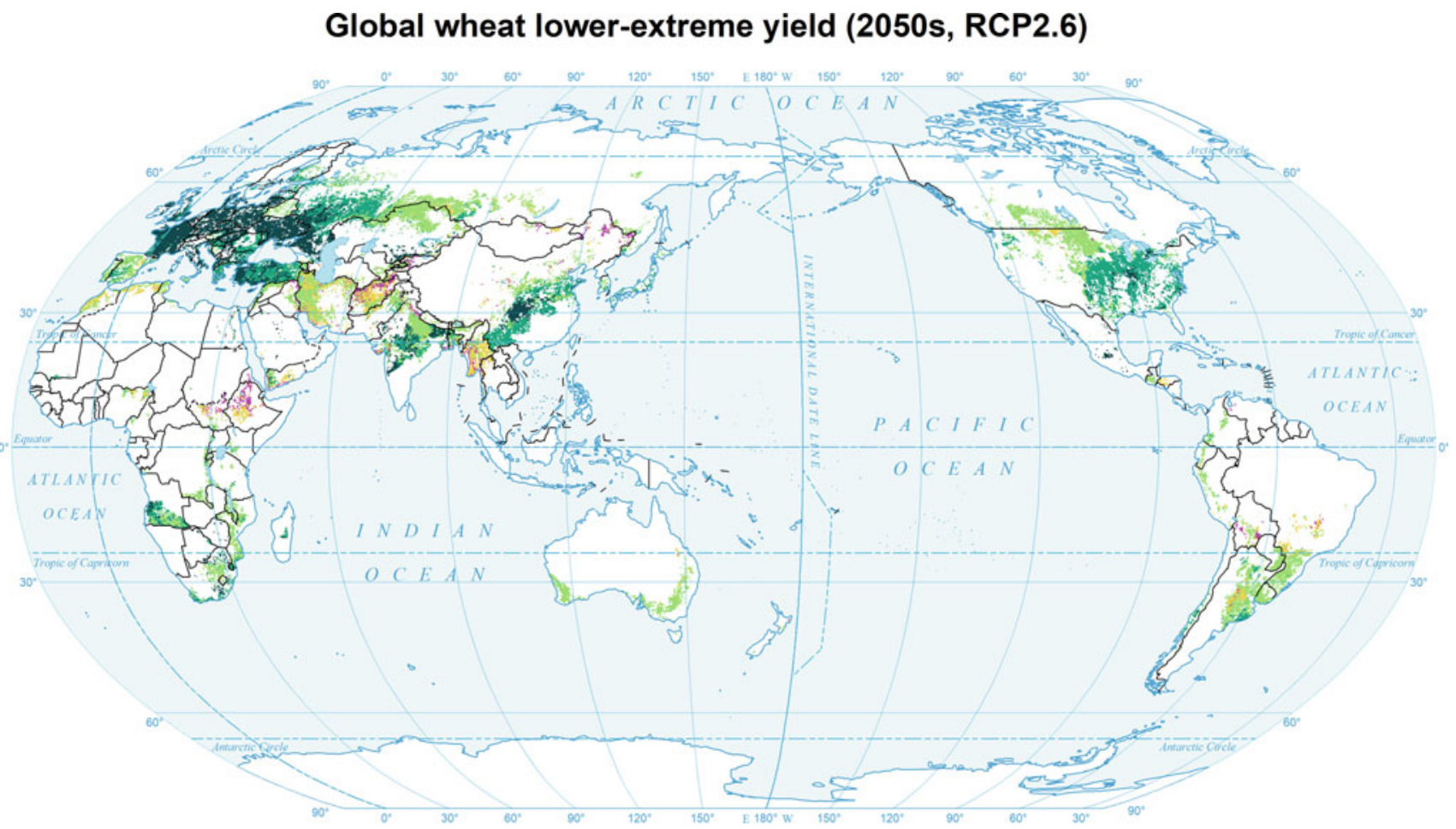

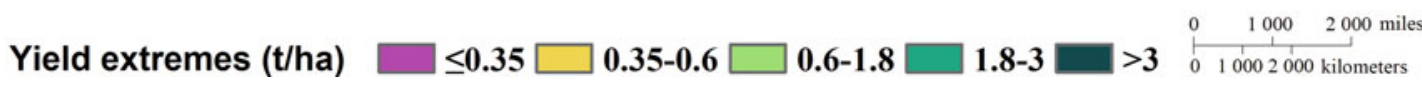




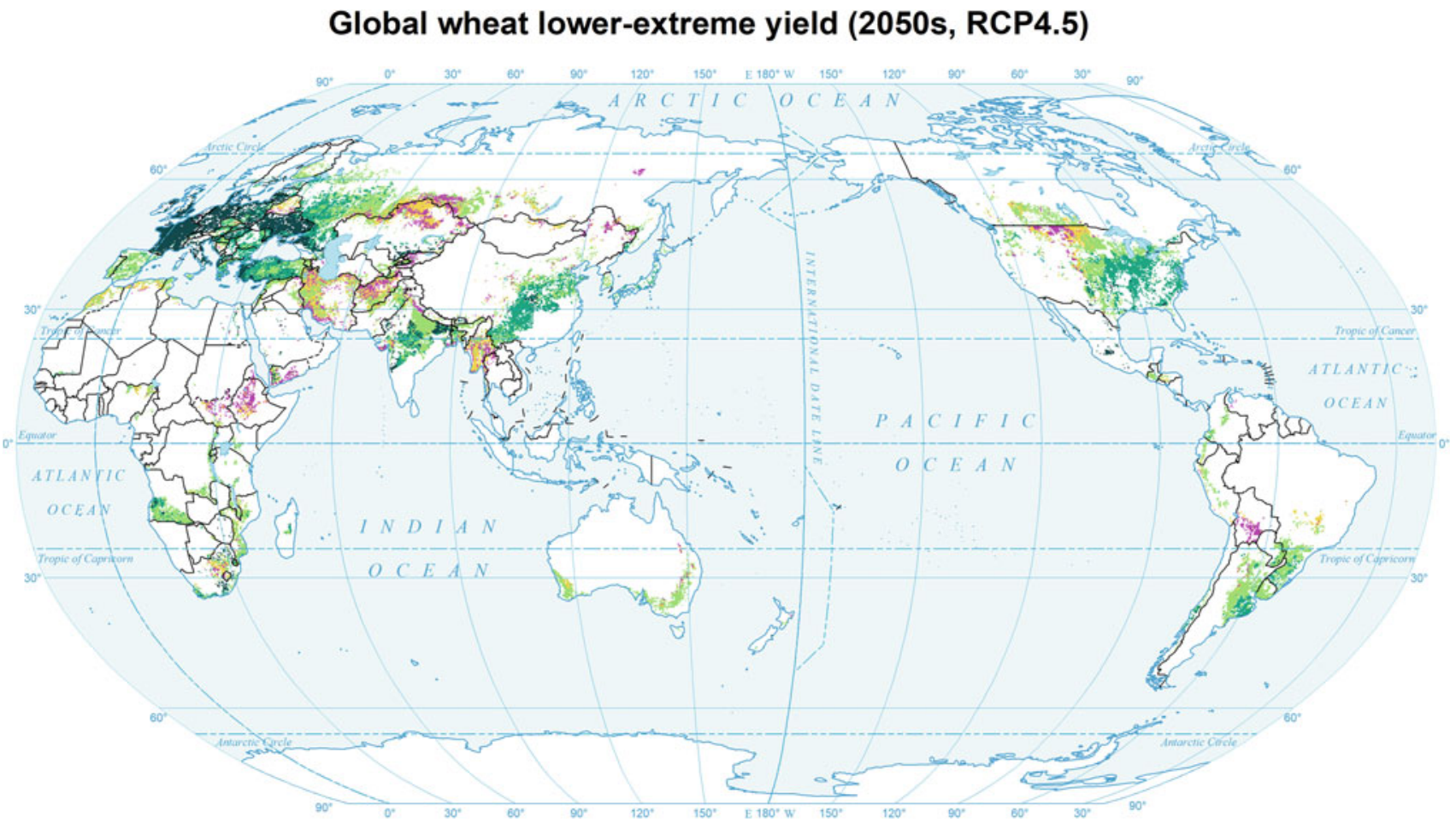

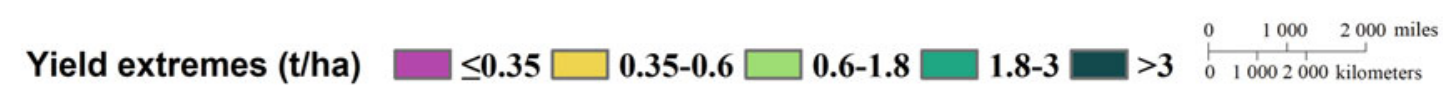

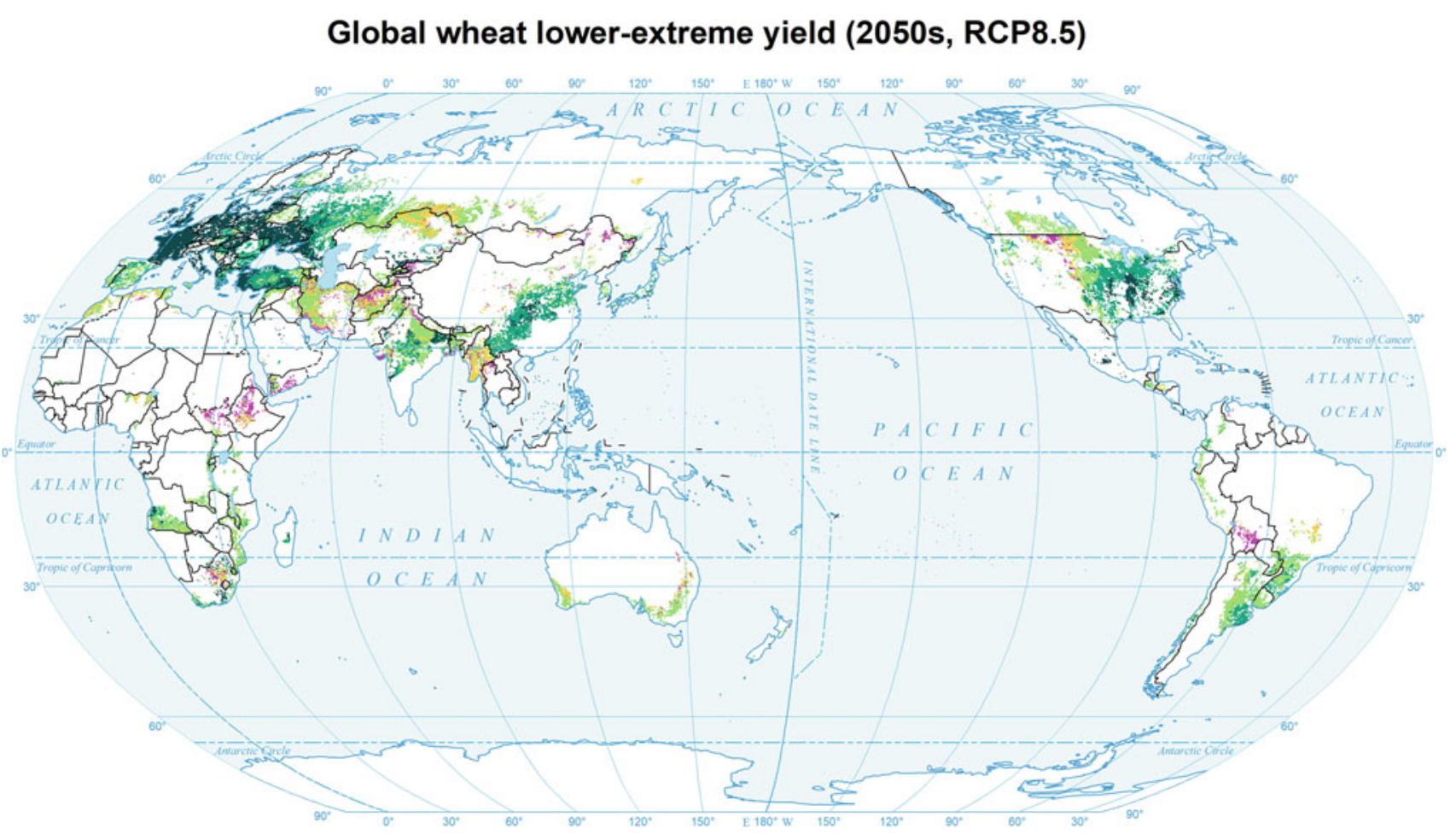

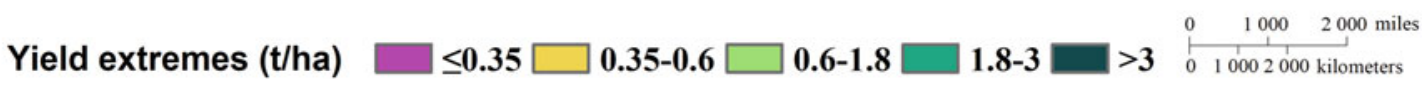




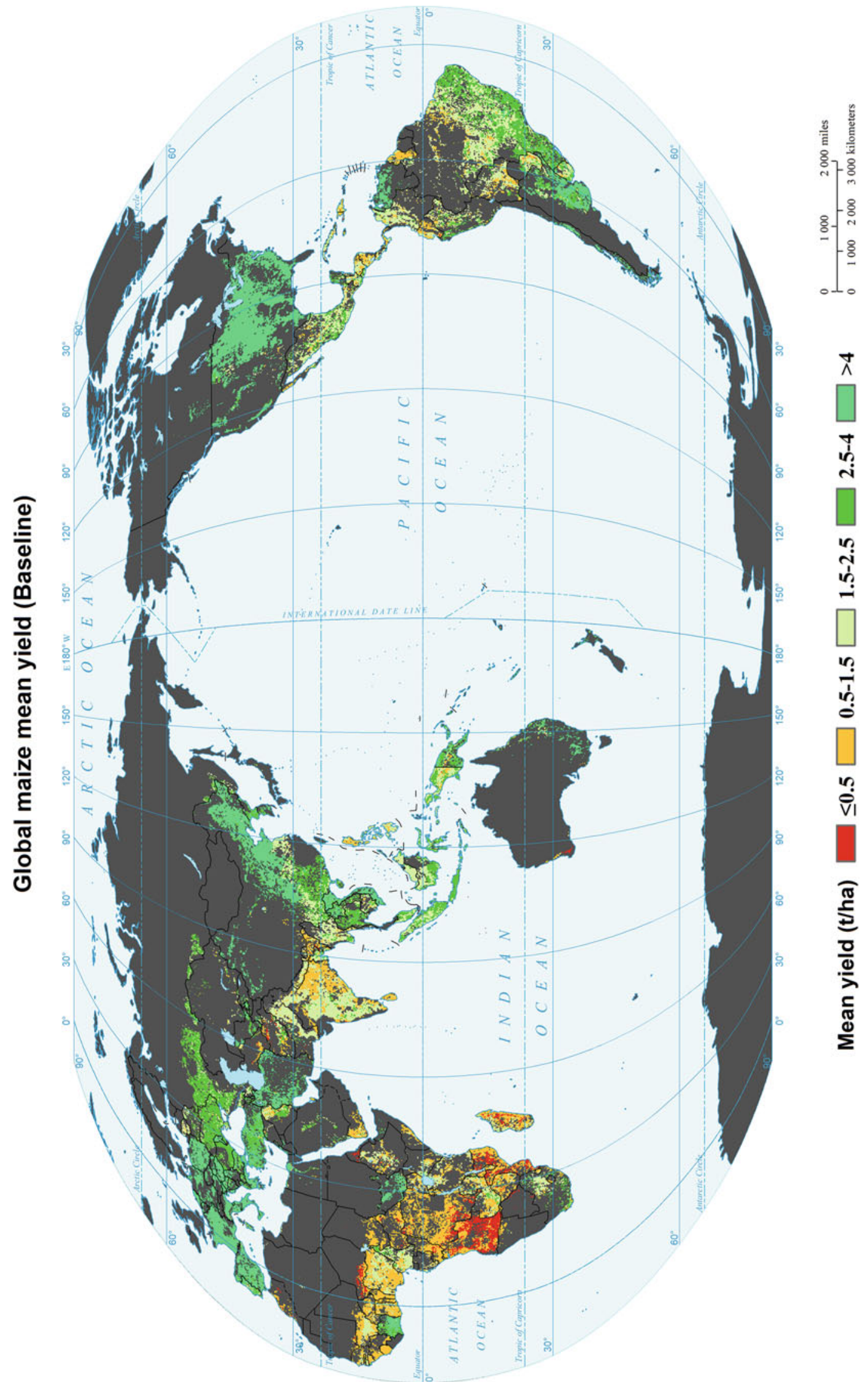




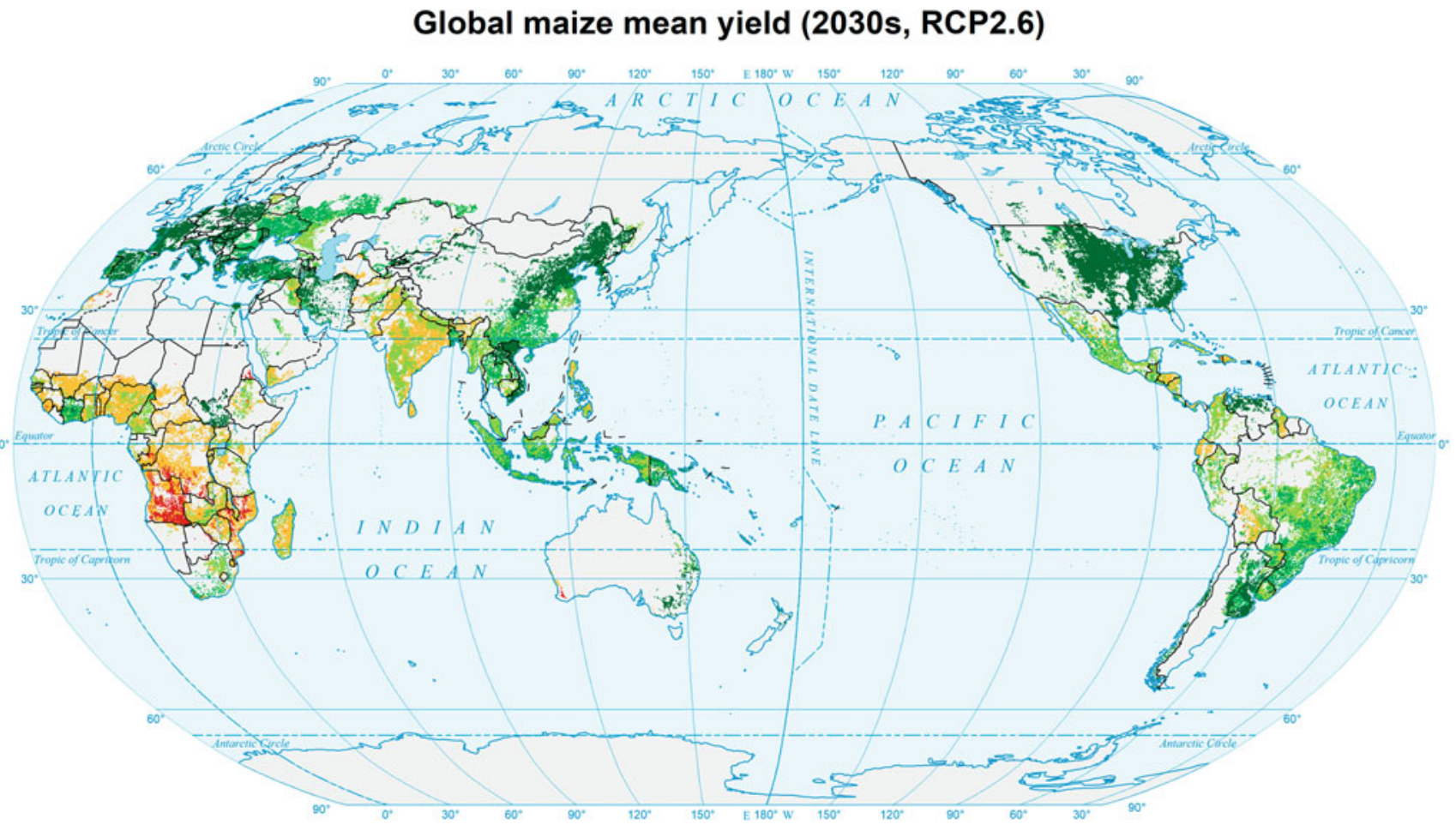

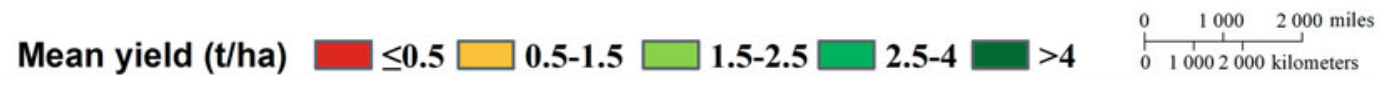

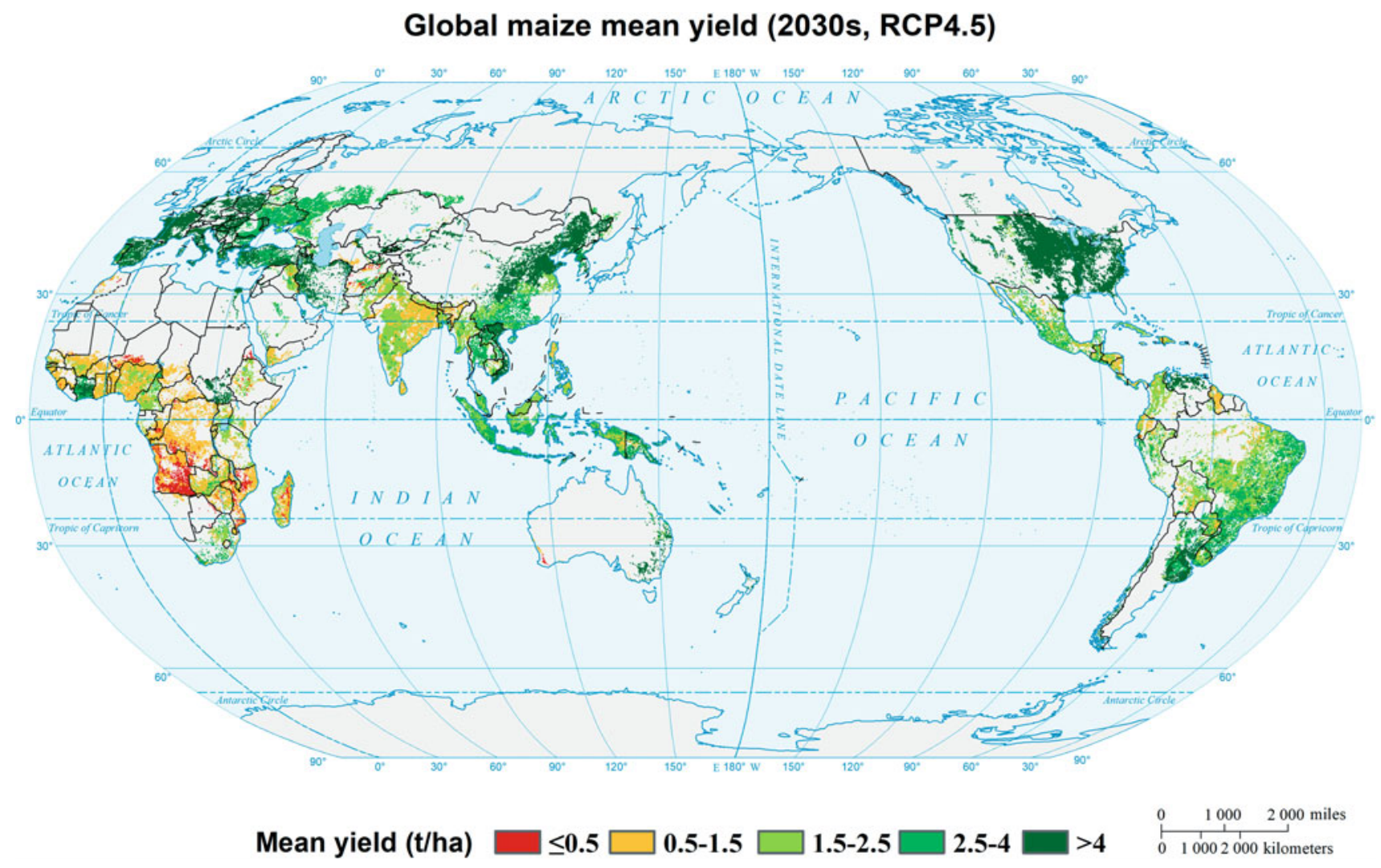


Global maize mean yield (2030s, RCP8.5)

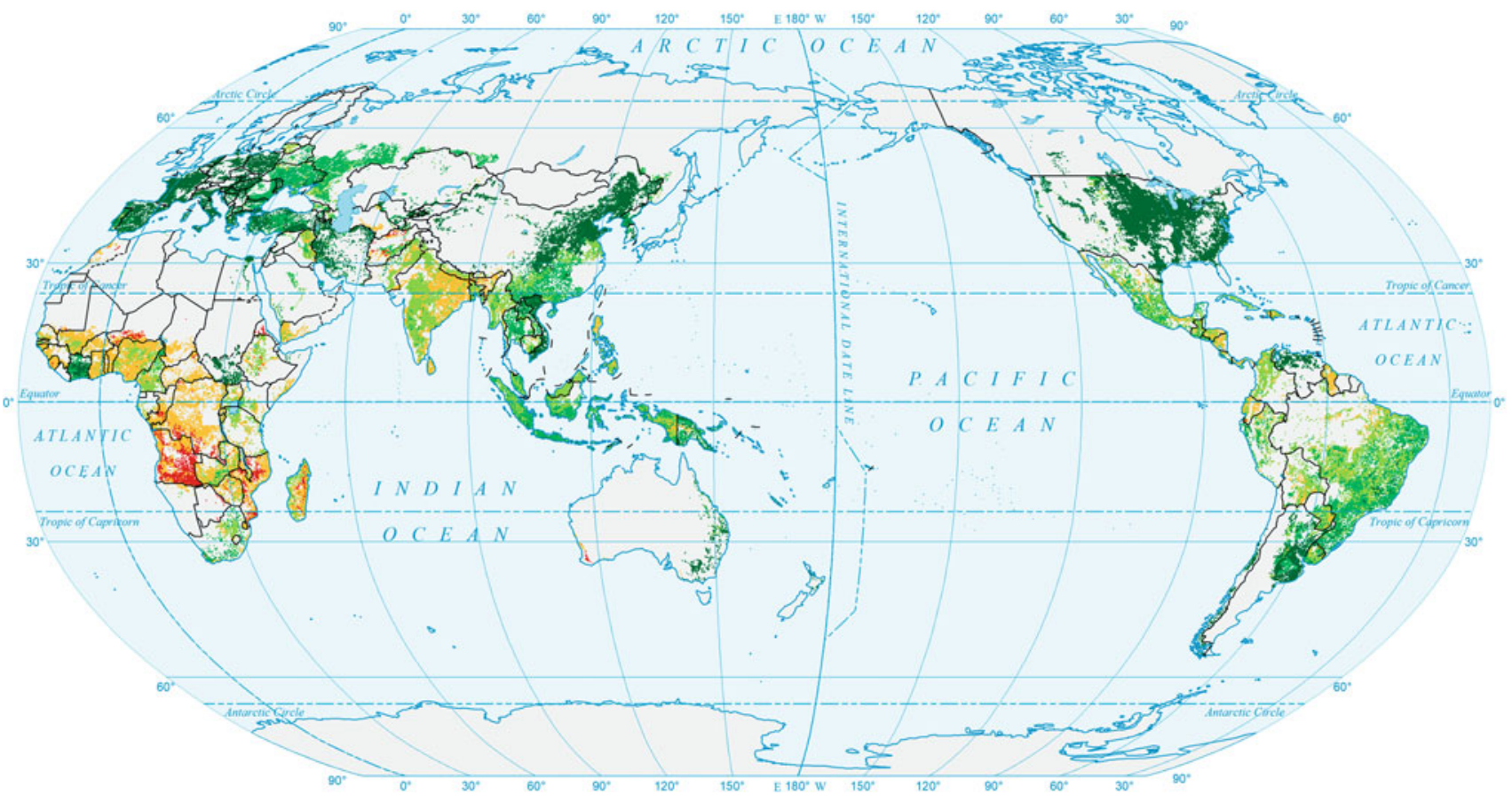

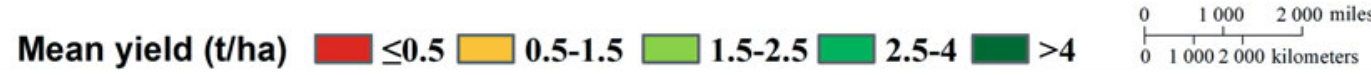

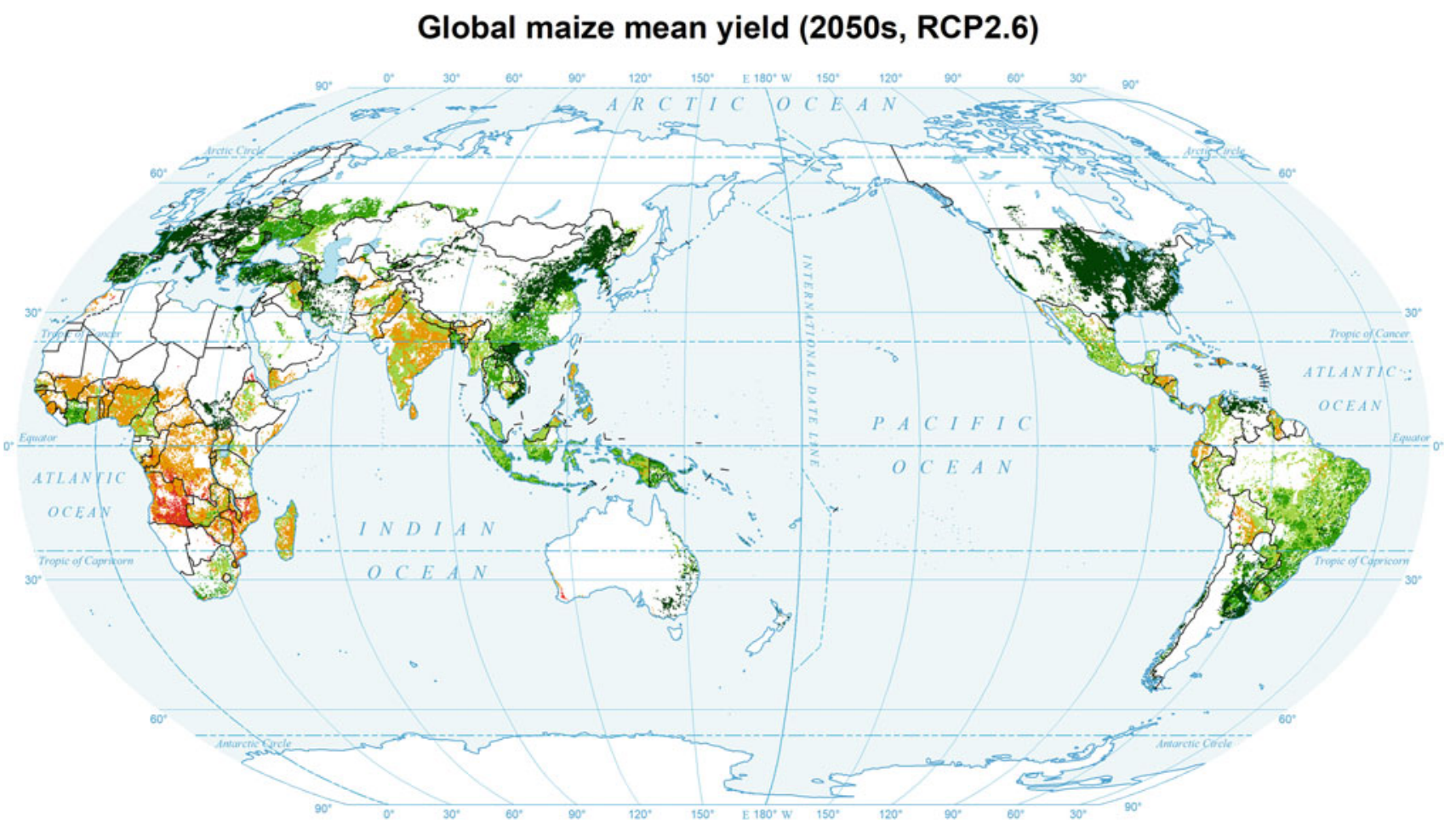

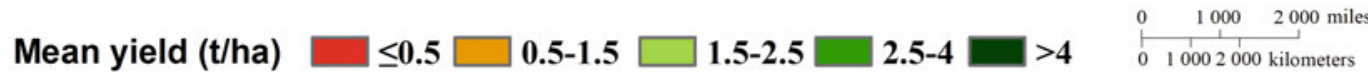




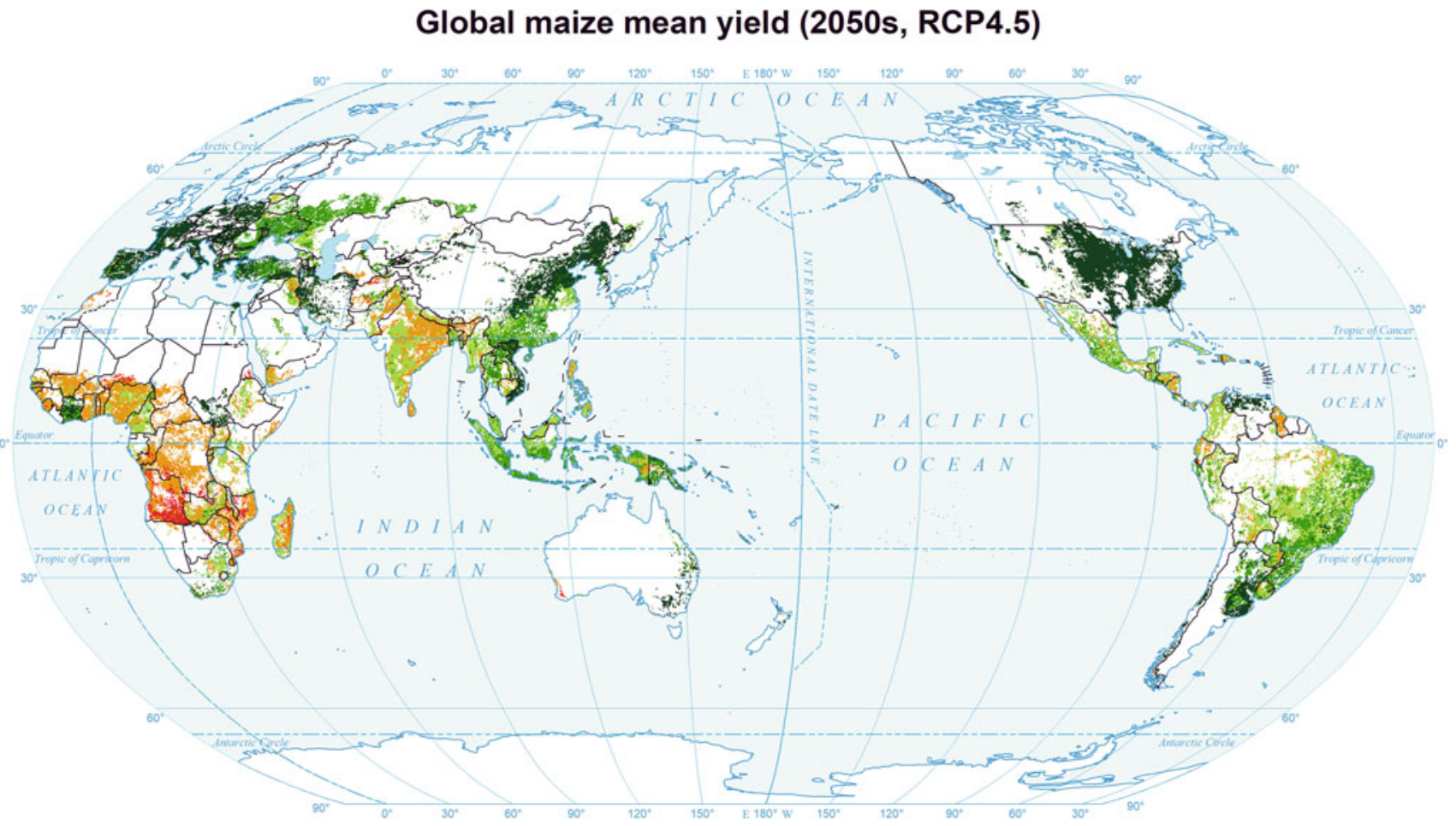

Mean yield (t/ha) $\square \leq \mathbf{0 . 5} \square \mathbf{0 . 5}-\mathbf{1 . 5} \square \mathbf{1 . 5}-\mathbf{2 . 5} \square \mathbf{2 . 5}-\mathbf{4} \square>\mathbf{4} \quad \begin{aligned} & 0 \quad 1000 \quad 2000 \text { miles } \\ & \qquad 10002000 \text { kilometers }\end{aligned}$

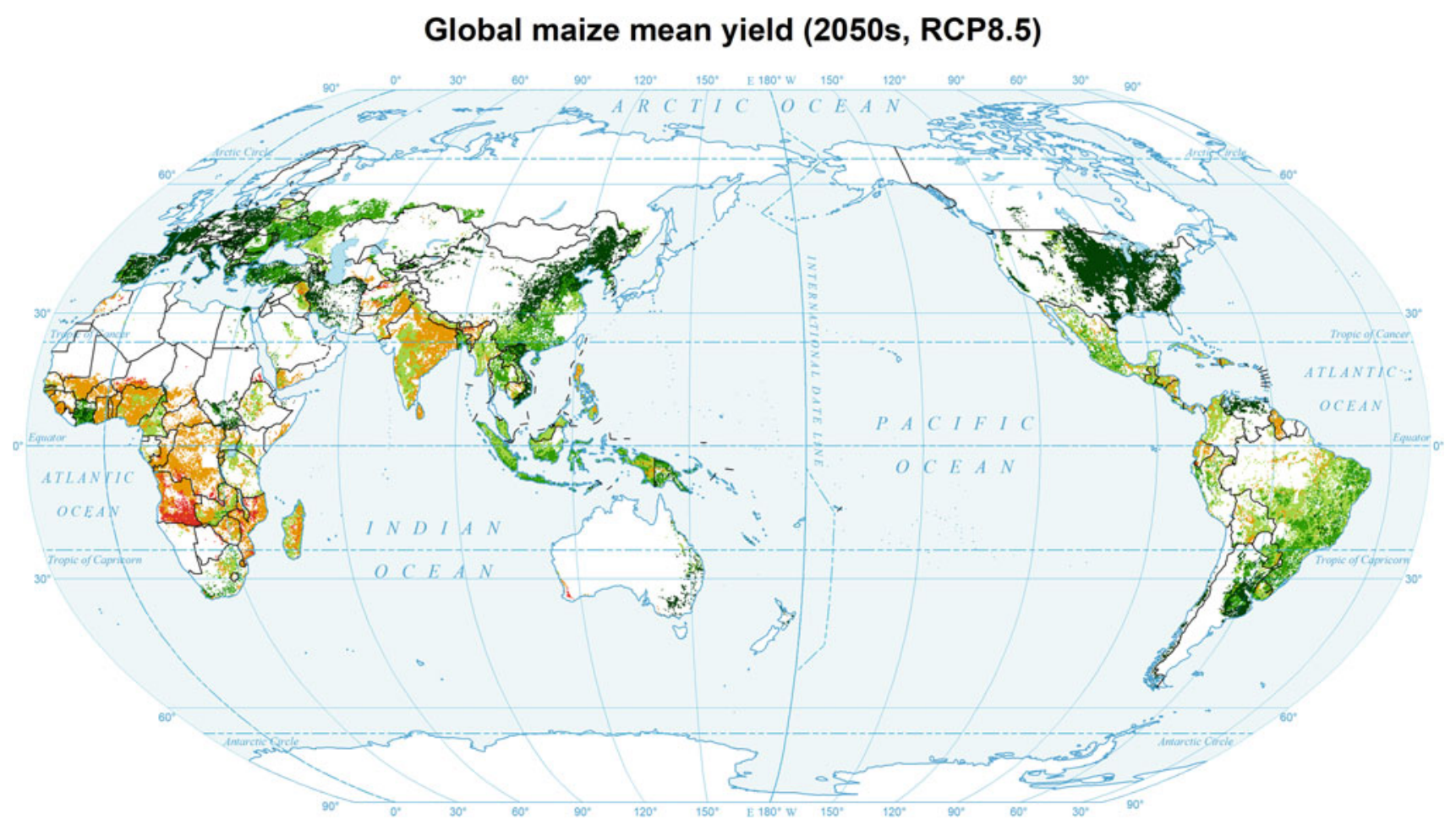

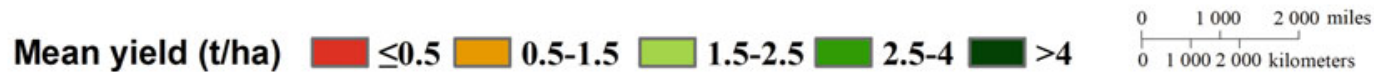




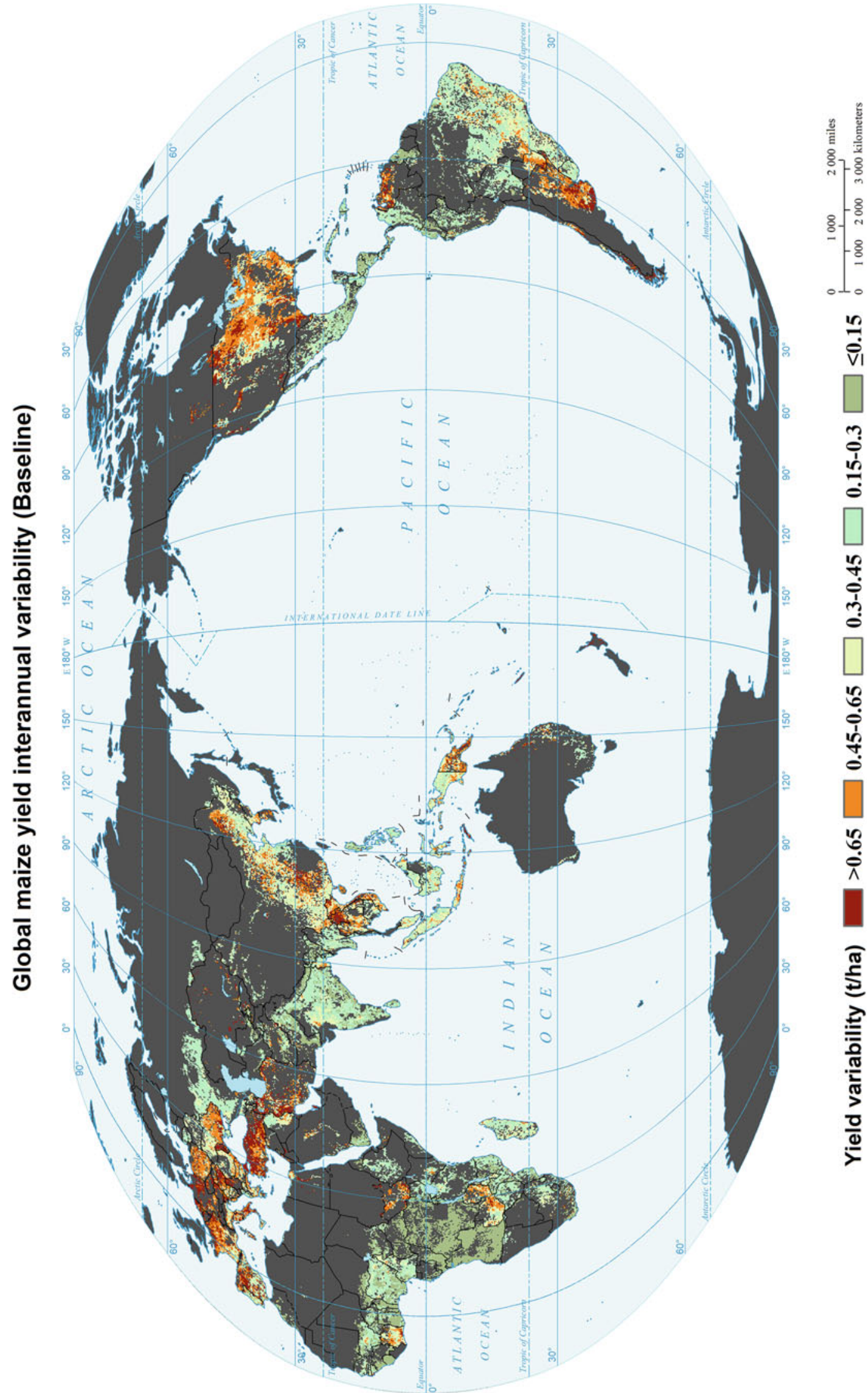


Global maize yield interannual variability (2030s, RCP2.6)

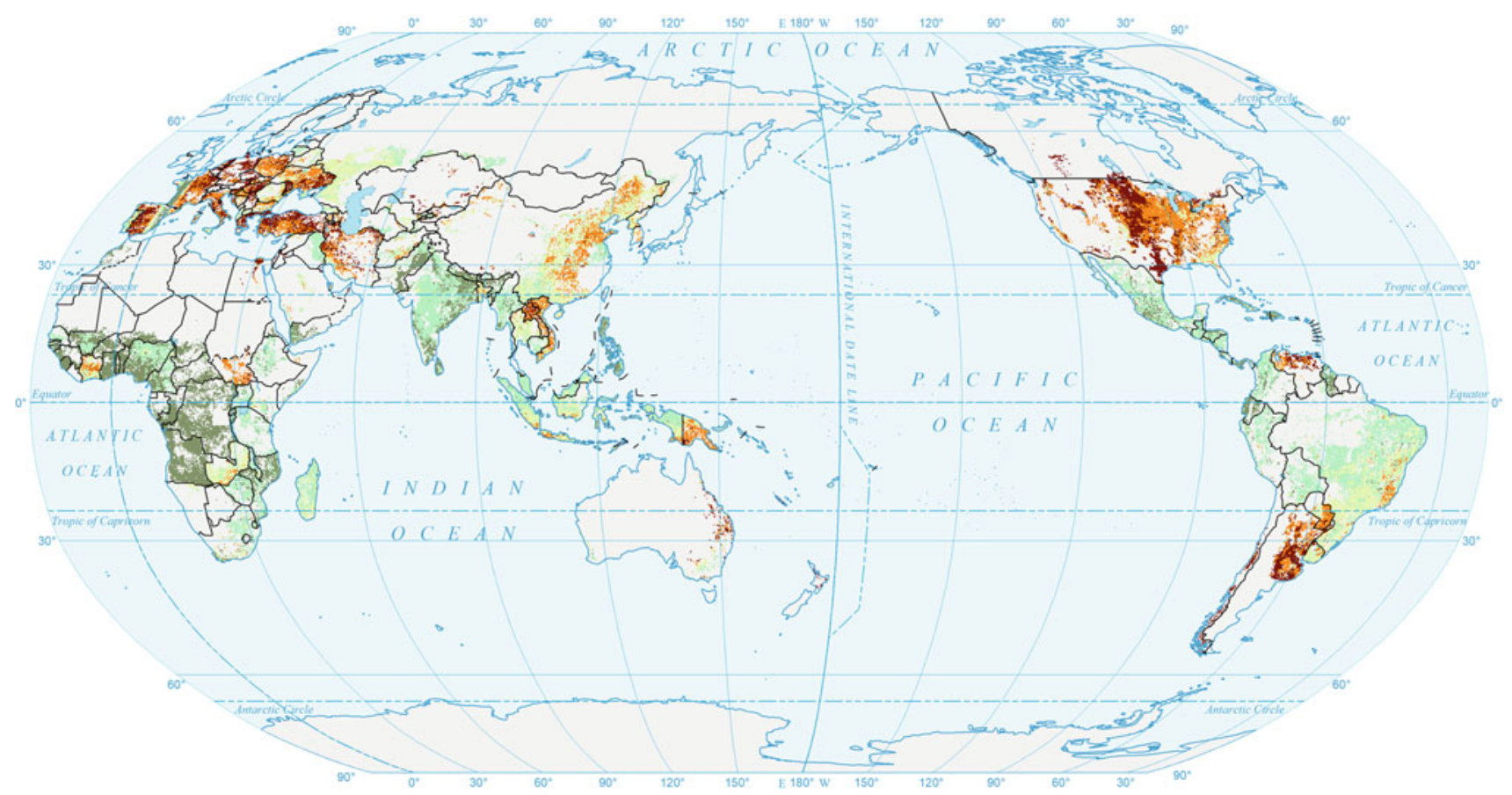

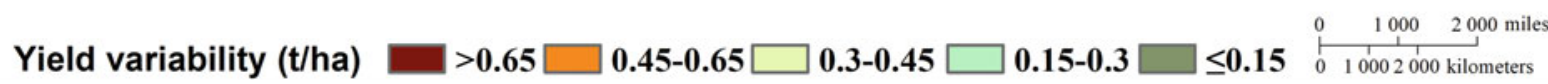

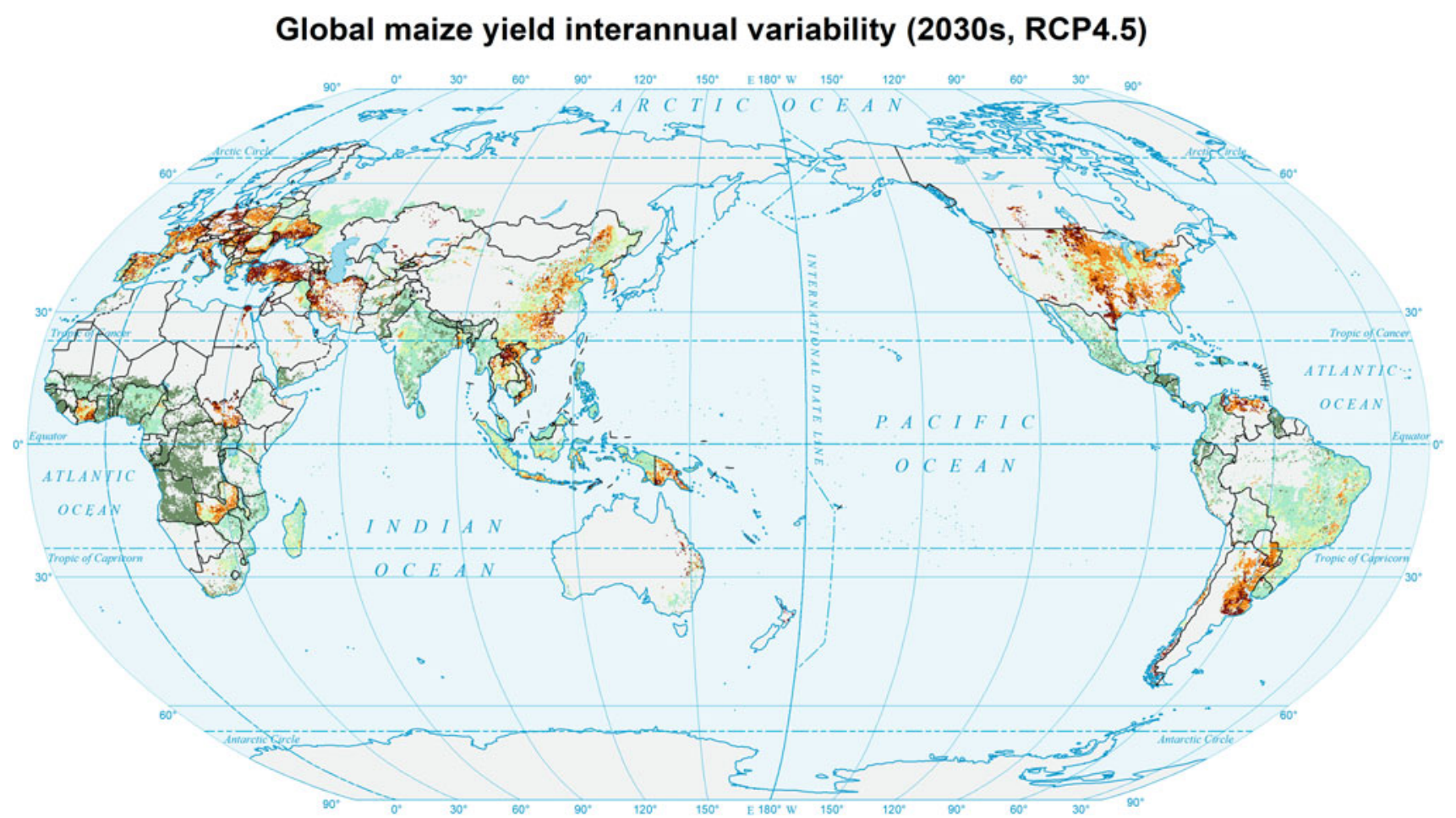

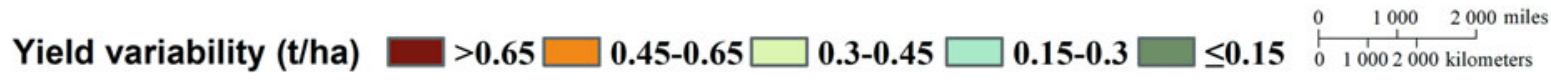


Global maize yield interannual variability (2030s, RCP8.5)

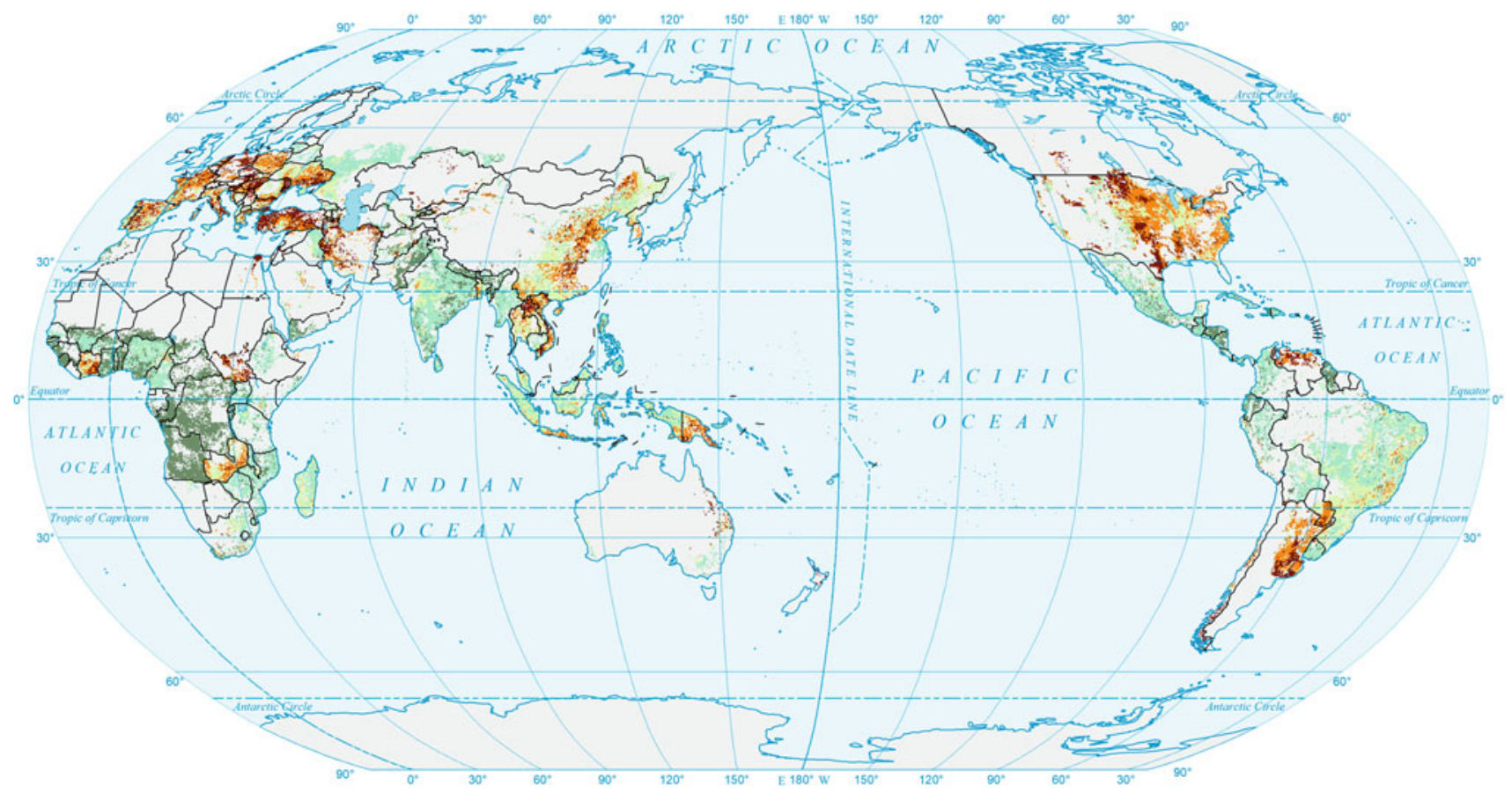

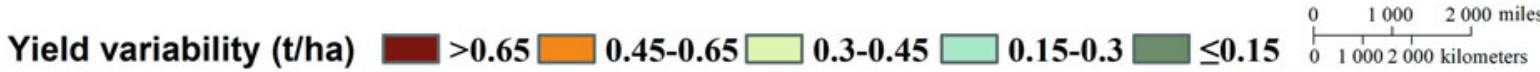

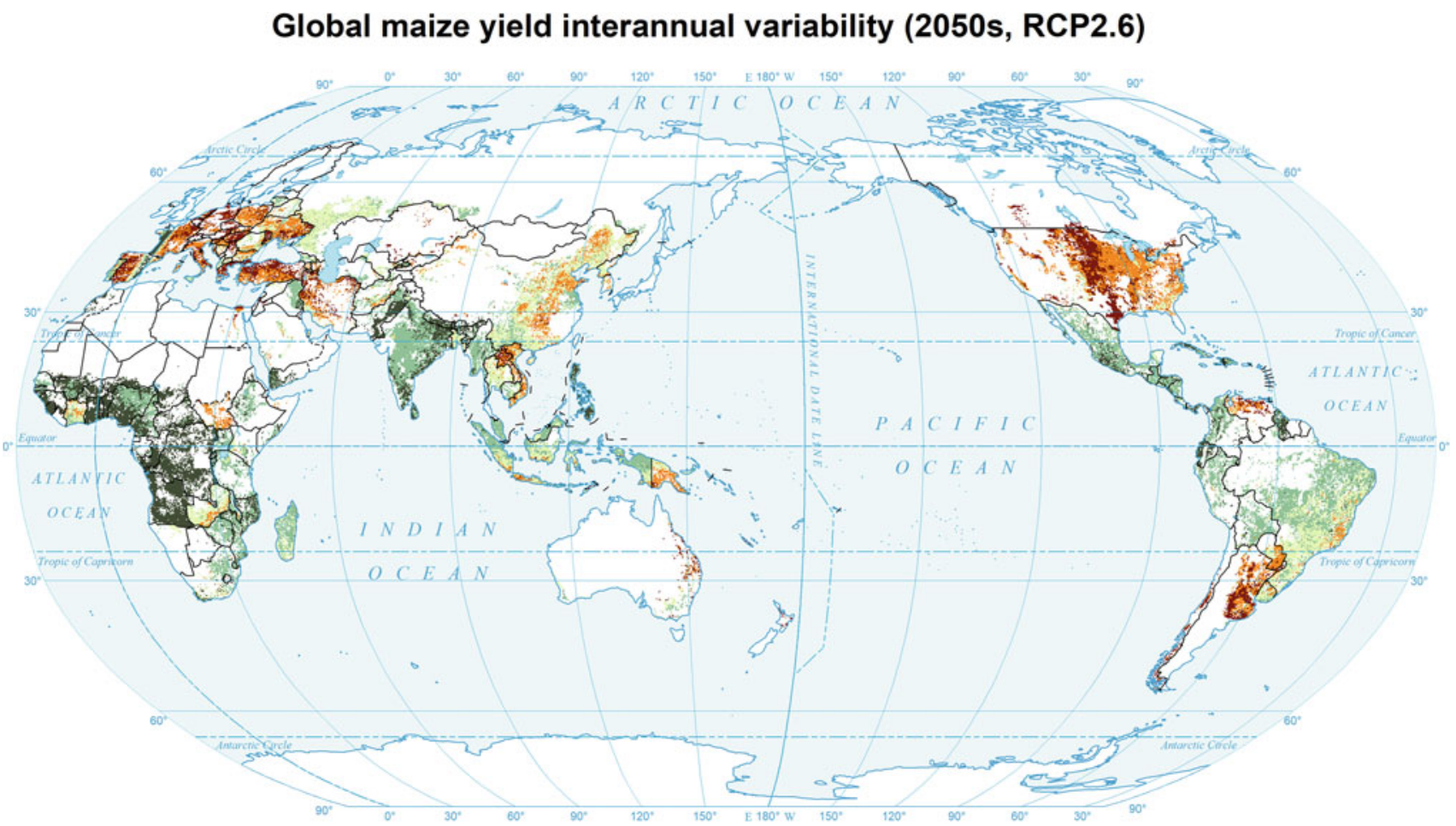

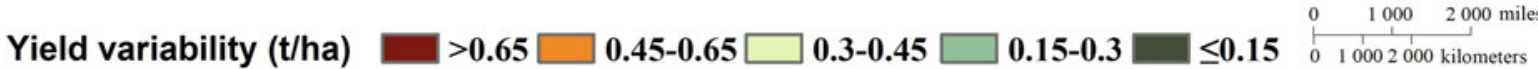




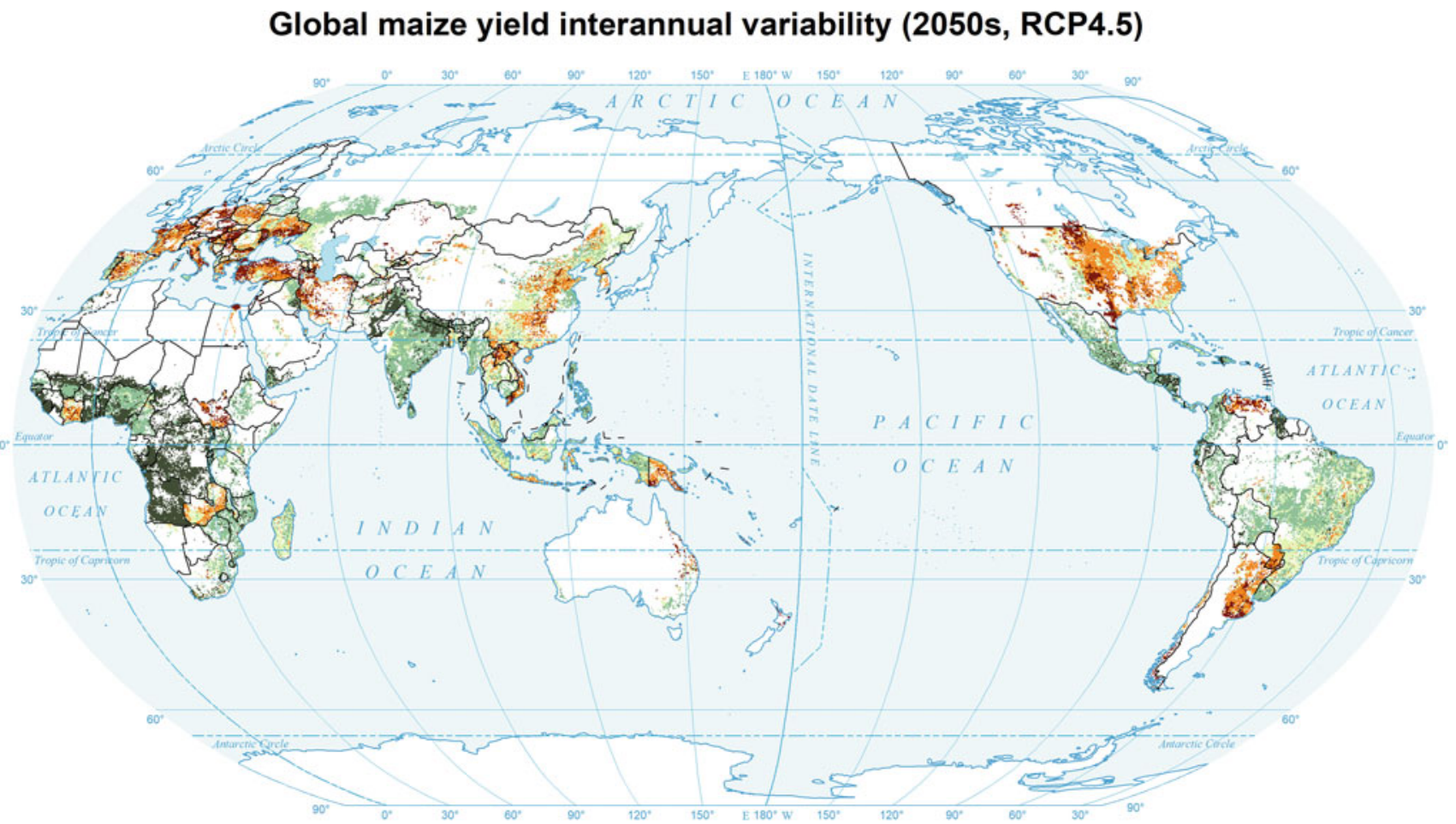

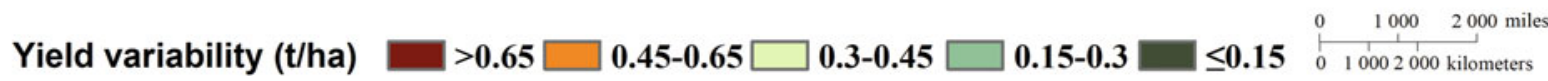

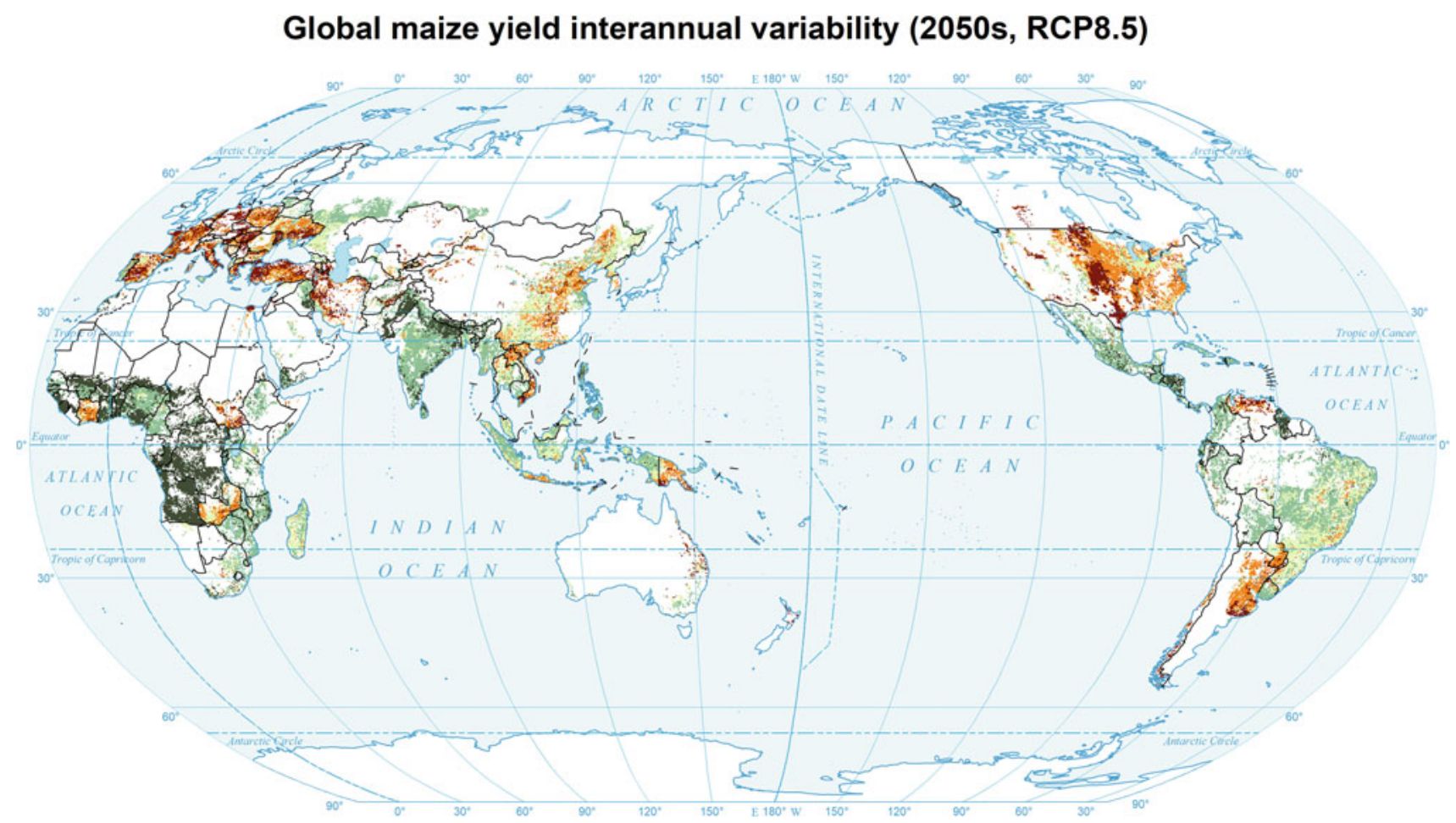

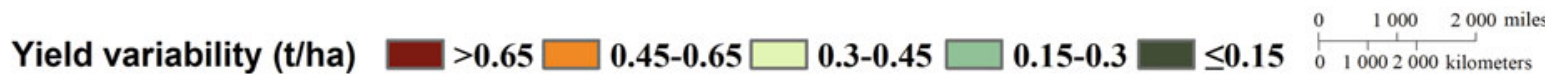




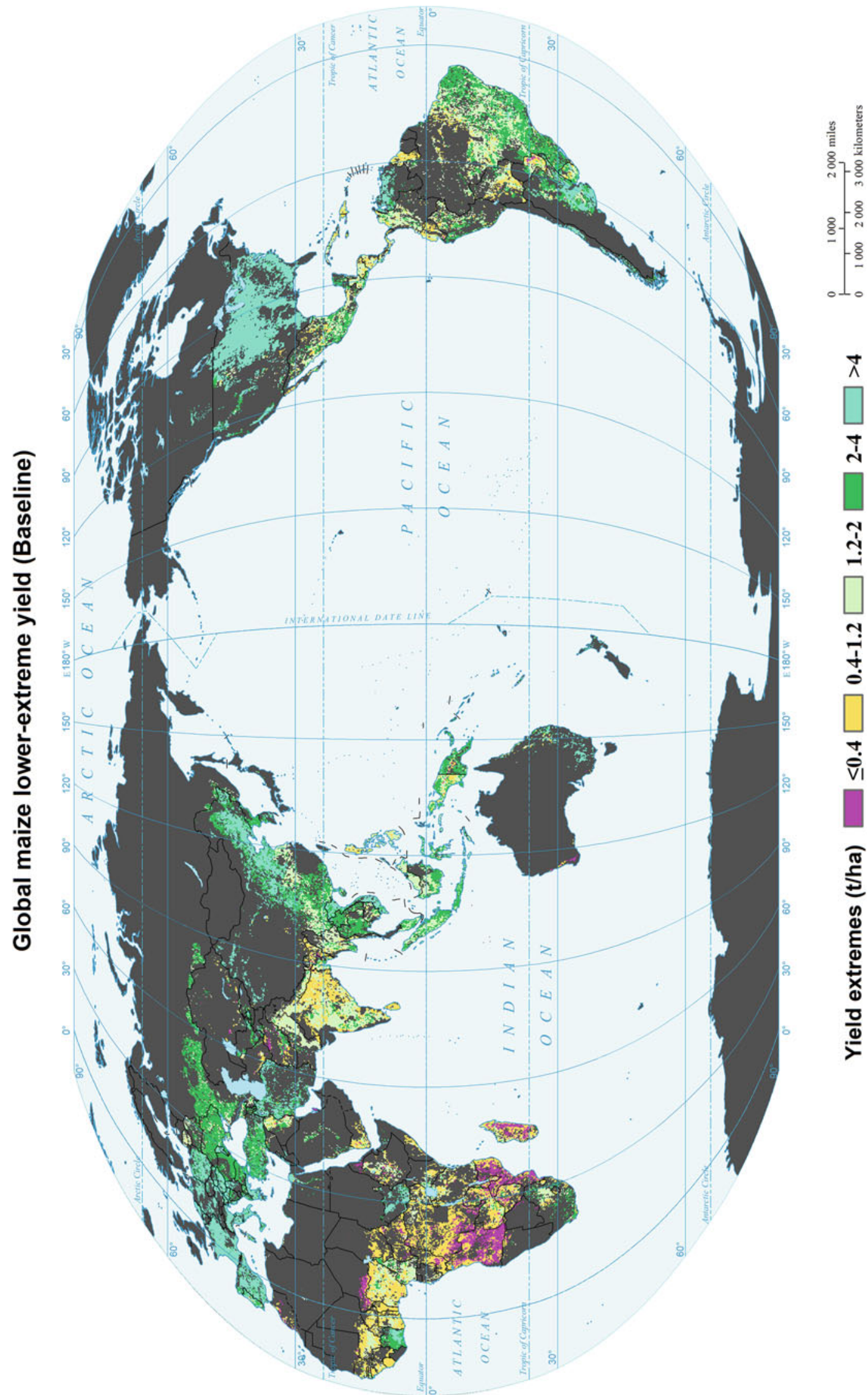




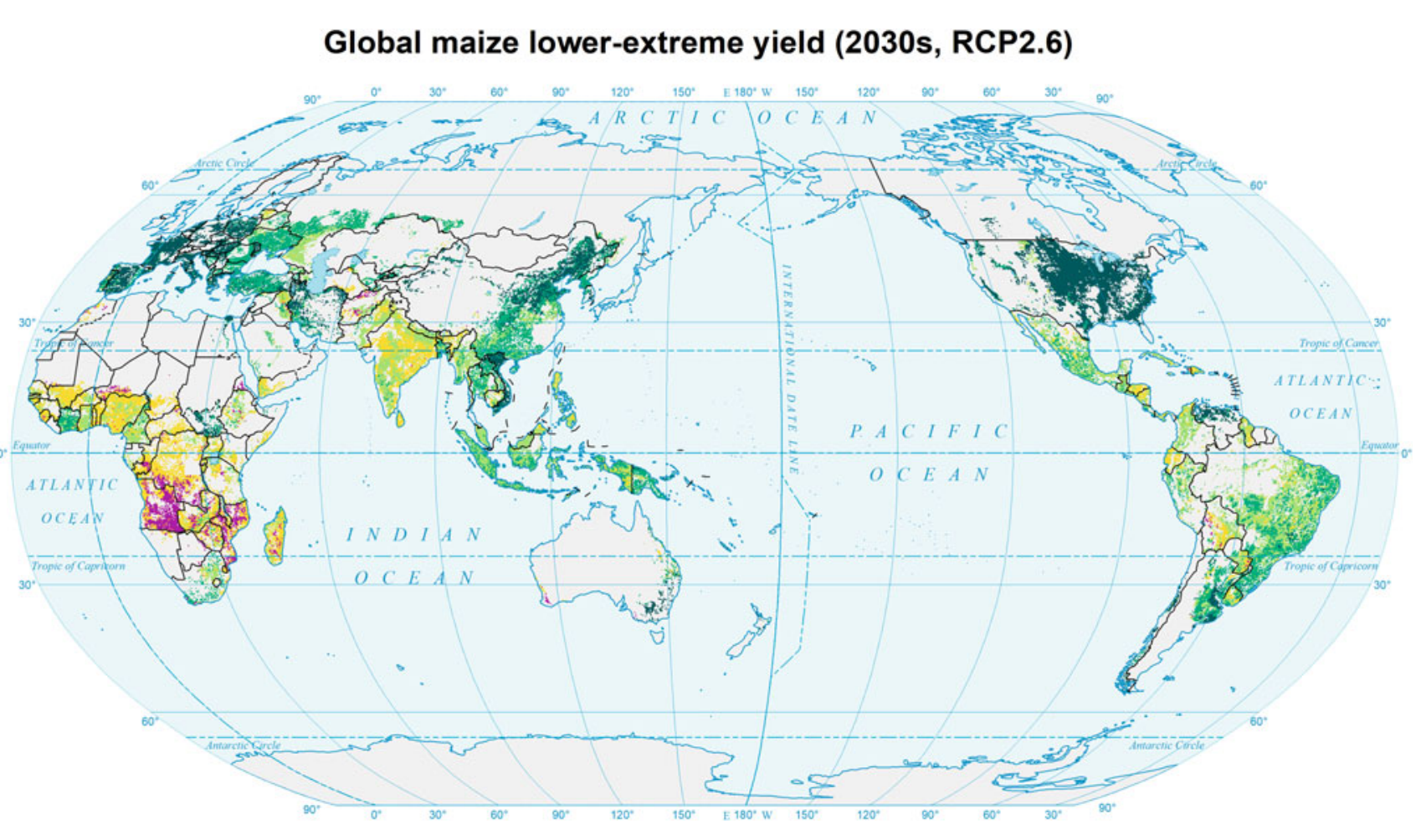

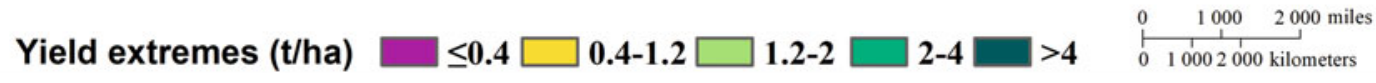

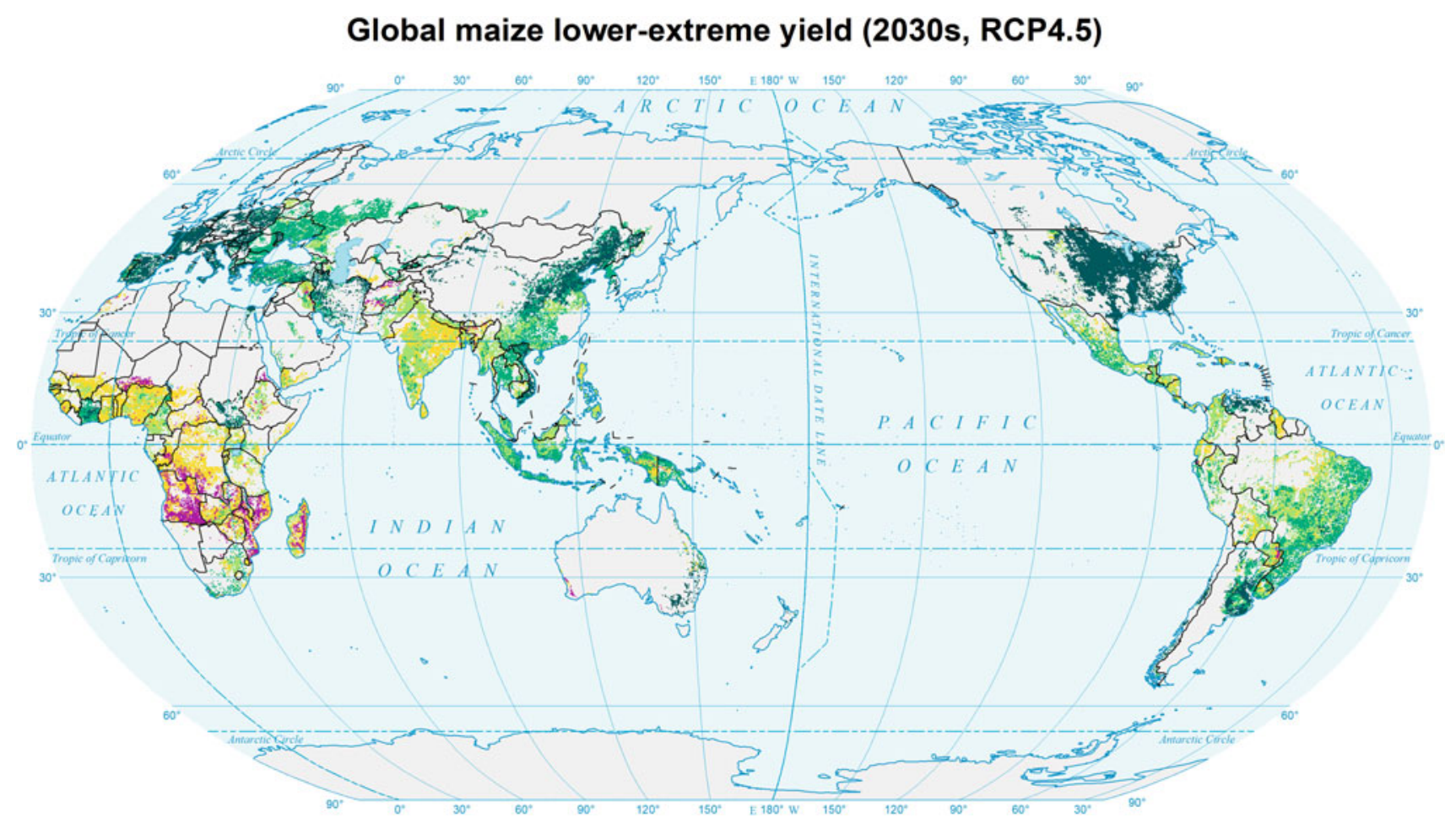

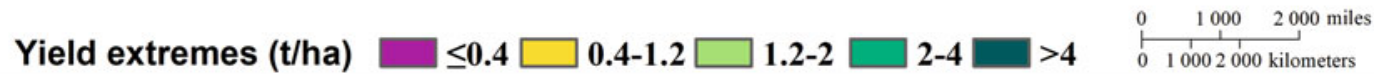


Global maize lower-extreme yield (2030s, RCP8.5)

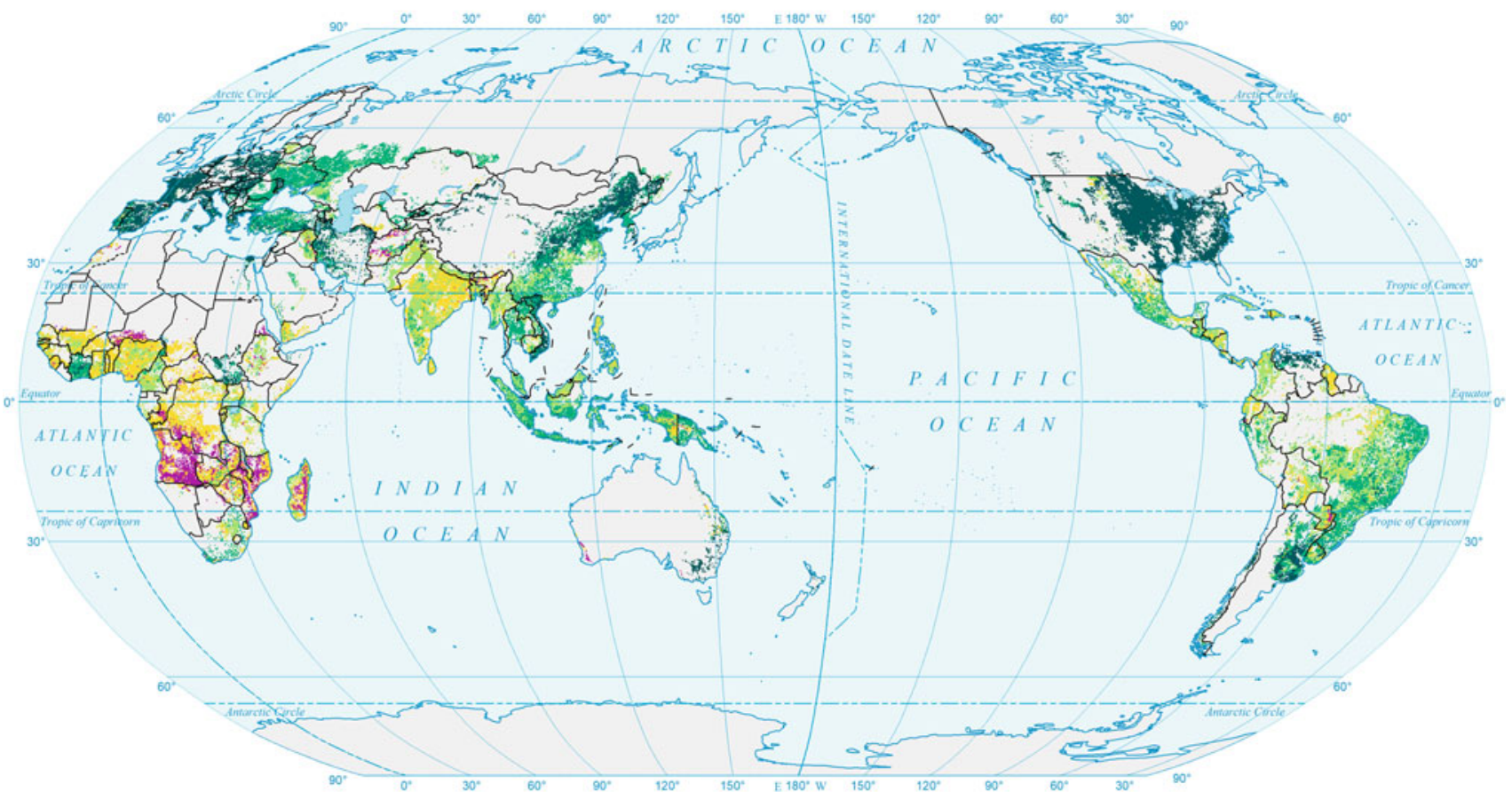

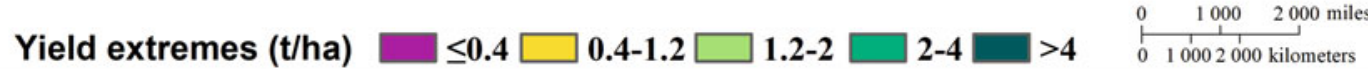

Global maize lower-extreme yield (2050s, RCP2.6)

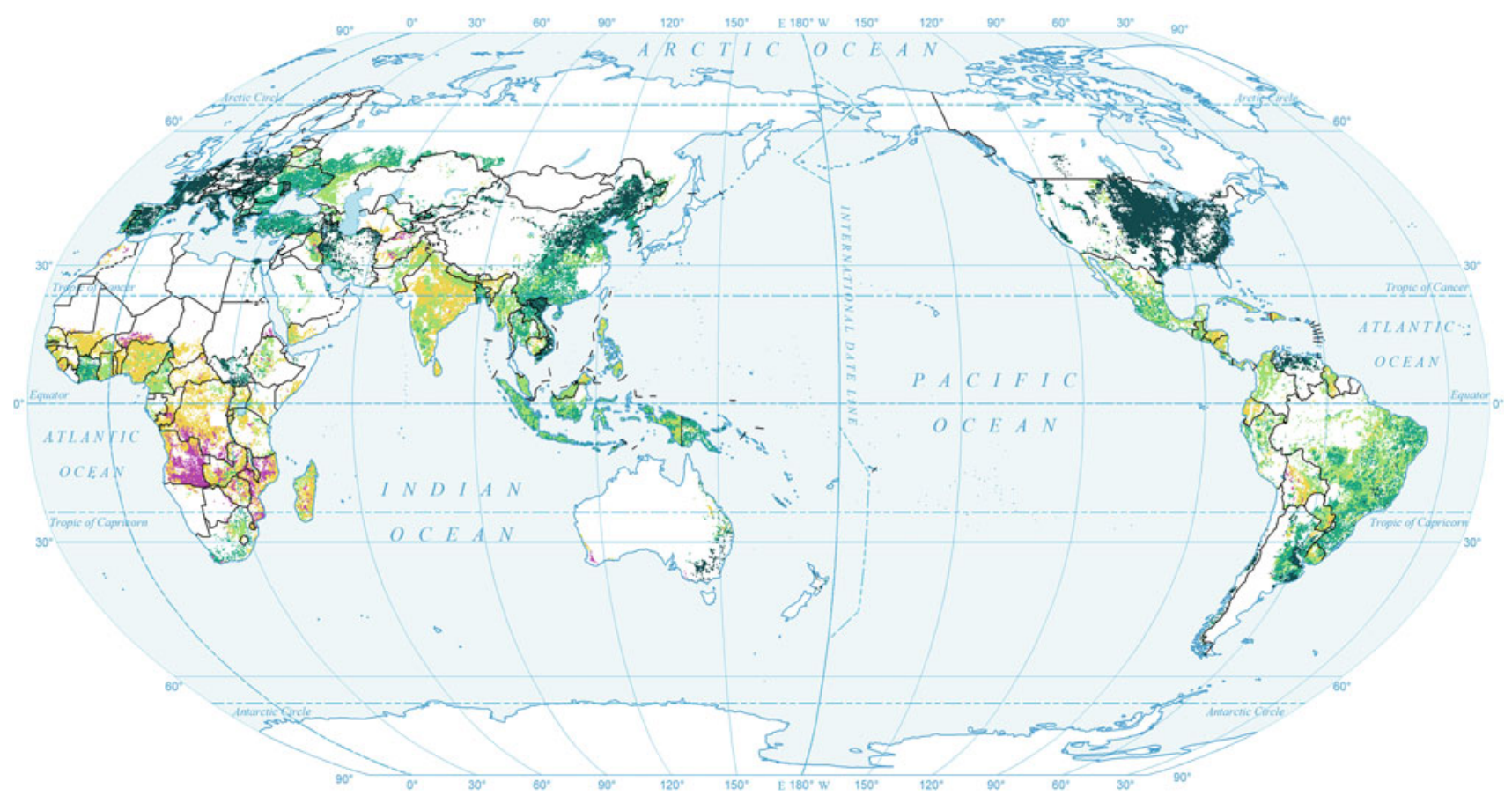

Yield extremes (t/ha) $\square \leq \mathbf{0 . 4} \square \mathbf{0 . 4 - 1 . 2} \square \mathbf{1 . 2 - 2} \square \mathbf{2 - 4} \square>\mathbf{4} \quad \begin{aligned} & 0 \quad 1000 \quad 2000 \text { miles } \\ & 0 \quad 10002000 \text { kilometers }\end{aligned}$ 
Global maize lower-extreme yield (2050s, RCP4.5)

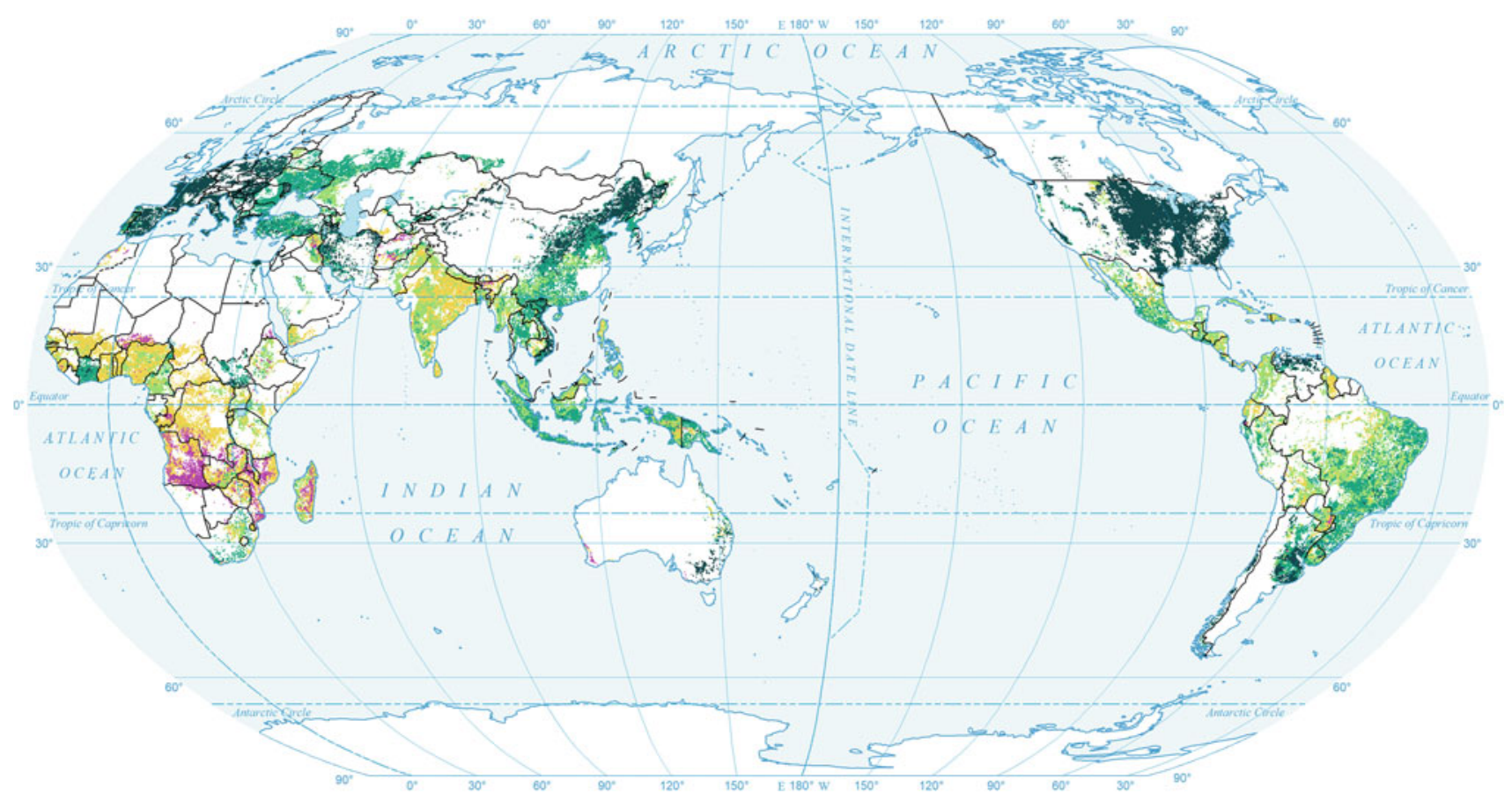

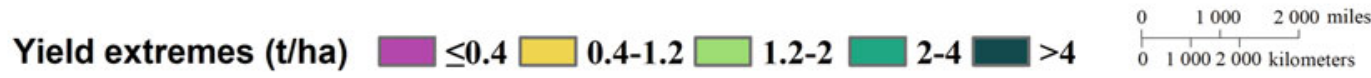

Global maize lower-extreme yield (2050s, RCP8.5)

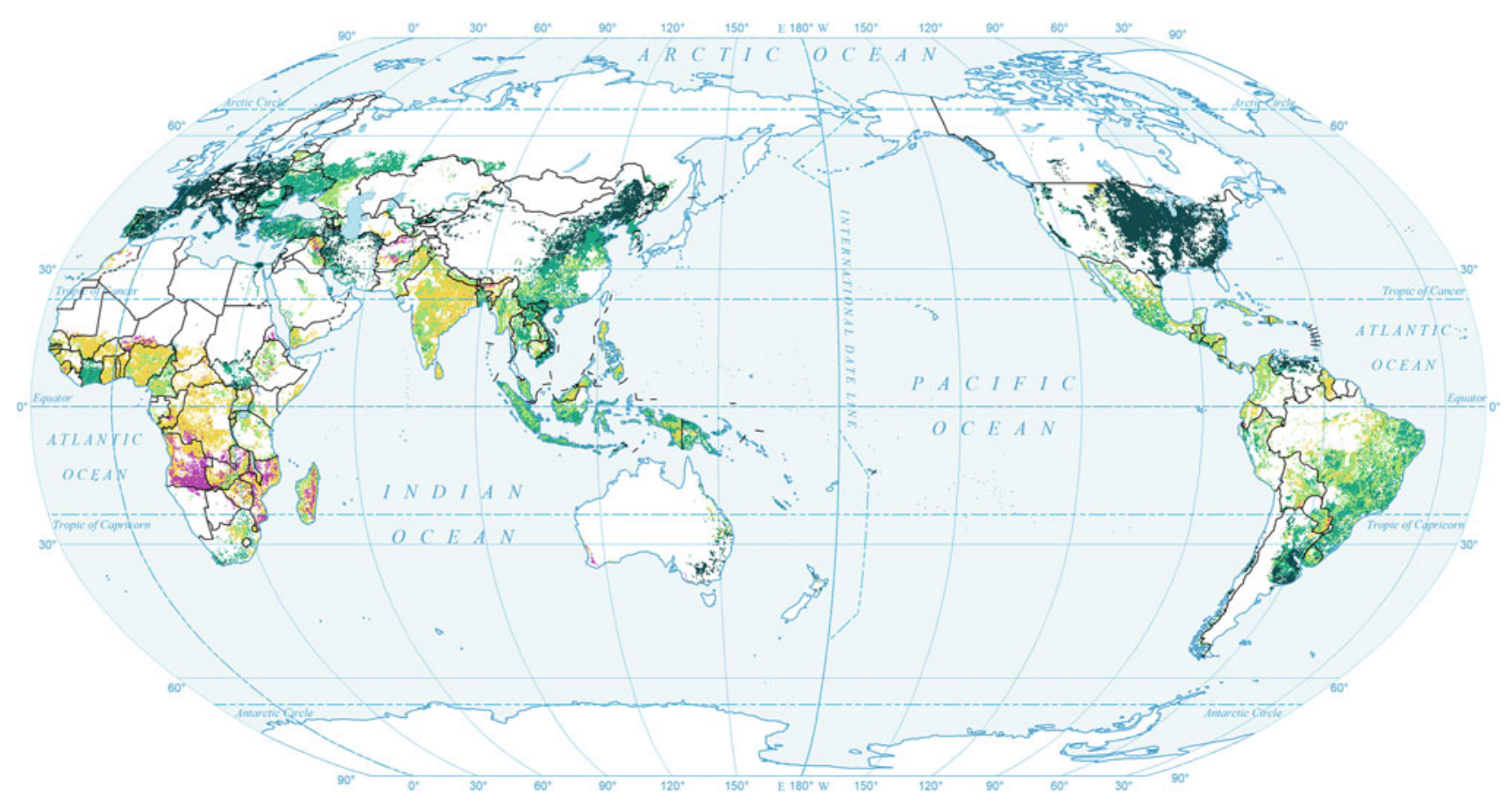

Yield extremes (t/ha) $\quad \leq \mathbf{0 . 4} \square \mathbf{0 . 4 - 1 . 2} \square \mathbf{1 . 2 - 2} \square \mathbf{2 - 4} \square>\mathbf{4} \quad \begin{aligned} & 0 \quad 1000 \quad 2000 \text { miles } \\ & \begin{array}{l}1 \\ 1\end{array} \mid 0002000 \text { kilometers }\end{aligned}$ 


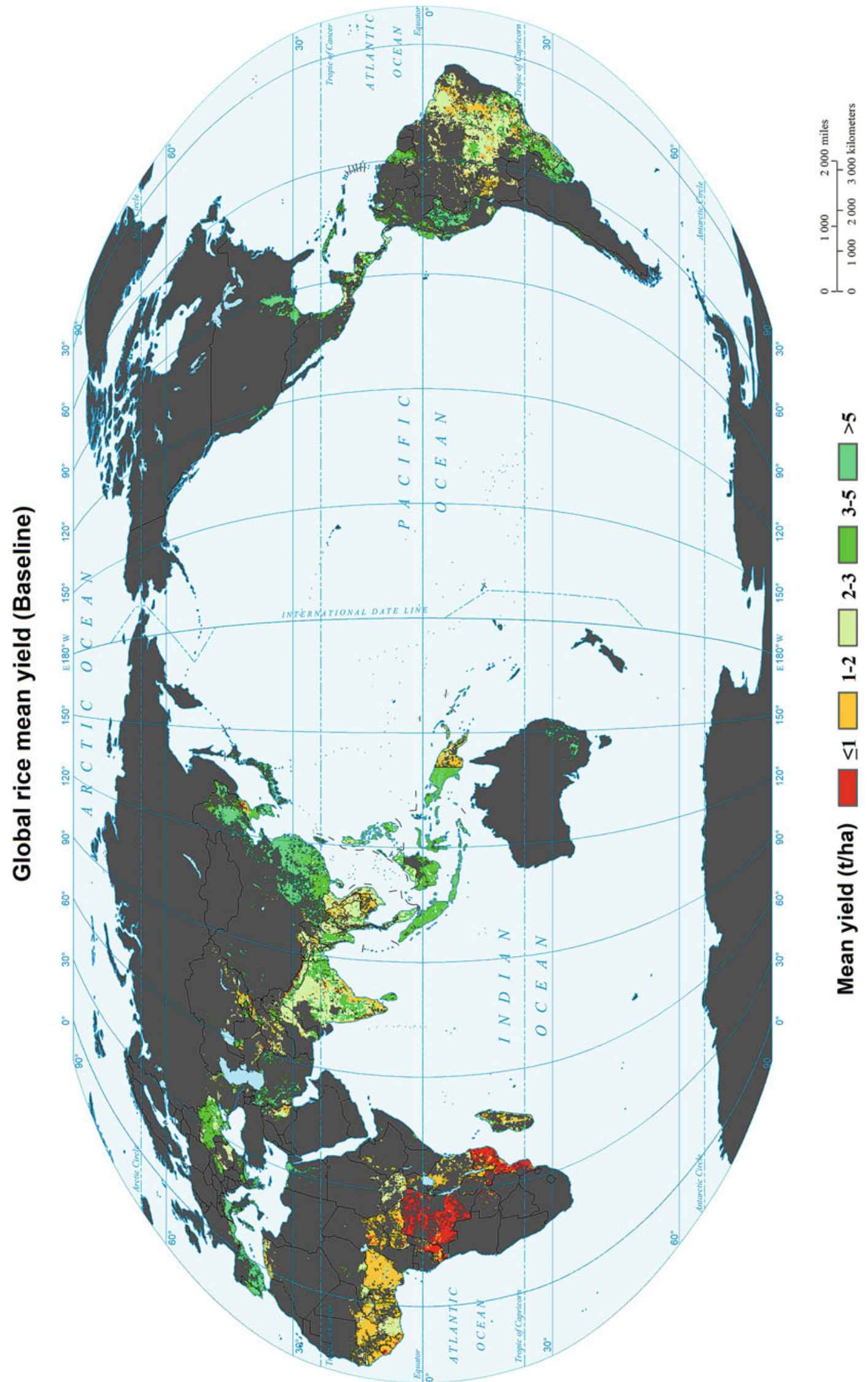



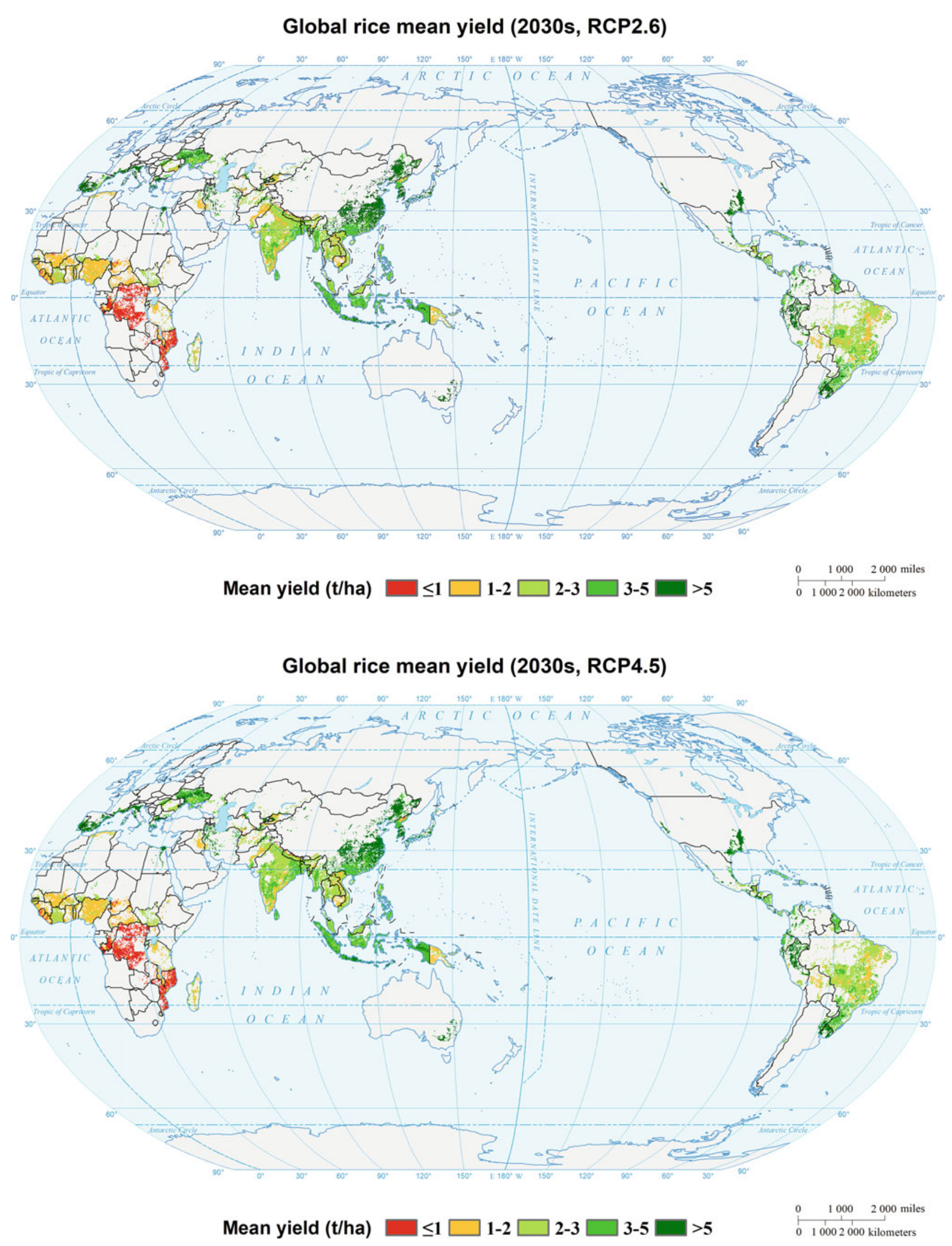

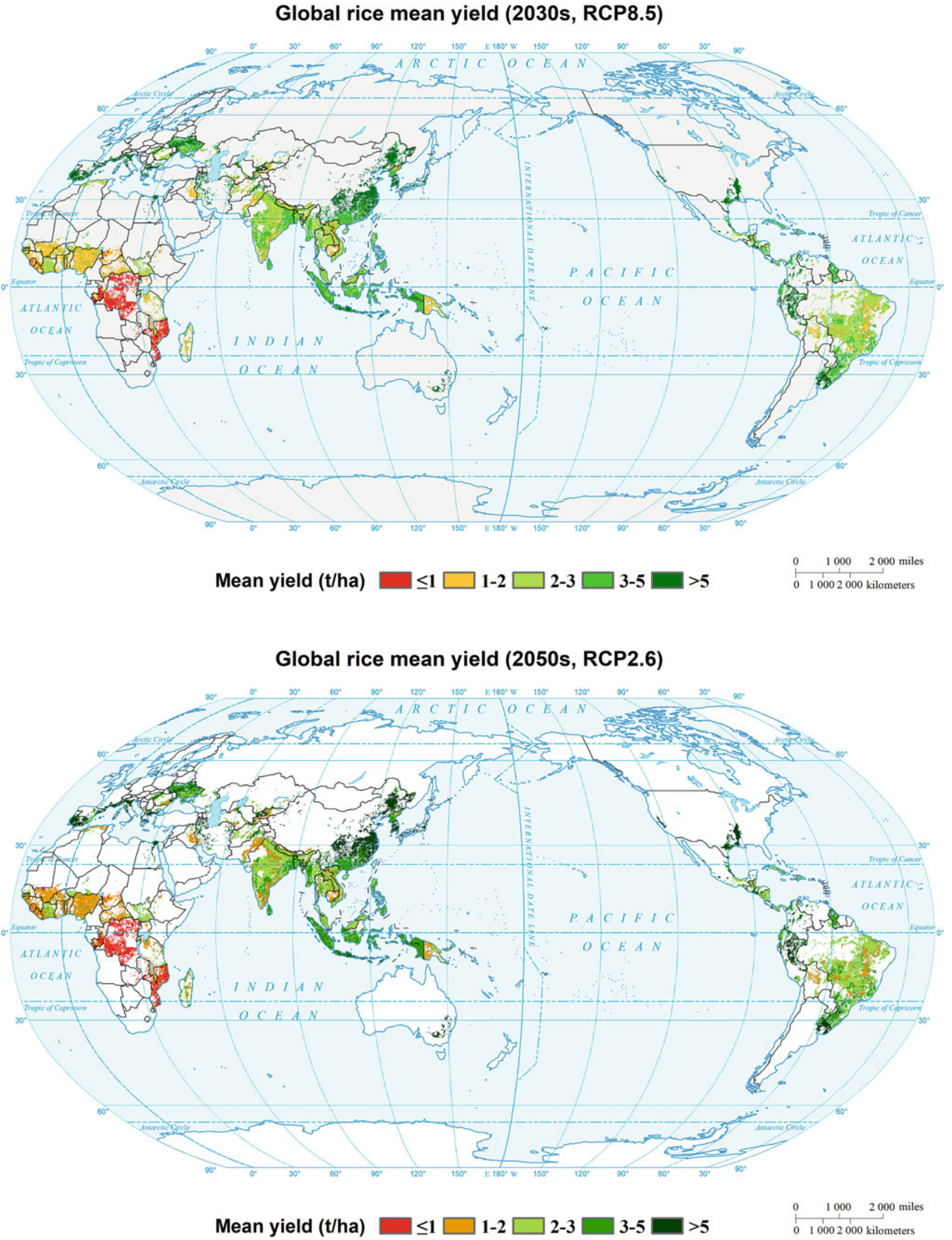

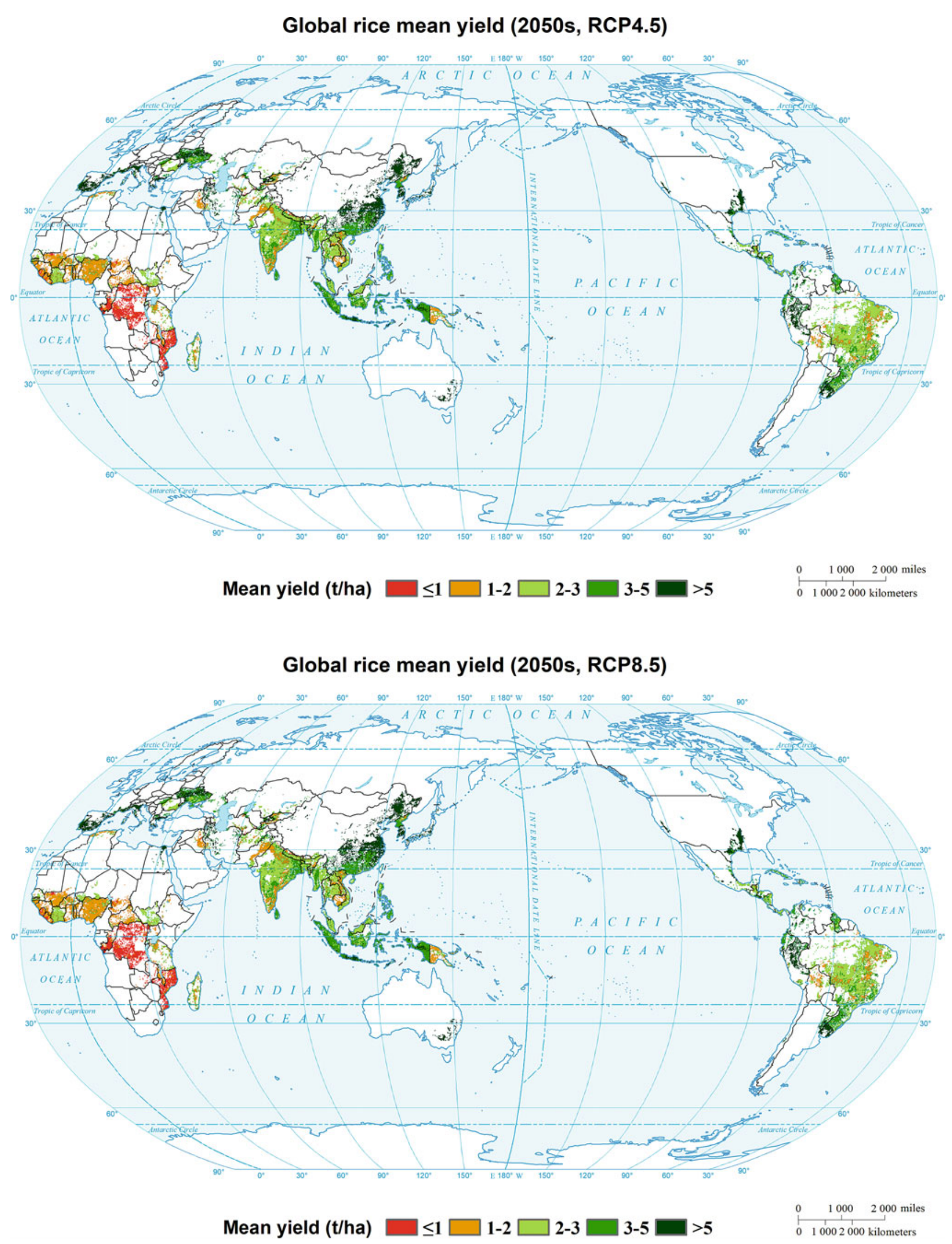
Global rice yield interannual variability (2030s, RCP2.6)

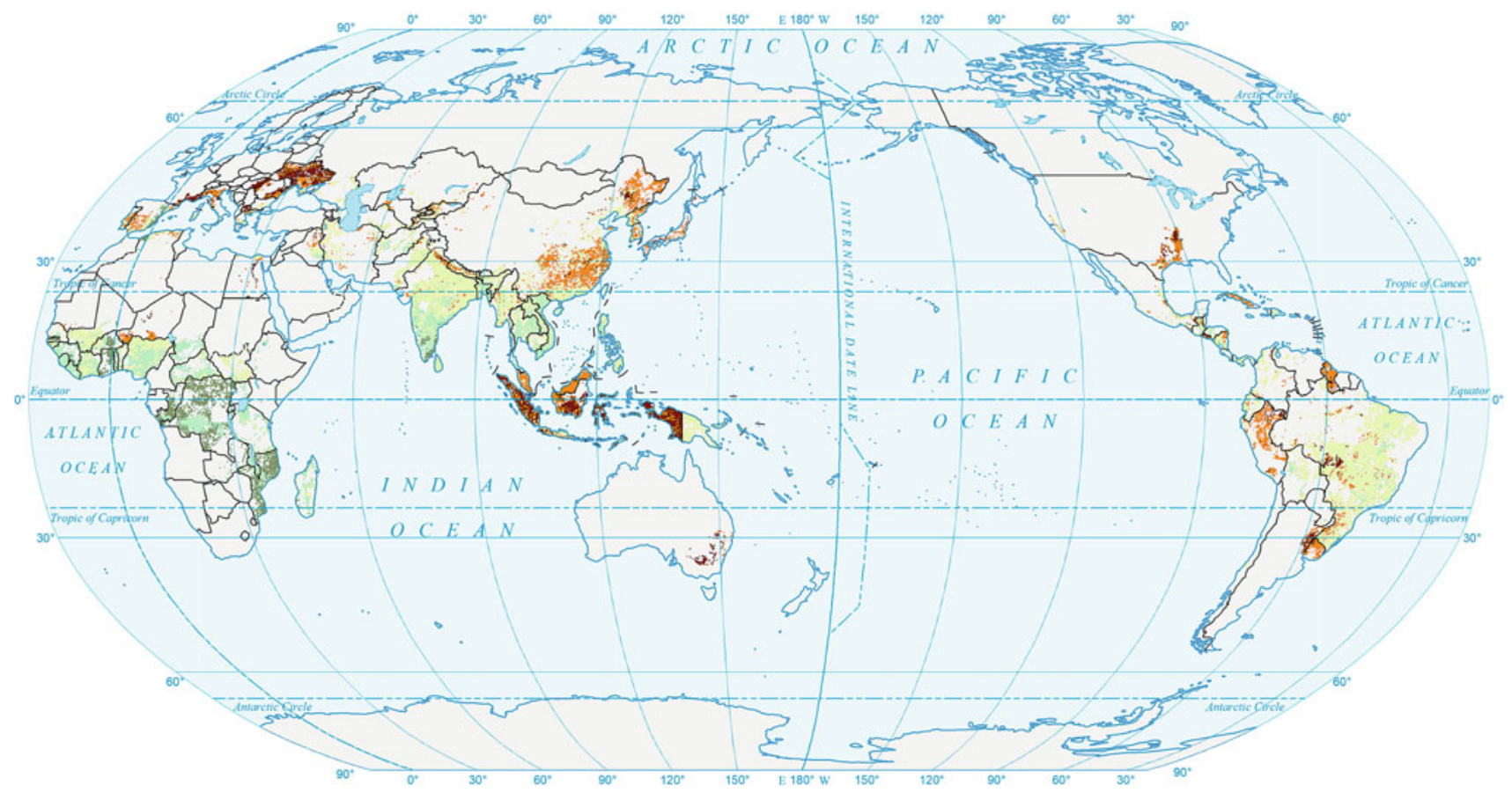

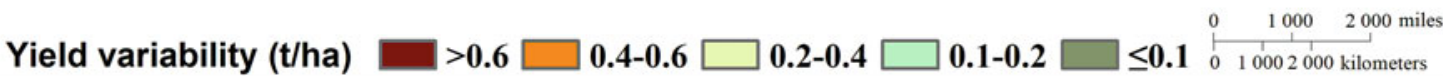




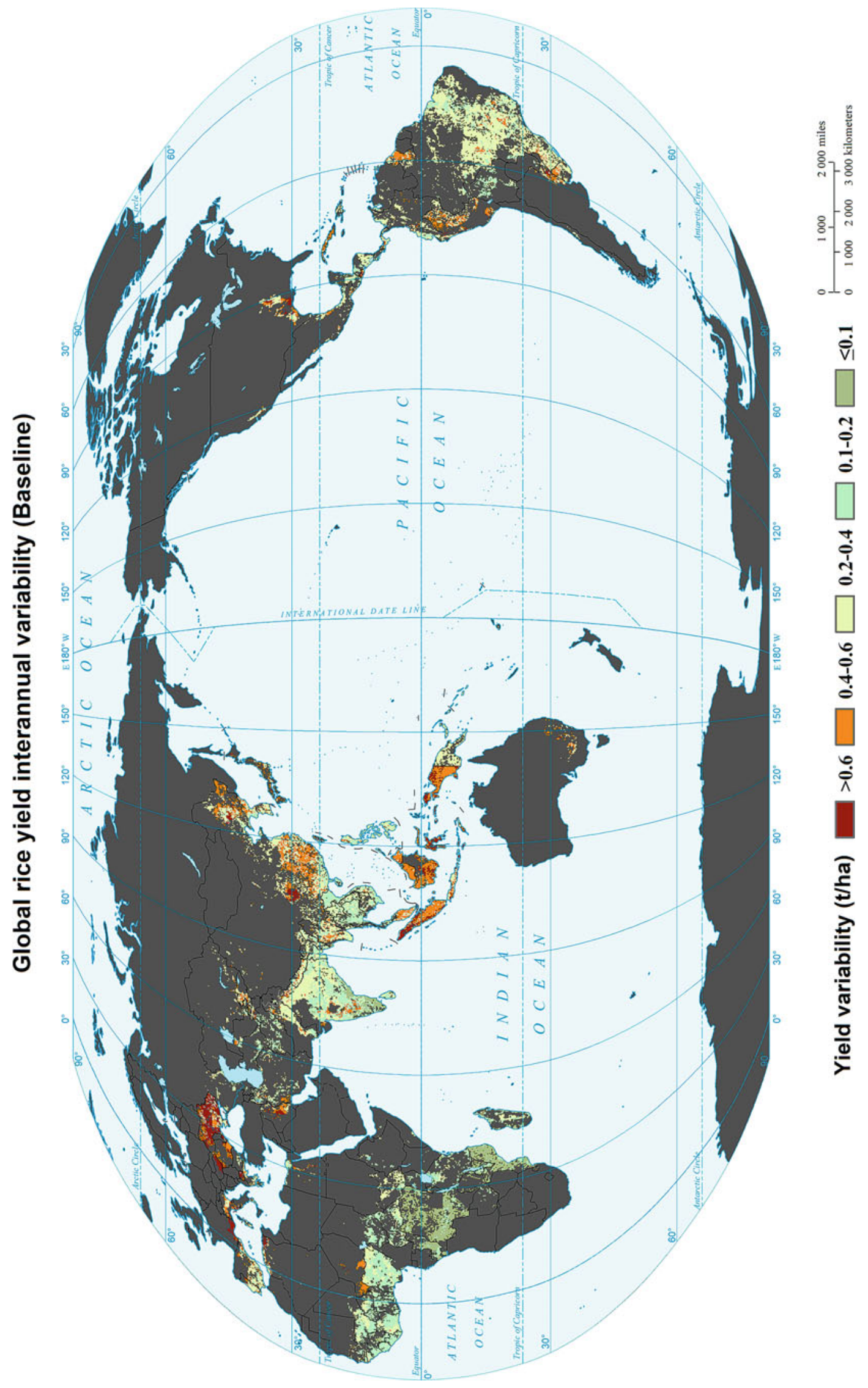




\section{Global rice yield interannual variability (2030s, RCP4.5)}

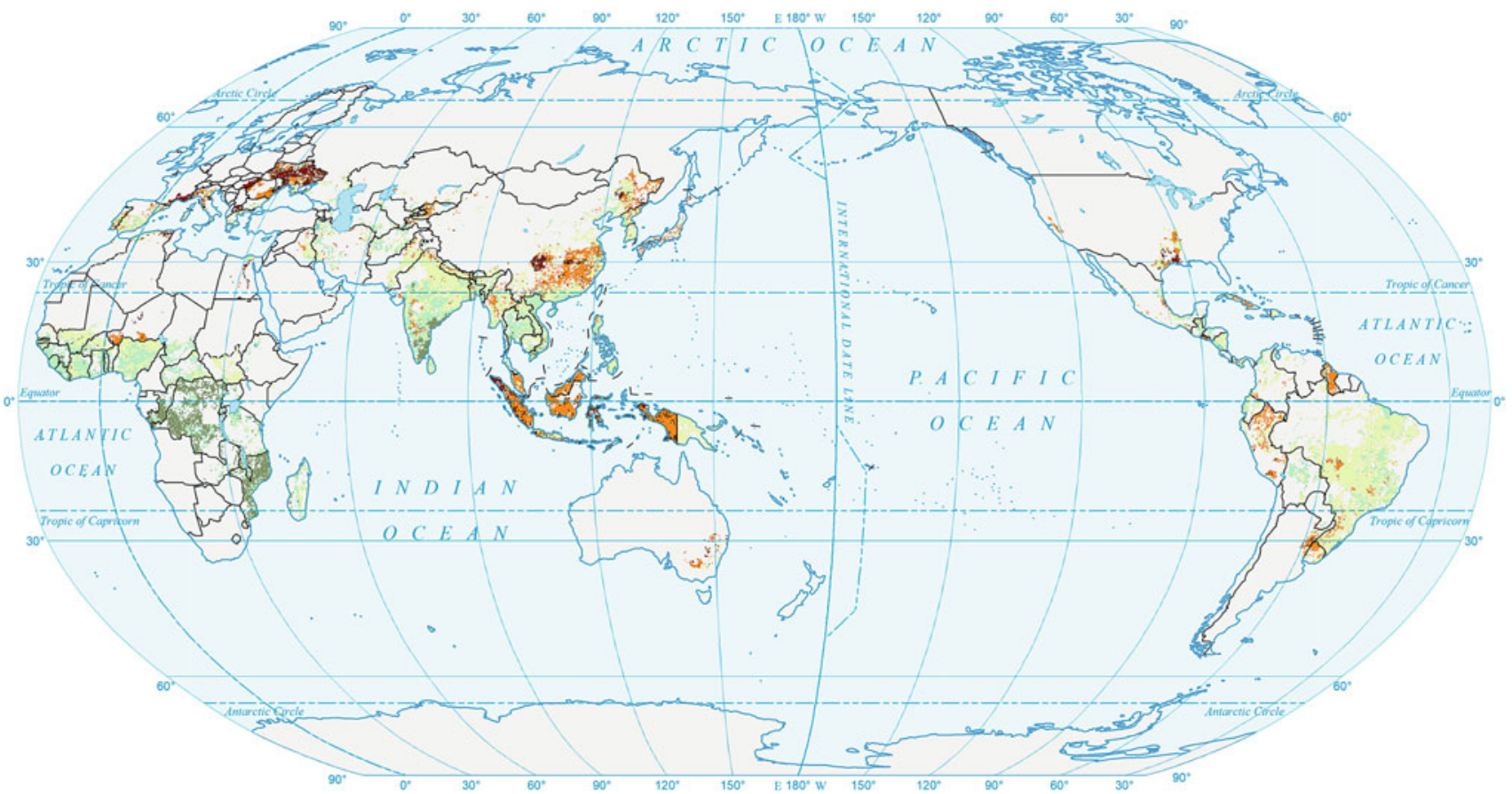

Yield variability (t/ha) $\square>\mathbf{0 . 6} \square \mathbf{0 . 4 - 0 . 6} \square \mathbf{0 . 2 - 0 . 4} \square \mathbf{0 . 1 - 0 . 2} \square \leq \mathbf{0 . 1} \stackrel{\stackrel{0}{0} \begin{array}{c}1000 \quad 2000 \text { miles } \\ 0\end{array} 10002000 \text { kilometers }}{10}$

\section{Global rice yield interannual variability (2030s, RCP8.5)}

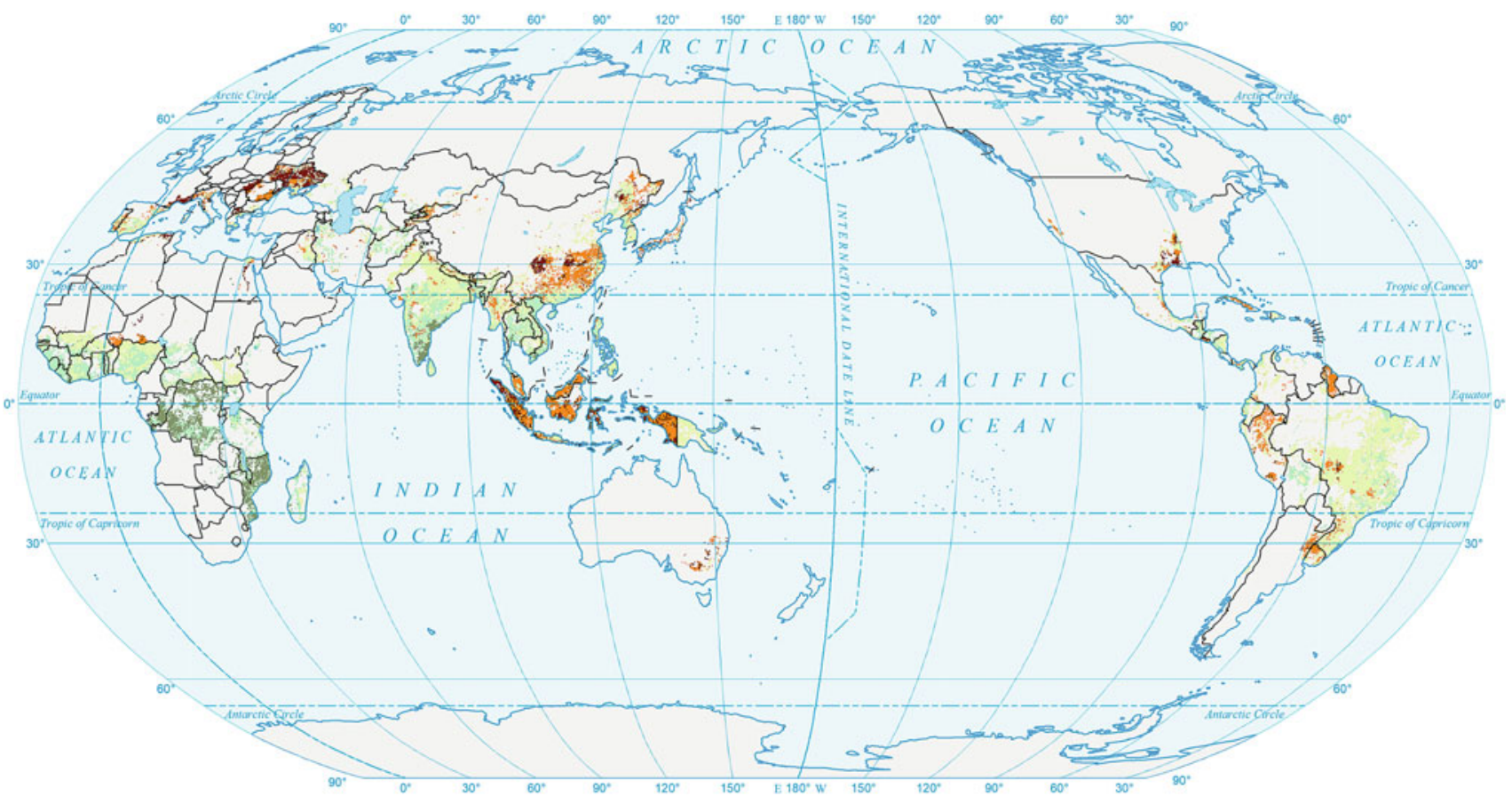




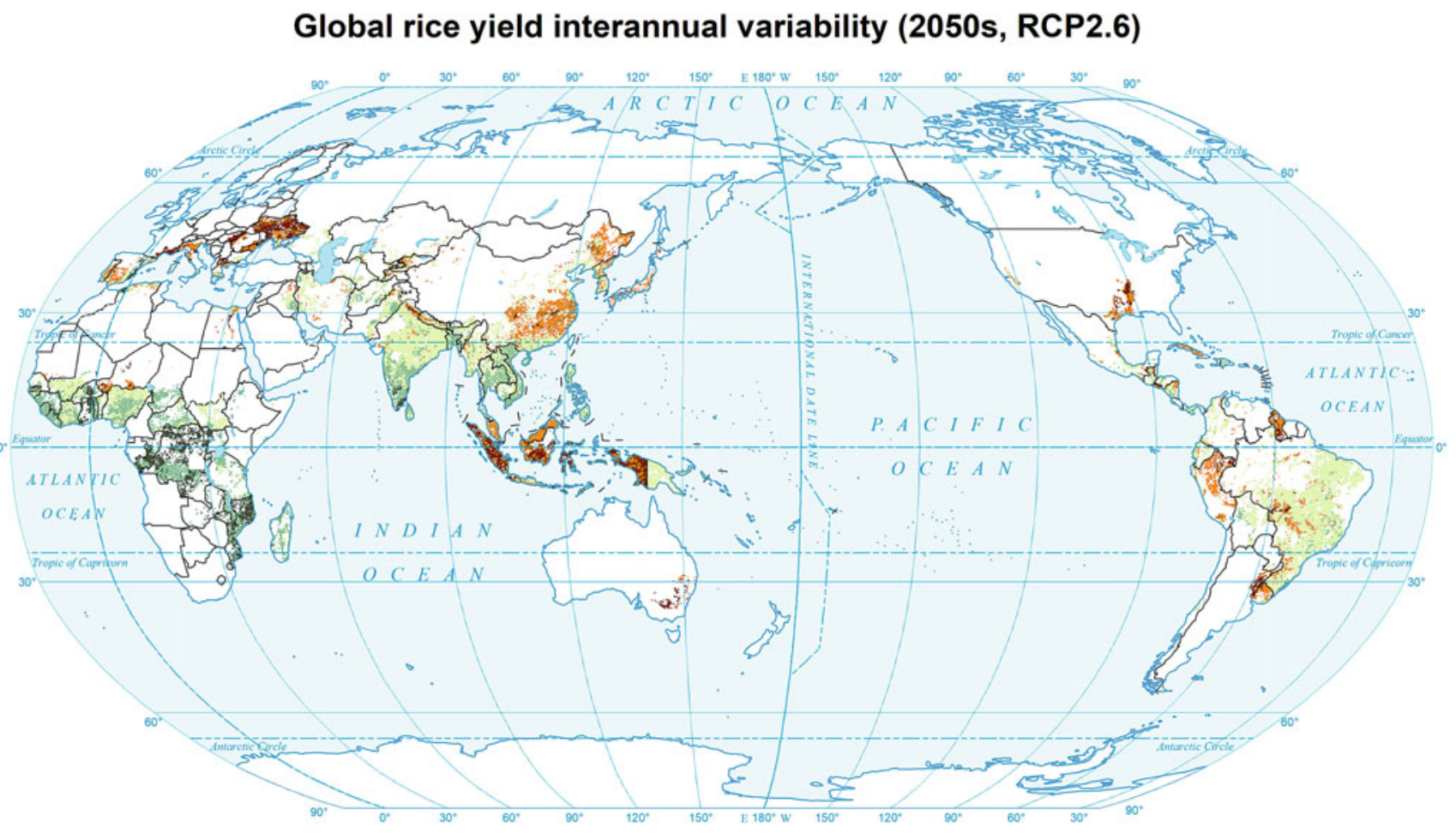

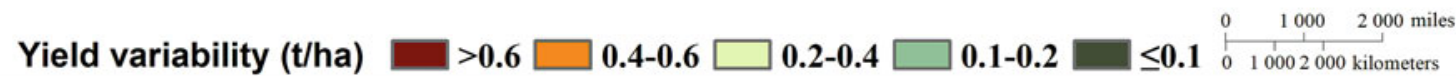

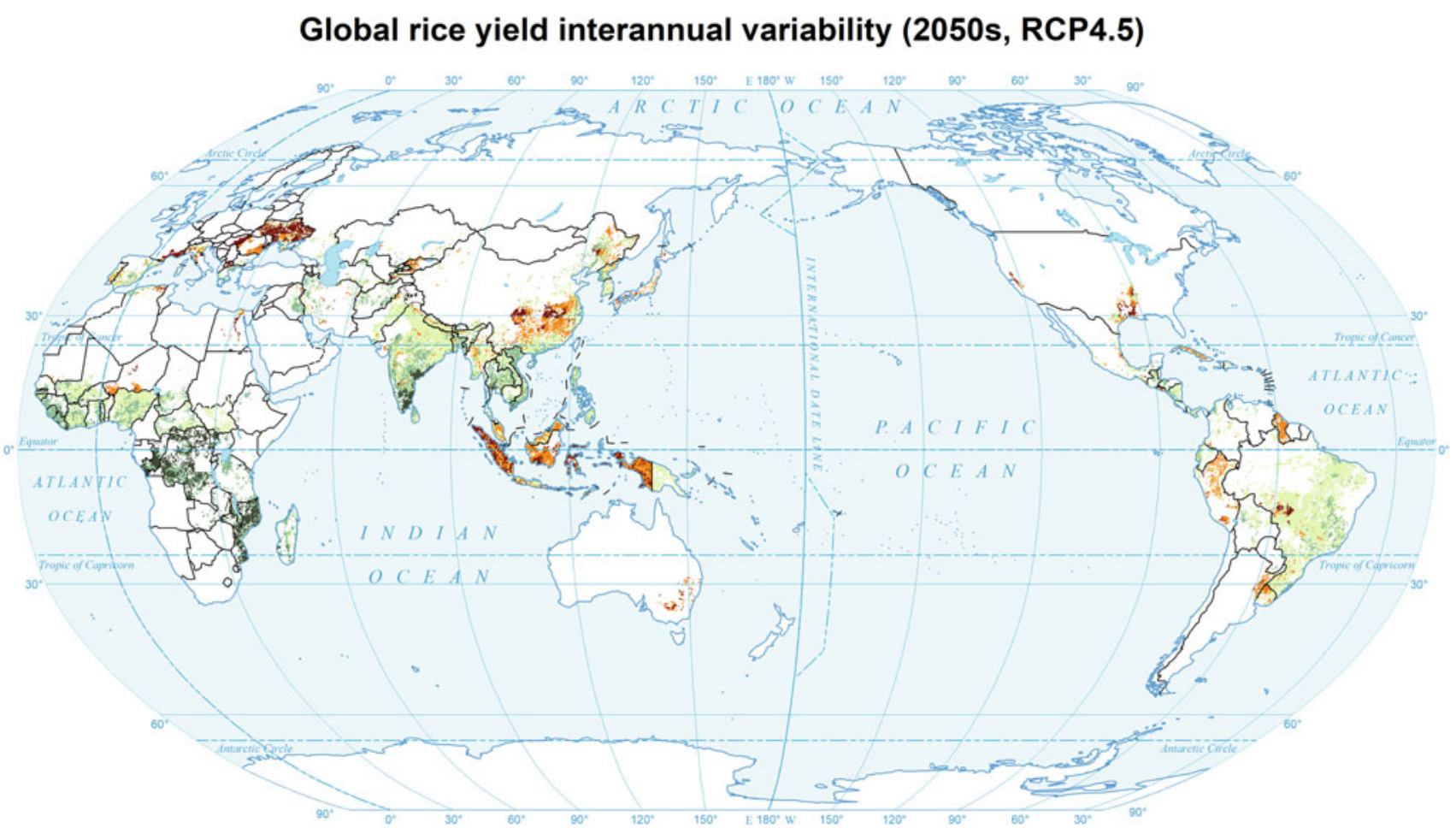

Yield variability (t/ha) $>0.6 \square 0.4-0.6$ $0.2-0.4 \square 0.1-0.2$

$0 \quad 1000 \quad 2000$ miles 


\section{Global rice yield interannual variability (2050s, RCP8.5)}

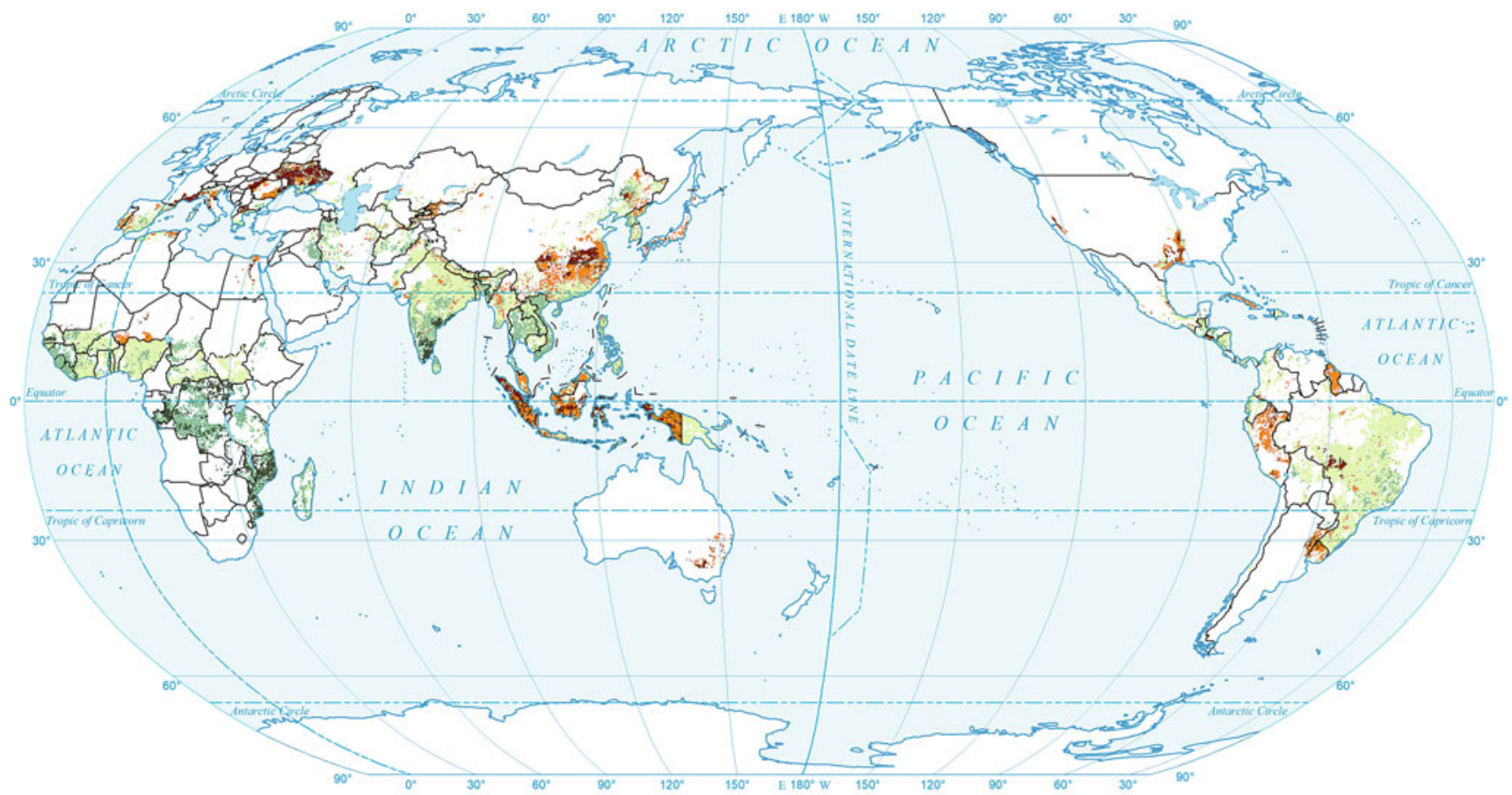

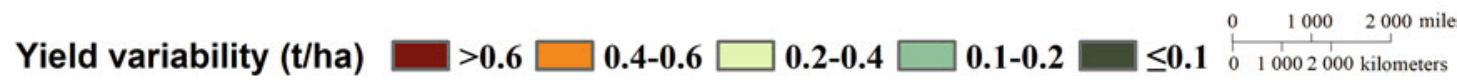

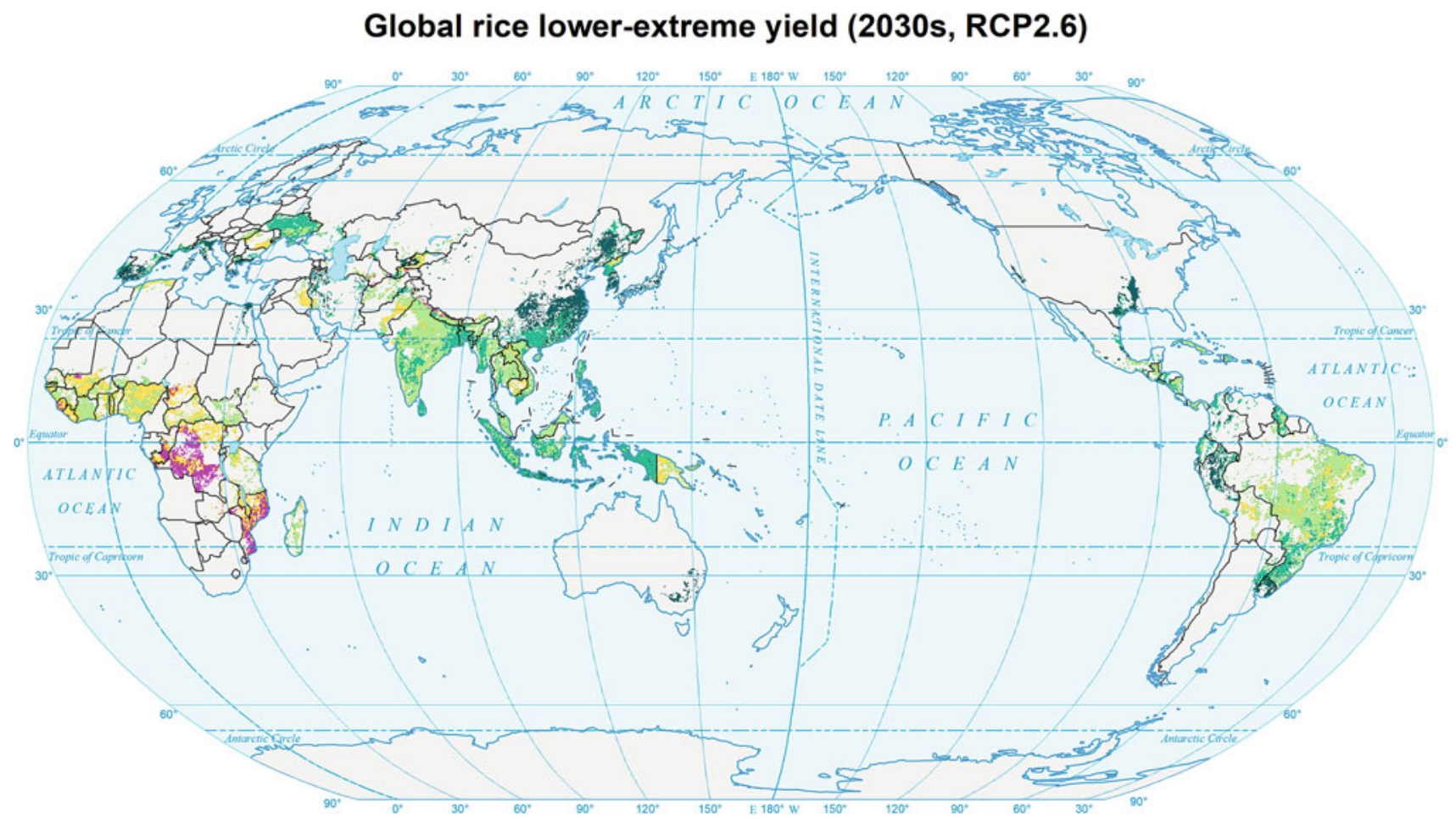

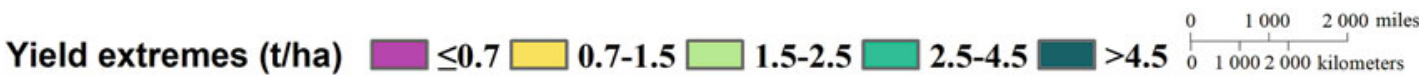




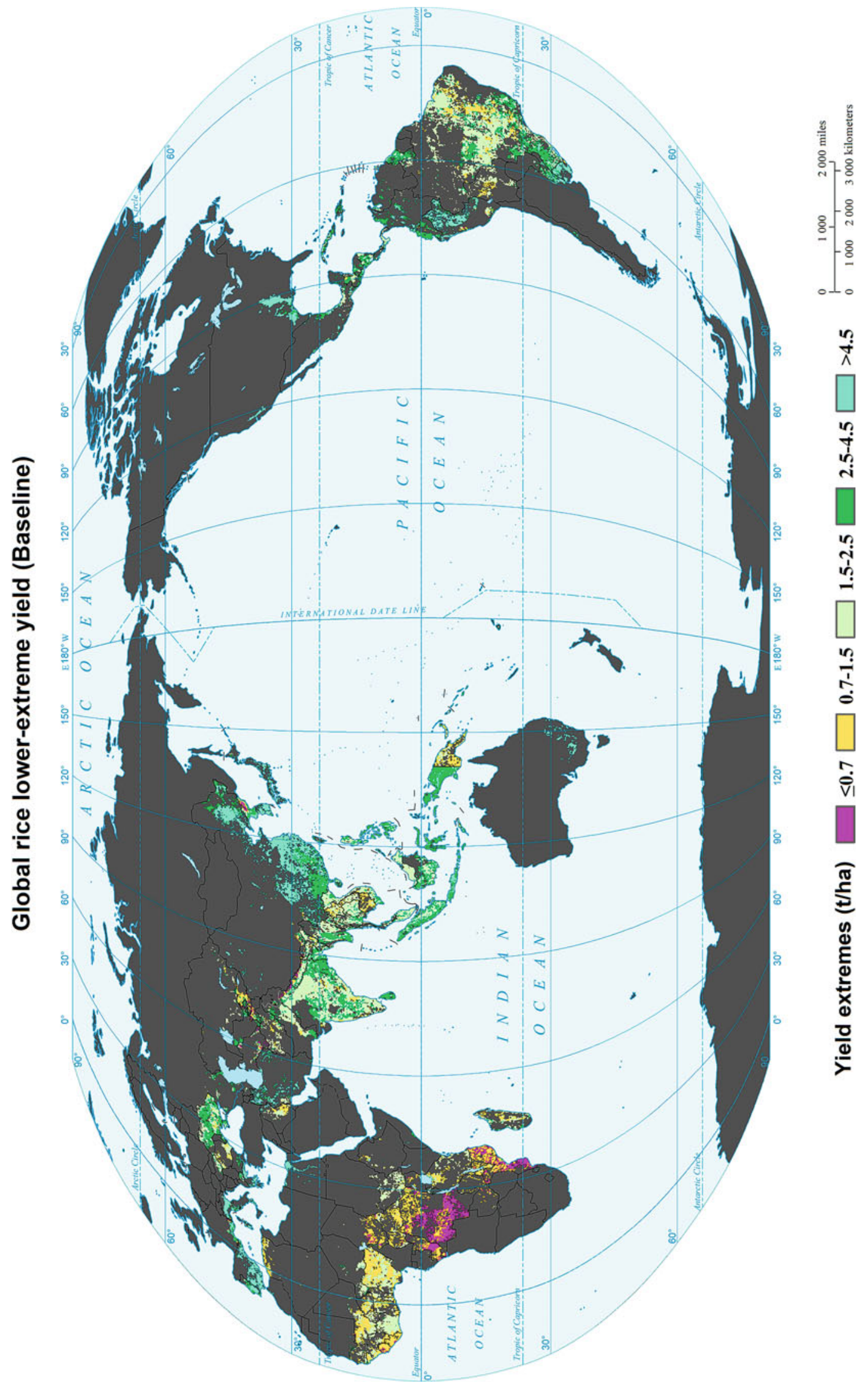


Global rice lower-extreme yield (2030s, RCP4.5)

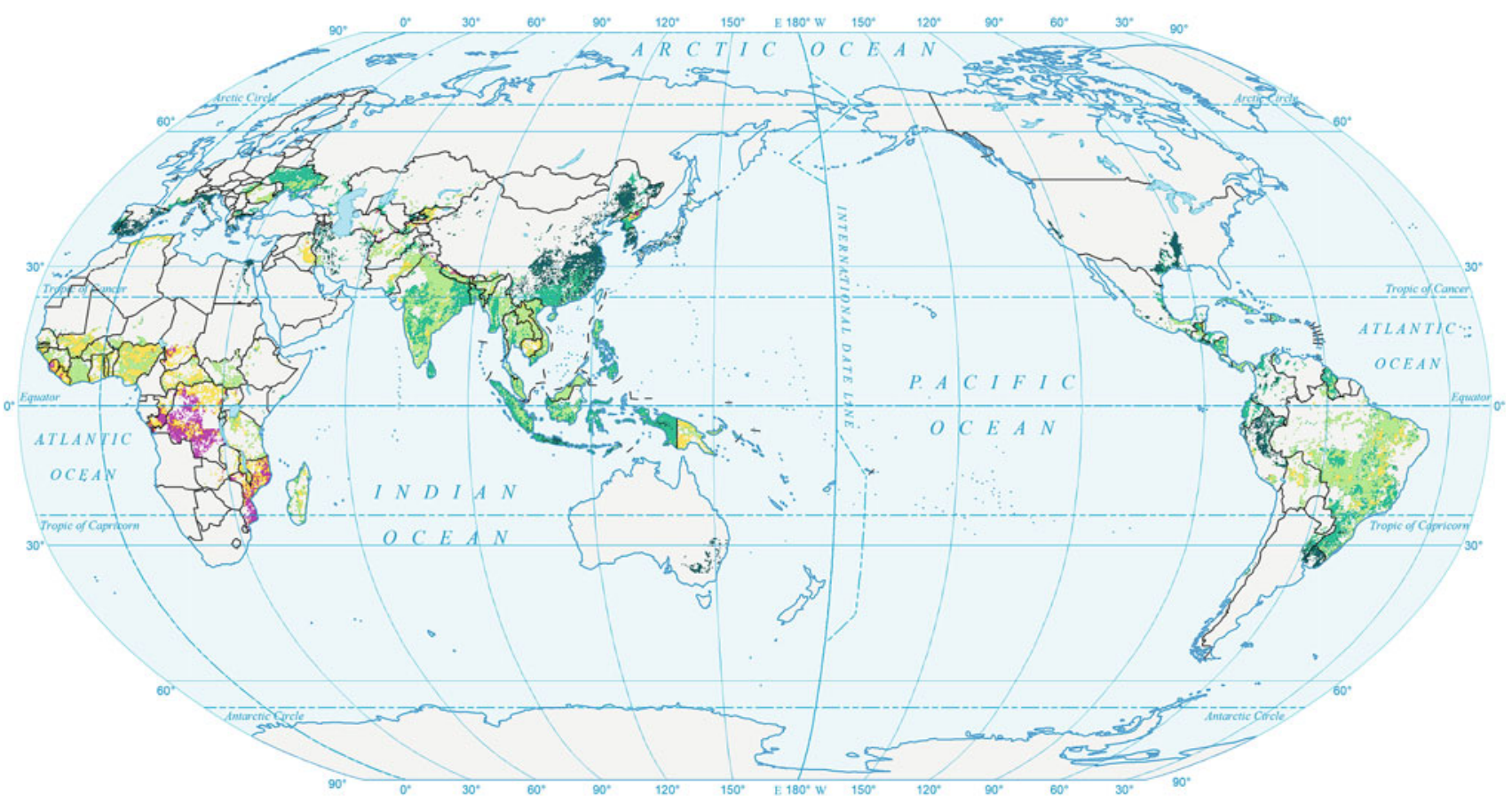

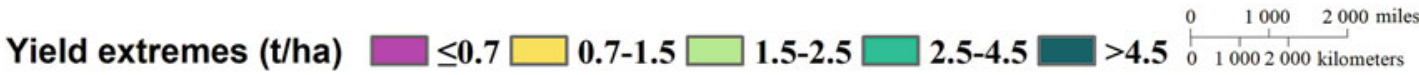

Global rice lower-extreme yield (2030s, RCP8.5)

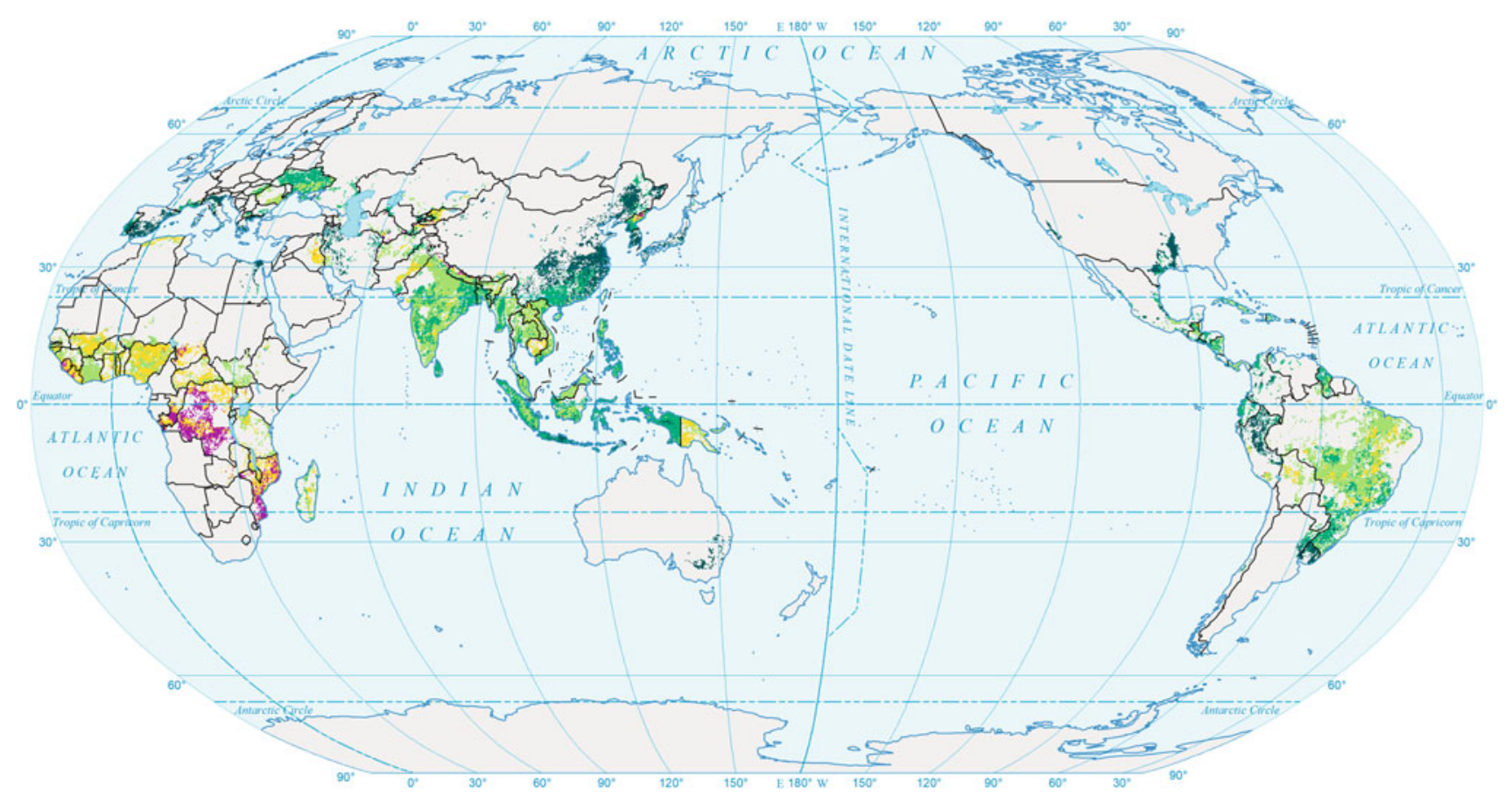

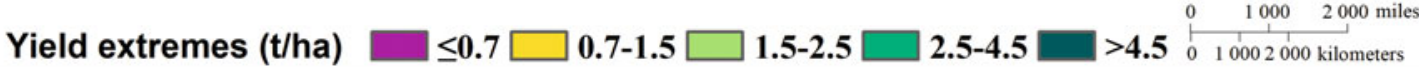




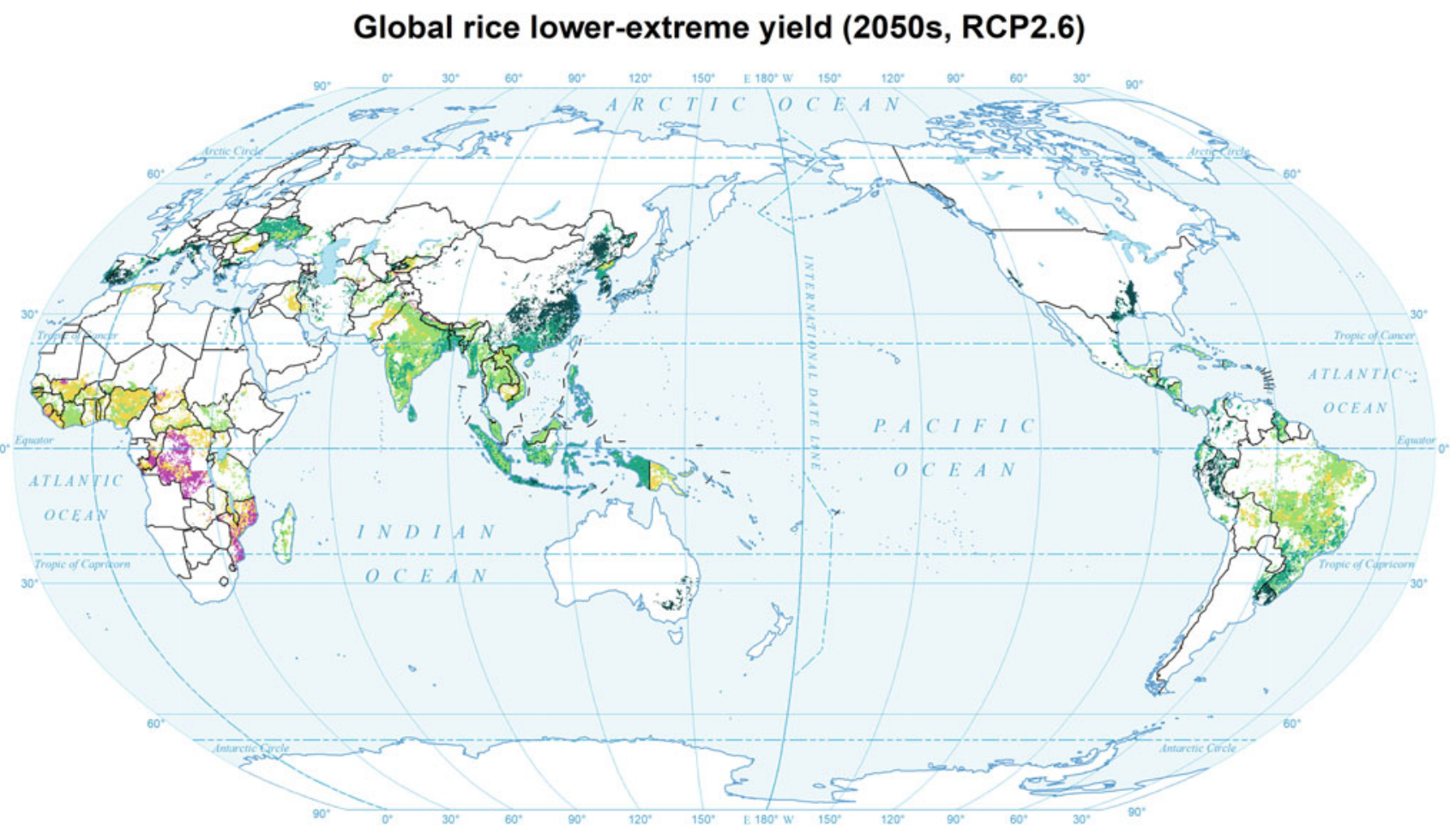

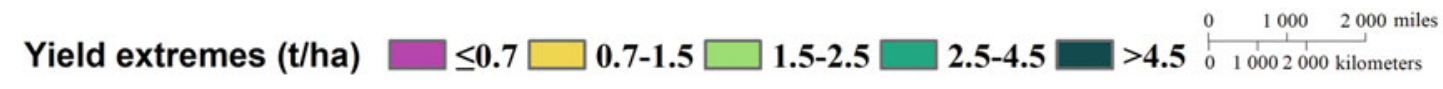

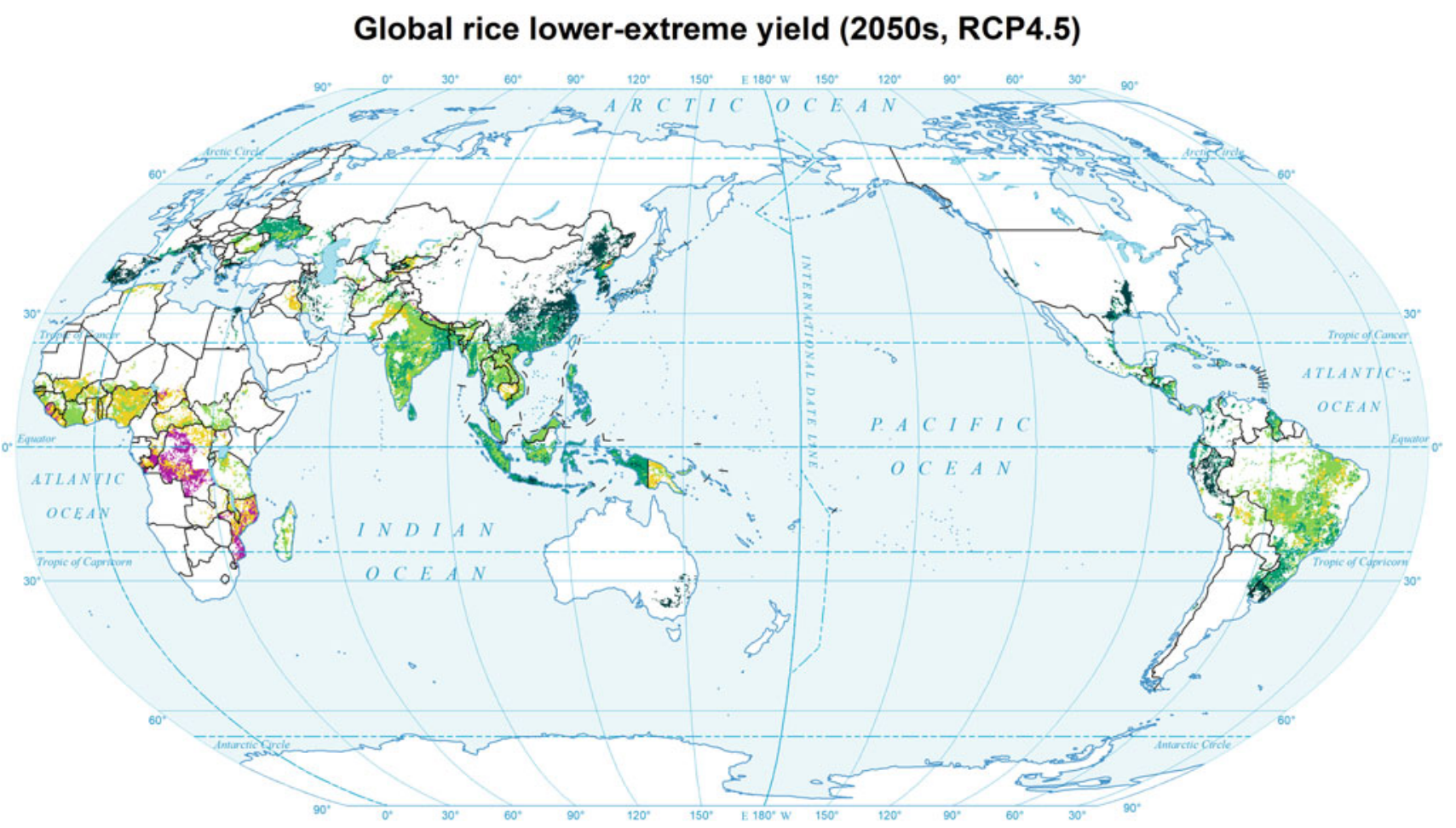

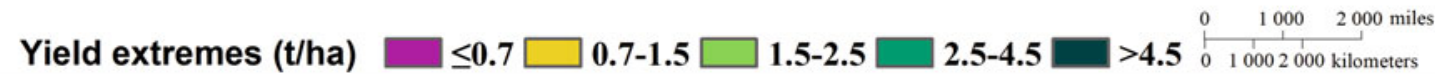




\section{Global rice lower-extreme yield (2050s, RCP8.5)}

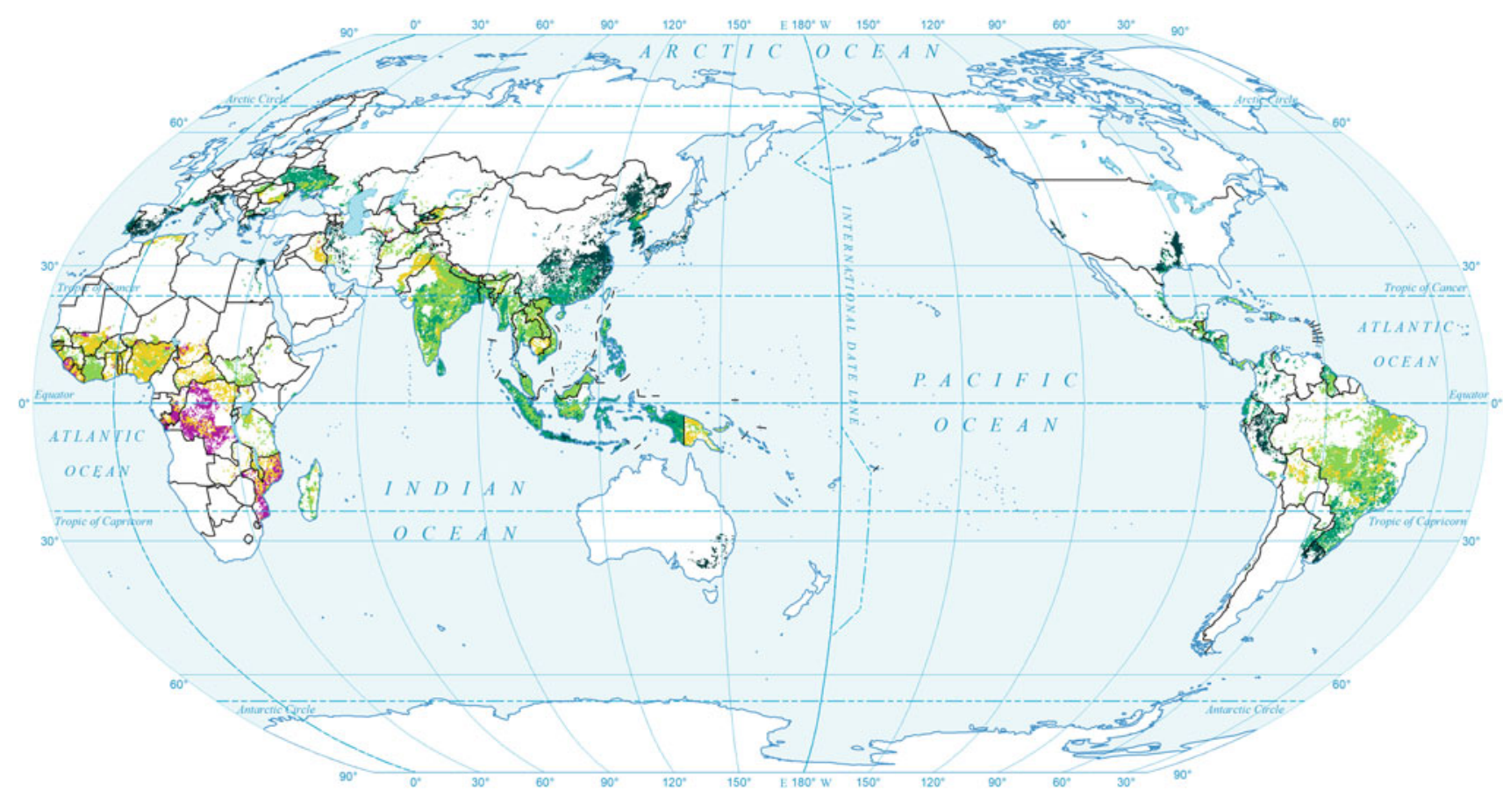

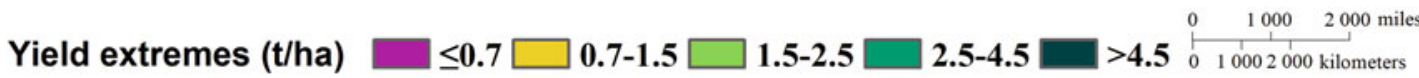

\section{References}

Asseng, S., F. Ewert, P. Martre, R.P. Rötter, D.B. Lobell, D. Cammarano, B.A. Kimball, M.J. Ottman, et al. 2015. Rising temperatures reduce global wheat production. Nature Climate Change 5 (2): 143-147.

Ben-Ari, T., J. Boé, P. Ciais, R. Lecerf, M. Van Der Velde, and D. Makowski. 2018. Causes and implications of the unforeseen 2016 extreme yield loss in the breadbasket of France. Nature Communications 9 (1): 1627.

Bobenrieth, E., B. Wright, and D. Zeng. 2013. Stocks-to-use ratios and prices as indicators of vulnerability to spikes in global cereal markets. Agricultural Economics 44 (s1): 43-52.

Coble, K.H., T.O. Knight, B.K. Goodwin, M.F. Miller, and R.M. Rejesus. 2010. A comprehensive review of the RMA APH and COMBO rating methodology. RMA Contract Report, Washington, DC. http://www. rma.usda.gov/pubs/2009/comprehensivereview.pdf.

FAO (Food and Agriculture Organization). 2019. World food and agriculture statistical pocketbook. http://www.fao.org/3/ca6463en/ ca6463en.pdf.

Folberth, C., A. Baklanov, J. Balkovič, R. Skalský, N. Khabarov, and M. Obersteiner. 2019. Spatio-temporal downscaling of gridded crop model yield estimates based on machine learning. Agricultural and Forest Meteorology 264 (January): 1-15.

Frieler, K., B. Schauberger, A. Arneth, J. Balkovič, J. Chryssanthacopoulos, D. Deryng, J. Elliott, C. Folberth, et al. 2017. Understanding the weather signal in national crop-yield variability. Earth's Future 5 (6): 605-616.

Hawkins, E., T.E. Fricker, A.J. Challinor, C.A.T. Ferro, C. Kit Ho, and T.M. Osborne. 2013. Increasing influence of heat stress on French maize yields from the 1960s to the 2030s. Global Change Biology 19 (3): 937-947.
Holzkämper, A., P. Calanca, and J. Fuhrer. 2012. Statistical crop models: predicting the effects of temperature and precipitation changes. Climate Research 51 (1): 11-21.

Iizumi, T., and N. Ramankutty. 2016. Changes in yield variability of major crops for 1981-2010 explained by climate change. Environmental Research Letters 11(3): 034003.

IPCC (Intergovernmental Panel on Climate Change). 2017. Climate change and land: an IPCC special report on climate change, desertification, land degradation, sustainable land management, food security, and greenhouse gas fluxes in terrestrial ecosystems. In Research handbook on climate change and agricultural law, issued 2017.https://doi.org/10.4337/9781784710644.

Leng, G.Y. 2017. Recent changes in county-level corn yield variability in the United States from observations and crop models. Science of the Total Environment 607-608: 683-690.

Liu, B., S. Asseng, C. Müller, F. Ewert, J. Elliott, D.B. Lobell, P. Martre, A.C. Ruane, et al. 2016. Similar estimates of temperature impacts on global wheat yield by three independent methods. Nature Climate Change 6 (12): 1130-1136.

Liu, B., P. Martre, F. Ewert, J.R. Porter, A.J. Challinor, C. Müller, A.C. Ruane, K. Waha, et al. 2019. Global wheat production with 1.5 and $2.0^{\circ} \mathrm{C}$ above pre-industrial warming. Global Change Biology 25(4): $1428-1444$.

Lobell, D.B. 2007. Changes in diurnal temperature range and national cereal yields. Agricultural and Forest Meteorology 145 (3-4): 229238.

Lobell, D.B., and M.B. Burke. 2010. On the use of statistical models to predict crop yield responses to climate change. Agricultural and Forest Meteorology 150 (11): 1443-1452.

Lobell, D.B., M.J. Roberts, W. Schlenker, N. Braun, B.B. Little, R.M. Rejesus, and G.L. Hammer. 2014. Greater sensitivity to drought accompanies maize yield increase in the U.S. Midwest. Science 344 (6183): 516-519. 
Lobell, D.B., W. Schlenker, and J. Costa-Roberts. 2011. Climate trends and global crop production since 1980. Science 333 (6042): 616620.

Martre, P., D. Wallach, S. Asseng, Frank Ewert, James W. Jones, Reimund P. Rötter, Kenneth J. Boote, A.C. Ruane, et al. 2015. Multimodel ensembles of wheat growth: many models are better than one. Global Change Biology 21 (2): 911-925.

Meijl, H. van, P. Havlik, H. Lotze-Campen, E. Stehfest, P. Witzke, I. P. Domínguez, B.L. Bodirsky, M. van Dijk, et al. 2018. Comparing impacts of climate change and mitigation on global agriculture by 2050. Environmental Research Letters 13(6): 064021.

Morton, J.F. 2007. The impact of climate change on smallholder and subsistence agriculture. Proceedings of the National Academy of Sciences 104 (50): 19680-19685.

Müller, C., J. Elliott, J. Chryssanthacopoulos, A. Arneth, J. Balkovic, P. Ciais, D. Deryng, C. Folberth, et al. 2017. Global gridded crop model evaluation: benchmarking, skills, deficiencies and implications. Geoscientific Model Development 10: 1403-1422.

Osborne, T.M., and T.R. Wheeler. 2013. Evidence for a climate signal in trends of global crop yield variability over the past 50 years. Environmental Research Letters 8(2): 024001.

Oyebamiji, O.K., N.R. Edwards, P.B. Holden, P.H. Garthwaite, S. Schaphoff, and D. Gerten. 2015. Emulating global climate change impacts on crop yields. Statistical Modelling 15 (6): 499-525.

Raimondo, M., C. Nazzaro, G. Marotta, and F. Caracciolo. 2020. Land degradation and climate change: global impact on wheat yields. Land Degradation \& Development 32 (1): 387-398.

Ray, D. K., Gerber, J. S., Macdonald, G. K. and West, P. C. 2015. Climate variation explains a third of global crop yield variability. Nature Communication 6 (1): 6989
Rosenzweig, C., J. Elliott, D. Deryng, A.C. Ruane, C. Müller, A. Arneth, K.J. Boote, C. Folberth, et al. 2014. Assessing agricultural risks of climate change in the 21 st century in a global gridded crop model intercomparison. Proceedings of the National Academy of Sciences of the United States of America 111 (9): 3268-3273.

Ruane, A.C., J. Antle, J. Elliott, C. Folberth, G. Hoogenboom, D. Mason-D'Croz, C. Müller, C. Porter, et al. 2018. Biophysical and economic implications for agriculture of $+1.5^{\circ}$ and $+2.0^{\circ} \mathrm{C}$ global warming using AgMIP coordinated global and regional assessments. Climate Research 76(1): 17-39.

Sternberg, T. 2011. Regional drought has a global impact. Nature 472 (7342): 169-169.

Tigchelaar, M., D.S. Battisti, R.L. Naylor, and D.K. Ray. 2018. Future warming increases probability of globally synchronized maize production shocks. Proceedings of the National Academy of Sciences 115 (26): 6644-6649.

Urban, D., M.J.J. Roberts, W. Schlenker, and D.B.B. Lobell. 2012. Projected temperature changes indicate significant increase in interannual variability of U.S. maize yields: a letter. Climatic Change 112(2): 525-533.

Ye, T., J.L. Nie, J. Wang, P.J. Shi, and Z. Wang. 2015. Performance of detrending models for crop yield risk assessment: evaluation with real and hypothetical yield data. Stochastic Environmental Research and Risk Assessment 29 (1): 109-117.

Yue, Y.J., P.Y. Zhang, and Y.R. Shang. 2019. The potential global distribution and dynamics of wheat under multiple climate change scenarios. Science of the Total Environment 688: 1308-1318.
Open Access This chapter is licensed under the terms of the Creative Commons Attribution 4.0 International License (http:// creativecommons.org/licenses/by/4.0/), which permits use, sharing, adaptation, distribution and reproduction in any medium or format, as long as you give appropriate credit to the original author(s) and the source, provide a link to the Creative Commons license and indicate if changes were made.
The images or other third party material in this chapter are included in the chapter's Creative Commons license, unless indicated otherwise in a credit line to the material. If material is not included in the chapter's Creative Commons license and your intended use is not permitted by statutory regulation or exceeds the permitted use, you will need to obtain permission directly from the copyright holder. 